Illinois State University

ISU ReD: Research and eData

Theses and Dissertations

$1-13-2014$

\title{
Academic Hiring Gatekeeper \& Employer Perceptions Of Online Degrees And The Acceptability Of Online Degrees For Faculty And Administrator Employment In Higher Education
}

Renee Sinow-Mandelbaum

Illinois State University, reneemandelbaum@gmail.com

Follow this and additional works at: https://ir.library.illinoisstate.edu/etd

Part of the Higher Education Administration Commons, and the Higher Education and Teaching Commons

\section{Recommended Citation}

Sinow-Mandelbaum, Renee, "Academic Hiring Gatekeeper \& Employer Perceptions Of Online Degrees And The Acceptability Of Online Degrees For Faculty And Administrator Employment In Higher Education" (2014). Theses and Dissertations. 84.

https://ir.library.illinoisstate.edu/etd/84

This Dissertation is brought to you for free and open access by ISU ReD: Research and eData. It has been accepted for inclusion in Theses and Dissertations by an authorized administrator of ISU ReD: Research and eData. For more information, please contact ISUReD@ilstu.edu. 


\title{
ACADEMIC HIRING GATEKEEPER \& EMPLOYER PERCEPTIONS \\ OF ONLINE DEGREES AND THE ACCEPTABILITY \\ OF ONLINE DEGREES FOR FACULTY AND \\ ADMINISTRATOR EMPLOYMENT \\ IN HIGHER EDUCATION
}

\author{
Renee M. Sinow-Mandelbaum
}

191 Pages

May 2014

Due to its flexibility and convenience, online education has become a feasible alternative for degree seeking students who are unable to attend a traditional higher education institution. Although online courses and programs have their benefits, there remains an ongoing debate on issues related to credibility, quality, and acceptability among certain stakeholders including faculty, administrators, and employers. The current study focuses on one group of academic stakeholders-namely, academic hiring gatekeepers and employers; that is, those who are directly involved in the hiring process of faculty and administrators. Specifically, the objective is to explore hiring gatekeeper and employer acceptability of online degrees as a sufficient credential for employment in institutions of higher education. While there are many assumptions and commonly held perceptions in the academic community regarding the value and quality of online degrees, the purpose of this study is to simply describe these views and attitudes. The 
data for this study were collected primarily through in-depth interviews and a survey apparatus that was implemented online. The overall design proposed for this study was grounded in the mixed-methods approach to data collection (Creswell, 2003). Data gathered from 102 surveys was examined using ANOVA and Chi-Square analysis and the statistical relevance of the findings suggest that within higher education, there continues to be a robust debate among academic hiring gatekeepers in higher education regarding the quality and rigor associated with online degrees. Moreover, study findings also reveal that academic hiring gatekeepers perceptions of online degrees do influence the hiring practices for positions. Finally, data from the in-depth interviews demonstrates that institutional reputation was a critical factor when making faculty and administrator hiring decisions. 
ACADEMIC HIRING GATEKEEPER \& EMPLOYER PERCEPTIONS

OF ONLINE DEGREES AND THE ACCEPTABILITY

OF ONLINE DEGREES FOR FACULTY AND

ADMINISTRATOR EMPLOYMENT

IN HIGHER EDUCATION

RENEE M. SINOW-MANDELBAUM

A Dissertation Submitted in Partial

Fulfillment of the Requirements

for the Degree of

DOCTOR OF PHILOSOPHY

Department of Educational Administration and Foundations

ILLINOIS STATE UNIVERSITY 


\section{ACADEMIC HIRING GATEKEEPER \& EMPLOYER PERCEPTIONS OF ONLINE DEGREES AND THE ACCEPTABILITY \\ OF ONLINE DEGREES FOR FACULTY AND \\ ADMINISTRATOR EMPLOYMENT \\ IN HIGHER EDUCATION}

RENEE M. SINOW-MANDELBAUM

COMMITTEE MEMBERS:

Lydia Kyei-Blankson

John Presley

Diane Dean

Mohammed Nur-Awaleh 


\section{ACKNOWLEDGEMENTS}

I would like to acknowledge the following individuals for their efforts on this dissertation.

Dr. Lydia Kyei-Blankson-Dr. Lydia for her dedication and serving as my Dissertation Chair. Dr. Lydia has gone above and beyond as my mentor and teacher throughout this entire process. Her in-depth reviews of all drafts have shaped the quality of this dissertation. She has given me so much knowledge, support, and guidance. I hope one day I can be as great of an instructor and advisor as Dr. Lydia. I am honored to have her serve as my chair. She is an outstanding scholar and friend.

Dr. John Presley_-Dr. Presley for his outstanding efforts as a committee member and instructor. Dr. Presley is so incredibly knowledgeable in all areas of education it is a gift to learn from him. He has taught me how to significantly improve my writing, and he has provided so many encouraging words and direction throughout my studies, career path, and this dissertation process. I will be honored the day he considers me a colleague. Dr. Diane Dean-Dr. Dean for her participation and support on this dissertation committee. It was a pleasure learning from Dr. Dean for the past 5 years and also working for her as the managing editor for the Review of Higher Education. She has taken so much time to help me achieve academic and professional success, and I am so grateful to have her as a part of this committee. 
Dr. Mohammed Nur-Awaleh-Dr. Mohammed has been with me since day one of this academic and dissertation process. Without him, I may never have joined the Illinois State Program. Dr. Mohammed has been a constant guide and source of encouragement since I joined the program. His insightful feedback and knowledge have helped shape the scholar I am today. I am so lucky to have him as a member of this committee.

I would like to dedicate this dissertation to several individuals. I could not have achieved this milestone without the help and support of my wonderful husband, parents, and sister. Words will never be able express the gratitude I have for the help and guidance I received from my father throughout this process. He is not only my father, but has been my mentor and the best teacher I have ever had. Learning from him has been a tremendous gift. This dissertation could not have been completed without the love and continuous support from my wonderful mother. Her giant heart never gave up a beat even when mine got tired. Next, my husband's unwavering support has allowed me to take off the past several years to focus solely on my research. His constant drive, help and dedication has allowed me to become a better scholar, and for that I am eternally grateful. Finally, my sister has always been my biggest fan. I believe in my dreams because I know she believes in me. I love you all so much, and thank you for taking this journey with me.

R.M.S-M. 


\section{CONTENTS}

Page

ACKNOWLEDGMENTS $\quad$ i

CONTENTS

TABLES vi vi

CHAPTER

I. INTRODUCTION 1

Statement of the Problem 3

Purpose of the Study 4

$\begin{array}{lr}\text { Research Questions } & 6\end{array}$

Significance of the Study $\quad 6$

$\begin{array}{ll}\text { Definition of Terms } & 7\end{array}$

Assumptions, Delimitations, and Limitations 8

$\begin{array}{ll}\text { Organization of the Study } & 10\end{array}$

II. REVIEW OF THE RELATED LITERATURE 11

Introduction and Organization $\quad 11$

History of Distance Education and its Associated Technologies 12

Characteristics of Online Courses, Programs, and Technologies 20

Growth Trends of Online Education in Non-Profits and For-Profit Institutions $\quad 22$

Standardization of Online Education: Stakeholder Interest 24

Quality Guidelines: The Employer Viewpoint 28

Establishing Quality in Online Education: The Sloan Consortium 29

Theory to Practice: Building Quality and Effective Online Courses and Programs 33

$\begin{array}{ll}\text { Stakeholder Overview } & 37\end{array}$

Arguments For and Against Online Education 37

Student Learning and Program Outcomes Obtained Through

Online Instruction 
Employer Perceptions of Student Online Learning Outcomes

and Performance

Institutional and Faculty Arguments For and Against Online Education 47

Credentialing versus Educating

Hiring Gatekeeper and Employer Perceptions 52

Factors Affecting the Acceptability of Online Courses and Degrees 58

Challenges: Promulgating an Acceptable Theory of Distance

Education and Online Learning

History: Theoretical Framework of Distance Education

Theory: Emerging Learning Theories in Online Education

Applying Theory to Practice: Online Learning

Theory: Determining the Value of an Online Degree as a Credential for Employment

Gap Analysis

Current Research Directions

Research Questions

Rationale for Mixed Method Design

Sample

Survey Instrument

Interview Protocol

Procedures: Survey and Interview

Ethical Considerations

90

Reliability and Validity

Quantitative Data Analysis

Researchers Subjectivity and Reflexivity

Quantitative Data Analysis

Summary

IV. RESULTS

Section 1: Participant Descriptions 
Section 2: Presentation of Findings by Research Questions

Director John

Dean Ron

114

Dean Sarah

118

Dean Jane

121

Dean Alan

125

Dean Wilson

V. SUMMARY, CONCLUSIONS, IMPLICATIONS, AND RECOMMENDATIONS

Summary

Quality of Online Education in Relation to Institutional Type and Institutional Reputation

Connections Between the Study Findings and Past Research

Convergence and Divergence in the Quantitative and Qualitative Findings

Conclusion

Implications for Future Practice

Recommendations for Future Research

$\begin{array}{lll}\text { APPENDIX A: } & \text { Survey Instrument } & 167\end{array}$

$\begin{array}{lll}\text { APPENDIX B: Interview Protocol } & 179\end{array}$

APPENDIX C: Mean Scores and Standard Deviation by Position Type and Institutional Size 


\section{TABLES}

Table Page

1. Gatekeeper Acceptability of Candidates 53

2. Influential Distance Education Theories and Theorists 64

3. Distribution of Survey Participants' by Position Type, Institution Type, Institution Size, and Number of Online Degree Offerings 99

$\begin{array}{lll}\text { 4. Participant Profiles } & 101\end{array}$

5. Hiring Gatekeeper and Employer Perceptions of Online Education 103

6. Hiring Gatekeeper and Administrator Hiring Practices 105

7. ANOVA Outcomes for Comparison of Perceptions to Online and Traditional Education by Position Type and Institution Type

8. A Comparison of Perceptions to Online and Traditional Education by Position and Institution Type

9. Summary of Interview Data in Relation to the Research Questions 


\section{CHAPTER I}

\section{INTRODUCTION}

Higher education is undergoing a profound transition. That is to say education is moving from a historic classroom model to an online delivery model. This transition should come as no surprise as new technology has provided the opportunity for students to obtain an online degree. In fact, students are demanding flexible educational opportunities with unlimited geographical borders. Allen and Seaman (2013) report that in the fall 2011 term, over 6.7 million students took at least one online course. Allen and Seaman also note that 32 percent of all higher education students now take at least one course online. For the purposes of this study, online courses are defined as those in which at least 80 percent of the course content is delivered online (Allen \& Seaman 2011).

Globalization has profoundly had an effect on education delivery models.

Dissolving the boundaries of space, language and time, the Internet and technological revolution have enabled global citizens to share, access, and distribute information inexpensively. In the virtual world, new technology brings like-minded people together from around the globe who otherwise would never meet and consequently inspire action and discussion. Ideas, technologies, and information, which previously took decades or even centuries to disperse across the globe, now take seconds to permeate into countless countries and cultures. Within an instant, electronic communication allows the most 
innovative ideas to reach global actors. Today, information or events on one continent can drastically affect financial markets or political actions and responses around the world. Additionally, with the onset of new technologies and communication channels in the educational realm, individuals who were once unable to pursue higher education for a myriad of reasons (i.e. location, job, family) are now able to utilize the flexibility offered through an online education program.

While stakeholders continue to articulate their concerns and simultaneously acknowledge the enormous potential of online learning models, the impact of globalization is driving higher education institutions to recognize the urgency of offering online learning opportunities (Bramble and Panda, 2008). More specifically, Bramble and Panda maintain that without providing new virtual learning opportunities, institutions will increasingly face the risk of having their student markets erode. Garrison and Kanuka (2008) also discuss a case study published by the Open Learning Foundation, which indicates a widespread perception that traditional higher education institutions are not effectively meeting the demands and needs of non-traditional learners, leaving the field open for innovative providers to meet these increasing market demands. Garrison and Kanuka specifically mention higher education institutions in countries such as the United Kingdom, Norway, and Australia. Further, many of these new providers highlight their commitment to the non-traditional learners and boast excellence in student services, online pedagogy, curriculum, and professional development (Bramble and Panda, 2008, p. 17). 


\section{Statement of the Problem}

While innovative instructional models in higher education continue to develop, important concerns remain. Among these concerns are issues related to the quality, effectiveness, acceptability and comparability between traditional classroom education and online education. Thus far the research in one of these areas, the acceptability of online learning, has failed to receive much attention. The literature on acceptability of online education among stakeholders, particularly employers and how acceptability influences hiring decisions when an online degree is presented as an employment credential is very limited. As students continue to make decisions for online education, it is essential that employer views surrounding credibility, value, effectiveness, and comparability to a traditional classroom learning experience be explored and updated.

In one of the few studies conducted on this topic, Adams and DeFleur's (2006) note that many hiring gatekeepers remained reluctant to employ individuals who earned their degrees from online programs. Again in 2007, Seibold found that national career counseling and job placement firms were advising clients not to disclose their online degrees or credentials because employers often view online degrees as less prestigious (than traditional degrees). With the continued expansion of online education and online degree offerings even from public and private prestigious institutions, it is important to find out whether these employer attitudes and perceptions still persist.

In this research study, academic hiring gatekeepers and employers at traditional higher education institutions attitudes and perceptions towards online degrees and the hiring of applicants with online degrees are examined. This study is significant as higher 
education institutions continue to push and support online education while arguing that this modality ensures the same quality of academic excellence as executed and accomplished through traditional education. Further, it is important to consider that there are many commonly held perceptions and current assumptions held by members of the academic community. These assumptions may include the perception that online degree candidates are not as qualified as traditional degree holding candidates. Essentially, members of the Academy may assume that an online degree candidate would not be fit for a faculty position. Ultimately, the intent of this study is to describe the current attitudes and perceptions in order to either discount or confirm these commonly held assumptions regarding online degrees and faculty hiring practices.

Finally, there have been a limited number of mixed method studies referencing academic hiring gatekeepers and their perceptions of online degrees and institutional hiring practices. Rather, a few studies that have been conducted to date have been primarily quantitative (Adams and DeFleur, 2005; DePriest, 2009). Further, other studies examining the acceptability of online degrees have focused largely on employers in the general business industry (Adams and DeFleur, 2006; Lamer, 2006; Adams, 2008). More specifically, there is a gap in the literature regarding the exploration of the online degree as a credential for faculty and administrator employment in institutions of higher education from both a qualitative and quantitative perspective.

\section{Purpose of the Study}

Why should we be concerned about employer perceptions of online degrees in the first place? Students are spending thousands of dollars annually for tuition applied to 
online degree programs in an effort to promote, enhance, or change their career path. While the annual expenditure by students for their online education is proprietary, there can be no question that online education is consuming more of the educational dollar. For example, according to Allen and Seaman (2013), in 2011, 20.9 million students were enrolled in a degree granting program. Of that number, 6.7 million students were enrolled in at least one online course - a 9.3 percent increase from 2010 . These students expect a solid return on their educational investment usually in the form of gaining employment or receiving a promotion. More importantly, the Academy needs to assure students that these expectations can be realized. One way to do this is by affirming evidence from employers. It is critical to examine whether or not academic employers believe that online degree programs have the same level of quality and excellence as traditional programs and also to explore employer perceptions when it comes to employing online degree holders. It is critical from a conceptual perspective to examine the value of an online degree especially as it is perceived by hiring gatekeepers and employers, and more particularly, those in academic institutions. For the purpose of this study, hiring gatekeepers and employers in academic institutions will consist of stakeholders who are directly involved in the hiring process of faculty and administrators. Further, to be specific individuals will include deans, chairs, and members of faculty hiring committees who are currently responsible for making or have made faculty hiring decisions in the past two years. 


\section{Research Questions}

The focus of this research is to assess the value of an online degree as a credential for employment in higher education from the perspective of academic hiring gatekeepers, academic administrators, deans, faculty hiring committees, or any individual responsible for making a faculty/administrator hiring decision. The research questions are as follows:

1. What are the current perceptions of academic hiring gatekeepers and employers regarding online education in general?

2. Do academic hiring gatekeepers' perceptions toward online education differ from the perceptions they hold toward traditional higher education?

3. Do academic hiring gatekeepers' perceptions toward online education differ by their position and institution type?

4. To what extent do academic hiring gatekeeper perceptions toward online education influence their hiring decisions?

\section{Significance of the Study}

According to the Pew Research Center (2011), among college graduates who have taken an online course, 15 percent have actually earned a degree entirely online (p.7). Additionally, Allen and Seaman (2011) report that 65 percent of higher education institutions (of those institutions included in their study) indicate online learning is a critical component of their long-term institutional strategy. With such a substantial number of traditional higher education institutions offering courses and degree programs in an online capacity, examining the perception of online education from an employer perspective should be a significant focus in the Academy. Consequently, from a practical viewpoint, online degree seekers will have more ability to protect themselves from making a poor financial decision if they have more knowledge and insight into the hiring 
attitudes and behaviors of an organization's hiring gatekeeper(s). Moreover, by

implication, it may well be necessary for the Academy to educate hiring gatekeepers as to the benefits and compatibility of an online degree from a traditional institution that historically offers the classic bricks and mortar degree. Indeed, the Academy may owe its student constituency an ethical responsibility to educate hiring gatekeepers as to the efficacy of an online degree from a traditional institution. This study is also significant to higher education institutions with regard to evaluation and assessment of their online learning programs and the different levels of acceptance online degree programs have achieved among other academic institutions. Clearly, these issues deserve the attention of all educators and a meaningful dialogue among the various actors and constituents.

\section{Definition of Terms}

Traditional Education: For the purposes of this proposal, a traditional education includes completing course work where there is no online technology used and content is delivered in writing or orally (Allen \& Seaman, 2011).

Distance Education: Distance education is, "planned learning that normally occurs in a different time and/or place from teaching, requiring special techniques of course design, special instructional techniques, special methods of communication by electronic and other technology, as well as special organization and administrative arrangements" (Moore \& Kearsley, 2005, p.7).

Online Course: For the purposes of this proposal, online courses are those in which at least 80 percent of the course content is delivered online (Allen \& Seaman, 2011). 
Blended/Asynchronous: According to Allen and Seaman (2001), blended learning

includes a: "Course that blends online and face-to-face delivery. Substantial proportion of the content is delivered online, typically uses online discussions, and typically has a reduced number of face-to-face meetings” (p. 7). Further, Moore and Kearsley (2005) describe asynchronous learning as communication with a delay that allows learners to respond at a different time than the original message/content was initially sent.

Hiring Gatekeeper: According to Columbaro and Monaghan (2009) a hiring gatekeeper is defined as, “... anyone who stands between you and the person who might want to hire you. Gatekeepers come in many forms, including receptionists, HR recruiters, and resume screeners" (p. 2). For the purposes of this study, a hiring gatekeeper will be defined as any academic administrator or faculty member who has served on a faculty hiring committee or made a faculty hiring decision within the past two years.

\section{Assumptions, Delimitations, and Limitations}

The assumptions for this research include:

1. Data collected from the survey will be significant enough to formulate a valid conclusion.

2. A purposeful sample of hiring gatekeepers will provide the result needed to formulate a valid conclusion.

3. Academic hiring gatekeepers included in this study will have prior knowledge or experience with online degree candidates/applicants.

4. Employers are sound evaluators of the quality of education with regard to current employees, potential employees, and other relevant employment concerns.

5. There remain several commonly held perceptions by academic hiring gatekeepers. One of these perceptions includes the belief that an online degree is not as valuable or credible as a traditional degree. Therefore, it may be assumed that many academic 
hiring gatekeepers have negative perceptions of online degrees and essentially would not hire an individual with an online degree.

The limitations and delimitations for this research include:

1. This study will be limited to the viewpoint of those academic hiring gatekeepers and will not examine the viewpoints of students.

2. This study is limited to individuals who make faculty and top administrator hiring decisions in their respective institutions (i.e. hiring gatekeeper). This study excludes staff hiring decisions and/or processes.

3. This study includes self-reported data from participants and consequently may not be 100 percent accurate or truthful due to self-reporting errors.

4. This study sample only includes participants employed in academia.

5. The generalizability of this study is limited to colleges and universities in the Midwestern region of the United States.

6. Academic hiring gatekeepers in this study will not include individuals from proprietary and specialty trade schools due to their likely "favorable" bias toward online degrees in general.

Additionally, it is expected that the hiring gatekeepers who participate in this study will have diverse employment backgrounds, academic experiences, and credentials. It is also expected that the hiring gatekeepers included in this study will have different experiences in terms of organizational culture, expectations, and hiring practices. These circumstantial differences may reveal unique hiring practices and beliefs regarding online education that cannot be generalized or re-created by other individuals. Finally, this study used volunteer participants only. Therefore, those who are interested in the subject of this study are more likely to make time to participate. Ultimately, there is the potential that the sample may lead to an overly positive or negative perception of online education and hiring practices due to participant bias. 


\section{Organization of the Study}

Chapter One introduces the study and provides an overview of online education, a statement of the problem, the purpose of the study, the significance of the study, the delimitations and limitations of the study, and a definition of terms for the reader. Chapter Two includes a review of the literature that offers a foundation for this study, including research on the history of online education and its associated technologies, quality and standardization guidelines, stakeholder arguments for and against online education, hiring gatekeepers and employer perceptions, and a proposed theoretical framework for the study. Next, Chapter Three describes the mixed method research strategy that will be utilized to examine and present the data for this study, and Chapter Four provides a description of the study's results. Finally, Chapter Five offers the study's summary, conclusions, implications and recommendations. 


\section{CHAPTER II \\ REVIEW OF THE RELATED LITERATURE}

\section{Introduction and Organization}

It is a misconception that online education began with the Internet and the high-tech revolution. Rather, after careful examination of the literature, online education should be categorized as a subset of distance education. Therefore, the following analysis begins by tracing the history of distance education to its current state in higher education. The review also highlights trends in enrollment and discusses the role accrediting agencies and organizations have played in developing quality assurance for teaching and learning in online environments. Next, this review provides an overview of stakeholder arguments for and against the value and outcomes of online education as documented in past research. While there has not been a meaningful amount of research conducted on employers' perceptions of online education (or degrees), this literature review presents information on the value and acceptability of an online degree as an entry credential from the hiring gatekeeper and employer perspective. Finally, this review presents the applicable theories that have been used to explain stakeholder reactions to online learning and especially the acceptability of an online degree as a credential for employment. This theoretical review will also provide a foundation and analytical lens for which the research questions, data, themes, and conclusions of this study can be essentially formulated and evaluated. 


\section{History of Distance Education and its Associated Technologies}

According to Brewer, DeJonge, and Stout (2001), "The very earliest form of an extended classroom, or distance education, was paper-based correspondence. As early as 1840, Isaac Pittman was teaching shorthand in England by correspondence” (p. 28).

Moreover, Keegan's (1996) definition of the practice of "distance education" can also be traced back 150 years. In fact, Keegan (1996) provides several early definitions of distance education. For example, in 1967, distance education was defined by G. Dohmen as:

"...a systematically organized form of self-study in which student counseling, the presentation of learning material and the securing and supervising of students' success is carried out by a team of teachers, each of whom has responsibilities. It is made possible at a distance by means of media which can cover long distances. The opposite of 'distance education' is 'direct education' or 'face-to-face education': a type of education that takes places with direct contact between lecturers and students (p. 41).

Additionally, Holmberg (2001) roots his definition of distance education in “correspondence learning." According to the American Journal of Distance Education (2011), Holmberg has served as a leader in the study of distance education as a theorist and practitioner for more than fifty years and is the former president of a distance teaching university in Germany. When discussing the term distance education and its evolution, Holmberg (2001) states, “Teaching and learning by correspondence is the origin of what is today called distance education... References to what was probably correspondence education occur as early as the 1720 's...Correspondence education is taken to denote teaching in writing, by means of so-called self-instructional texts, combined with communication in writing..." (p. 3). Moreover, according to the 
American Journal of Distance Education (2011), when traditional print and communication evolved beyond written correspondence, the definition of correspondence education was altered and essentially morphed into the term presently identified as distance education.

Additionally, in an interview appearing in the American Journal of Distance Education (2011), Holmberg is asked to characterize present day distance education. Homberg cites Moore and Kearsley's (2005) definition that states, “...distance education is planned learning that normally occurs in a different place from teaching, requiring special techniques of course design and instruction, communication through various technologies, and special organizational and administrative arrangement" (p.1).

Moore and Kearsley (2005), also provide a comprehensive, historical background for distance education. These authors maintain that in order to comprehend the methods and issues associated with distance learning today, one must examine its historical background.

First, according to Moore and Kearsley (2005), there are five generations that can be linked to distance education, the evolution of online education, and its technologies:

1. Correspondence

2. Broadcast radio and television

3. Open universities

4. Teleconferencing

5. Internet/Web 
Initially, the authors explain that the history of distance education began with courses of instruction that were delivered by the mail system. In fact, "beginning in the early 1880 's people who wanted to study at home or at work could, for the first time, obtain instruction from a distant teacher. This was because of the invention of a new technology--cheap and reliable postal services...” (Moore \& Kearsley, 2005, p. 24).

Early in distance education history, Bishop John H. Vincent was credited with creating the Chautauqua Literary and Scientific Circle. This organization offered a 4-year correspondence course to students, and it was designed to complement the summer schools held at the Lack Chautauqua college site. In 1883, the State of New York authorized the College to award diplomas and degrees by correspondence. Additionally, the Colliery Engineer School of Mines, (a private vocational school in Scranton, Pennsylvania) also began to offer a correspondence course in mine safety. After experiencing success with this program, according to Moore and Kearsley (2005), the institution grew to offer other courses and is now known as Education Direct-an online and distance learning organization.

Authors Moore and Kearsley (2005), also note that Isaac Pitman used the national postal system in the 1840 's to carry out his shorthand system of distance education. Additionally, William Rainey Harper of Chicago also adopted a distance education model by initiating a correspondence program at the University of Chicago. Harper was inspired by his experiences with correspondence learning at Chautauqua Institute. Ultimately, he implemented the world's first official program of university distance education.

Similar to today's primary objective associated with distance learning, Moore and Kearsley (2005) explain that early correspondence educators utilized technology to 
extend educational services to those who were unable to obtain an education elsewhere.

For example, the authors state the important role women played in the history of distance education. Women were often denied access to formal education institutions and consequently several significant women emerged as leaders in the distance education movement. According to Moore and Kearsley (2005), trailblazers in the movement included Anna Eliot Ticknor who established the Society to Encourage Studies at Home. Additionally, the authors discuss several other instances where women played prominent roles in distance education. More specifically:

“...in 1900, Cornell University appointed Martha Van Rensselaer to its faculty to develop a program for women in rural up-state New York; within three years there were three credit courses offered by correspondence. In 5 years, the program enrolled more than 20,000 women" (Moore and Kearsley, 2005, p. 26).

Further, Moore and Kearsley (2005) observe that the Morrill Act of 1862 was a condition precedent for developing correspondence education at land grant universities. Moreover, in fulfilling the democratic ideals associated with Land Grant universities, (i.e. providing educational opportunities for expansive and diverse populations of students) correspondence learning became an effective tool for these institutions to expand their educational reach. In fact, Moore and Kearsley (2005) report that by 1930, thirty-nine American universities offered correspondence teaching.

Clearly, distance learning today is often associated with for-profit institutions and organizations. The authors note that as correspondence learning became more prevalent there was a simultaneous surge in the growth of the for-profit educational sector. As a result of this growth, Moore and Kearsely (2005) report that in an effort to regulate and encourage ethical practices and professionalism at for-profit institutions, a major 
regulatory organization (known today as the Distance Education and Training Council) was formed in the mid 1920's. Further, in 1968 a correspondence education study was launched. According to the authors, results of the study indicated that approximately 3 million Americans were studying through correspondence learning nationwide. While this number pales in comparison to enrollment numbers associated with today's distance education and online learning programs, it still highlights the popularity of nontraditional methods of education. It is also important to consider the role correspondence education played in the Armed Forces. More specifically:

"By 1966, USAFI (United States Army Institute) offered over two hundred correspondence courses in elementary, high school, college, technical and vocational subjects, catering for some half million students. More than 7,000,000 members of the armed services took high school courses and approximately 261,222 enrolled in college courses" (Moore and Kearsley, 2005, p. 30).

Moore and Kearsley (2005) refer to the second generation of distance education as one that included the use of radio and television. More specifically, "Radio as a delivery technology for education, however, did not live up to expectations" (Moore and Kearsley, 2005, p. 31). Lack of faculty enthusiasm, amateurism, and commercial broadcast media/advertising influence was attributed to its "lukewarm interest". The authors also group television under the second generation of the distance education umbrella. For example, “By the mid-1980's, there were around 200 college level courses produced by universities, community colleges, private producers, public and commercial broadcasting stations, distributed either by the producers themselves or by the Corporation for Public Broadcasting (CPB)" (Moore and Kearsley, 2005, p.32). 
Moore and Kearsley (2005) refer to the third generation of distance learning as $A$ Systems Approach: AIM and the OU. First, to provide definition and context, AIM (Articulated Instructional Media Project) was initiated to test the possibility of linking various communication technologies. Next, the concept of the OU (Open University) was rooted in television and radio technologies and essentially allowed open access to higher education across the globe. Moreover, the AIM project's goal was to deliver effective, high-quality education at a low cost to off-campus learners/students. The AIM project director was Charles Wedemeyer from the University of Wisconsin at Madison. Wedmeyer believed that through the employment of a cocktail of different technologies (i.e. radio, television, recorded audiotapes, telephone conferences etc.) learning would not be limited to one method. Additionally, students with different learning styles could capitalize on which combination of technologies best suited to their learning preferences. More importantly, Moore and Kearsley (2005) point out,

"AIM invented the idea of the course design team, formed of instructional designers, technology specialists, and content experts...AIM represented a historic milestone and turning point in the history of distance education. This was the first test of the idea of distance education as a total system. AIM tested the viability of the theory that the function of the teacher could be divided, and teaching could be improved when those functions were assembled by a team of specialists and delivered through various media" (p. 34).

Essentially, Moore and Kearsley (2005) link AIM to the creation of the first national distance education university. More specifically, in 1967 the British Government formed a committee (which included Wedemeyer) to organize an innovative educational institution. Eventually, the Open University $(O U)$ was born. This university enrolled both domestic and international students. In fact, it boasted an annual enrollment of more than 200,000 adult students and graduated approximately 20,000 students each year. 
Essentially, the UK Open University, “...demonstrates not only the potential of distance education to provide opportunity regardless of geographic location... it demonstrates that distance is no barrier to the delivery of education that is of very high quality. In official evaluations, the OU is ranked near the top of UK universities in both research and teaching...” (Moore and Kearsley, 2005, p.35).

Due to its overwhelming popularity with student enrollment and the ability to obtain both institutional quality and effectiveness, the authors provide a table highlighting the establishment of other open universities in various countries. For example, China TV University System was established in 1979 and Turkey opened Anadolu University in 1982. Interestingly, the authors discuss the lack of initiative of the United States government with regard to establishing a national open university. It is recognized that the United States has always been a leader in the higher education realm. Therefore, the authors speculated, "The distributed political control of higher education in the United States, with each state having to deal with its own higher education establishment, made it impossible to obtain a national policy or set up a national delivery system" (p. 36-37).

Clearly, the evolution of the Open University continues to thrive and develop today. For example, according to WJLA News (2012), the University of Virginia is one of several U.S. institutions that plan to offer free, non-credit courses through its Internetbased learning system. The University has launched this initiative in an effort to raise its profile as a global higher education leader and reinforce its core missions of teaching, research, and public service. Additionally, according to Terence Chea (2012), the Massachusetts Institute of Technology also offered its first free and open online course in the spring 2012 semester. A striking 154,000 students from more than 160 countries were 
documented as registered for MIT's first online course. Obviously, online education in this form has reinvented the word "access" in relation to education.

Finally, Moore and Kearlsy (2005) refer to the fifth generation" of distance learning as one most people associate with distance learning today: "Computer and Internet-Based Virtual Classes". According to the authors, the earliest method of networking computers intended for the instruction of groups (instead of individuals) was defined as audio-graphics. Moreover, as early as 1989, The Pennsylvania State University began testing the use of audio-graphics as a means of internationalizing distance learning in America. For example, graduate courses were delivered online to cohorts of students in Mexico, Finland, Estonia in addition to several groups in the United States.

In their seminal discussion regarding the cultures of the Academy, Bergquist and Pawlak (2008) identify collegial, managerial, developmental, and advocacy as four staple cultures present in the academy. However, due to global changes and external influences found in North American Higher Education, Engaging the Six Cultures of the Academy is an expanded version of the first edition of The Four Cultures of the Academy.

Accordingly, Bergquist and Pawlak (2008), propose that there are two new cultures emerging in the academy; the virtual and tangible cultures. The virtual culture is driven by the technological and social influences that have appeared over the past twenty years. Further, the virtual culture is one:

“...that finds meaning by answering the knowledge generation and dissemination capacity of the postmodern world: that values the global perspective of open, shared, responsive educational systems; that holds assumptions about its ability to make sense of the fragmentation and ambiguity that exists in the postmodern world; and that conceives of the institution's enterprise as linking its educational resources to global and technological resources, thus broadening the global learning network" (Bergquist \& Pawlak, 2008, p. 147). 
As a consequence to this rapidly evolving educational landscape, institutions of higher education are playing catch-up as they struggle to develop an effective educational delivery and learning model which meets the needs of all institutional stakeholders. For example, according to Allen and Seaman (2011), a study including data from 2,500 colleges and universities revealed that sixty-five percent (of all reporting institutions) indicate online learning is a critical part of long-term institutional strategy.

\section{Characteristics of Online Courses, Programs, and Technologies}

Clearly, online courses and technologies differ from the traditional academic model. Obviously, the online classroom is not a venue where instructors teach in the traditional sense and students learn in conventional ways. In fact, virtual students are

often required to take on more responsibility for their individual learning, and instructors must adapt to a timeless and less structured teaching environment. Further, there are characteristics associated with online learning that are critical to understand and distinguish. First, according to Haythornthwaite and Kazmer (2004), two forms of instruction which can be considered distance (online) learning are: real-time distance learning and asynchronous distance learning. Real-time distance learning occurs when students and instructors interact simultaneously but in different locations. For example, a student and instructor could be engaged in online dialogue through a chat or messaging platform. Asynchronous learning interaction occurs at different times and in different places. An example of asynchronous communication could include online assignments and bulletin message postings. In an asynchronous learning environment, according to Miller (2010), students can process information outside of classroom instruction, and 
subsequently, class time can then focus more substantially on faculty and peer interactions.

Further, according to Salmon (2002), email, chat groups, bulletin boards, and computer-generated conferencing were developed to facilitate interaction and communication between students and faculty. These activities and technologies help define online education. Proponents of online learning argue that, "The Web allows learner control of information access. Students can experience online labs at any time and from any location. It is easier to move around on a Web site and attend to the portions that meet learning needs...Material on the Web is hyperlinked, both within a document to show connections of concepts, and between one document and another. A consequence is that learners can more easily move from one idea to another" (Haythornthwaite \& Kazmer, 2004, p. 25).

Brewer, DeJonge, and Stout (2001) explore the implementation of online learning by further delineating key characteristics of online courses and programs. For example, the authors discuss management systems for online courses and highlight techniques for interaction which include:

1. Discussion boards

2. Small-group formation

3. Chat availability for class and small groups

3. E-mailing the entire class or selected class members

4. Group or individual assignment posting (Brewer, DeJonge, and Stout, 2001, p.31). Next, offering several contributions and recommendations to the understanding of online instruction and pedagogy, Goodyear (2002) examines study findings linked to the 
philosophy, beliefs, and tutorial action of higher education teachers conducting class in an online environment. More specifically, this analysis provides information on several of the frequent methods used in online instruction and also highlights the critical areas of knowledge and beliefs that are associated with online learning. Goodyear provides definitions linked to online learning (i.e., e-learning, online learning, asynchronous learning, networked learning) More specifically:

"A distinguishing feature of contribution to an asynchronous communication is that it does not allow interruption-individual contributions to an asynchronous electronic discussion are relatively self-contained and well-formed and cannot depend on linguistic supports such as rapid turn-taking" (Goodyear, 2002, p. 83).

\section{Growth Trends of Online Education in Non-Profits and For-Profit Institutions}

When examining hard data and growth trends between non-profits and for-profit institutions, it is instructive to mine data from Allen and Seaman's (2011) Sloan Consortium report on online education in the United States. More particularly, one should address the question: how many students are learning online at postsecondary institutions? According to the report, in the fall of 2002, approximately 1,700,000 students were enrolled in at least one online course. By the fall of 2010, more than $6,142,000$ students were so enrolled. In other words, online student enrollment increased at an annual compounding growth rate of more than 17.4 percent. This is really an astounding growth rate, which in large measure accounts for significant growth in both the for-profit and non-profit sectors.

Online delivery is especially important to for-profit institutions. For example, according to the U.S. Department of Education (2011), 19 percent of all undergraduates at for-profit institutions were enrolled in at least one online course and 12 percent of the 
students were enrolled in an online degree granting program. These statistics contrast with four-year public institutions where 16 percent of students were enrolled in at least one online course and only 2 percent of students were enrolled in an online degree granting program. Moreover, according to the 2011 Pew Research Center report, presidents of both non-profit and for-profit post-secondary institutions are predicting a continued increase in the number of courses offered online as well as the number of students enrolled in these courses. Of particular importance is the fact that presidents of for-profit institutions are predicting, that within the next ten years, 54 percent of their undergraduate population will be enrolled in online courses. This contrasts with the prediction from Presidents of four-year public and four-year private institutions who forecast 37 to 45 percent undergraduate participation in online courses (p. 10).

Morey (2004) correctly predicted the emergence of for-profit, degree-granting institutions of higher education. He further predicted that "...this development has the potential of providing real competition and altering some segments of non-profit higher education" (p. 133). Indeed, the author notes several of the key players in the for-profit educational market that include the Apollo Group (i.e. University of Phoenix), DeVry University and Jones International University. In the final analysis, Morey recognized that online education was a game changer and four-year traditional brick and mortar institutions were slower to react.

While the history of distance education has essentially morphed into an online delivery model, nevertheless its structure continues to evolve and be influenced by the demands of accrediting agencies and their emerging guidelines. Frequent developments and changes to the educational delivery model have historically required different 
standardization and regulatory practices. According to elearners.com (2012),

accreditation is basically an authentication process by which institutions of higher education are evaluated against recognized standards to guarantee a high level of scholastic quality. The process is normally achieved through a peer-review process in which faculty from accredited institutions help to conduct assessments of either new nonaccredited institutions or accredited institutions seeking renewal. The criteria used to conduct these evaluations vary but in general they measure: the institution's mission, goals and objectives, resources and resource allocation, student admission requirements, student support services and the quality of the faculty and educational offerings (p.1).

\section{Standardization of Online Education: Stakeholder Interest}

"For-profits have grown by leaps and bounds in recent years, largely free of federal regulation...The institutions (for-profits) argue that they serve a class of students excluded from traditional higher education and that they are crucial for meeting the Obama administration's college completion goals. But many lawmakers worry that in fulfilling that mission, for-profits have relied too heavily on federal aid, forced students to borrow too much money, and produced degrees of questionable worth" (Miller, 2010, p. 1).

Miller's observations provide a sound rationale for regulation of the for-profit educational industry. Further, most for-profit institutions offer various forms of distance and online courses, programs, and degrees. In fact, more than a decade ago, Meyer (2002), recognized that there are a number of stakeholders vested in standardizing the quality of distance education including federal regulators, accreditors, state regulators, faculty, students, educational institutions, and independent learning and research organizations. For example, federal and state regulators are interested in determining quality (in distance education) for reasons linked to financial aid and distance education 
students. First, the Accrediting Council for Independent Colleges and Schools (ACICS)

(2010) defines accreditation as follows:

"Accreditation is an independent appraisal of an institution during which the institution's overall educational quality (including outcomes), professional status among similar institutions, financial stability, and operational ethics are selfevaluated and judged by peers. It is a voluntary activity separate and distinct from business licensing, authority to award educational credentials, and eligibility to administer student financial assistance" (p. 11).

Accrediting associations are concerned with monitoring quality in online instruction. Accordingly, Meyer (2002) indicates that the six regional accrediting agencies recognized by the U.S. Department of Education and the Council for Higher Education Accreditation (i.e. New England Association of Schools and Colleges, Middle States Commission on Higher Education, North Central Association-Commission on Institutions of Higher Education, Northwest Association of Schools and Colleges, Southern Association of Colleges and Schools, Western Association of Schools and Colleges) have collaborated to evaluate and recognize quality in online education programs. The author suggests stakeholders evaluate the value of an online degree based on the recommendations of one of the six regional accreditors.

Additionally, there are many other accrediting organizations that maintain similar missions and are committed to developing educational guidelines and high standards as well sound educational and business practices for academic institutions. For example, the Accrediting Council for Independent Colleges and Schools (ACICS) is incorporated as a non-profit education organization and is recognized by the U.S. Department of Education since 1956 as a national institutional accrediting body. The federal government, for purposes of distributing institutional and student financial funds, lists ACICS as an 
accrediting body on which it relies in determining the quality of education and training offered at institutions that ACICS accredits (ACICS, 2010, p. 9).

Clearly, the debate over quality in online education continues to place pressure on all institutional stakeholders. Therefore, this study intends to specifically examine academic employer perceptions of online degrees from traditional higher education institutions. However, to provide all stakeholders (i.e. students and academic/ nonacademic employers) a level of standardization and quality assurance with respect to distance and online education, they must first understand the institutional accreditation process. According to the 2012 College Blue Book, historically, authority over U.S. educational institutions is decentralized. Essentially, the states have the power to regulate educational institutions within their territory lines. Therefore, quality and standards would vary considerably from one state to another. Consequently, in order to guarantee a baseline level of quality, the practice of accrediting institutions emerged. Fast-forward to the 1990's when controversy surfaced over the accreditation of online programs within traditional higher education institutions versus those of entirely virtual universities. The College Blue Book (2012) maintains:

“...many felt that online degree programs should be evaluated using the same criteria as other degree programs within institutions of higher education. Others thought that new standards were needed to properly evaluate distance education. Although this issue has not yet been settled, the six regional accrediting agencies have proposed uniform guidelines for evaluating distance education" (p. 31). However, since accreditation is awarded by private entities, The College Blue

Book (2012) discusses potential for fraudulent practices — especially with regard to online education and diploma mills. For example, some diploma mills have actually created their own accreditation agency to deem themselves as an "accredited institution". 
Essentially, fraudulent practices in online education have made it imperative that stakeholders (i.e. student and employers) are protected by the accrediting standards imposed by legitimate governing agencies. According to Miller (2010), "Colleges are forbidden by law to make false promises of jobs or to inflate salary data, so they play on emotions, appealing to students' desires to be valued in their careers" (p. 4). Clearly, enrollment costs for students and hiring decisions for employers are significant on both ends. Therefore, a student enrolling in an online program will want assurance their credential is valued and accepted by employers. In comparison, employers need assurance that a potential employee (with a degree from a for-profit institution) has not only achieved, but can also demonstrate the skills and competencies necessary for employment.

Also addressing the issues and fallout associated with degree fraud, Brown (2006) explains how new technology and the demand for degrees have led to the proliferation of "diploma mills" and "degree mills". Consequently, the incremental rise of fraudulent degree granting providers has created new challenges for regulators and accreditation agencies. Essentially, in an effort to help "the assessor," Brown's paper highlights issues of degree legitimacy, authenticity, and further suggests an assortment of applicable resources.

Brown (2006) outlines the main methods by which an individual may obtain or claim a degree qualification (i.e., traditional degree program, claiming a degree without proof, diploma and degree mills). Further, the author proceeds to recommend several paper-based resources in order to validate the legitimacy of a higher education institution. Additionally, Brown provides a snapshot of several efforts currently being used to battle 
"qualification fraud" from around the globe. Finally, Brown ends his paper with the following conclusions and recommendations:

1. The status of the degree granting institution must be confirmed.

2. Confirmation of the conferral of the claimed award must be sought from the host institution.

3. The use of security features for both testamurs and transcripts is highly recommended (Brown, 2006, p. 78).

\section{Quality Guidelines: The Employer Viewpoint}

It is extremely important that higher education organizations and employers join forces and collaborate to institutionalize legitimizing policies. This task cannot be independently accomplished by accrediting organizations and agencies. Irrespective of the best efforts of accrediting agencies, committed faculty, institutions, and motivated students, employers are the major force behind the scenes. In other words, if the employer doesn't perceive an online program as high quality, students won't be hired by the employer; and, the online program will not be sustainable. Therefore, a fundamental question that must be addressed is: what qualities should an online graduate possess? Branch (2007) examines this question and concludes from the scholarly research that employers are seeking the following qualities in online graduates:

1. Communication Skills

2. Honesty/Integrity

3. Teamwork

4. Interpersonal Skills

5. Motivation/initiative (p. 25) 
In addition, employers presume that the graduating student also possesses "hard skills" which include basic mathematics and critical thinking faculties. There is a serious gap in the research conducted on the posited question above. It is important that further research be conducted since employers are a major piece of the quality paradigm.

\section{Establishing Quality in Online Education: The Sloan Consortium}

"Like the proverb about beauty, quality in education appears to be in the eye of the beholder. While quality always has been important to education, it has remained an elusive concept" (Kidney, Cummings, \& Boehm, 2007, p. 17). In fact, many institutions offering online courses and programs claim and boast quality assurance in online pedagogy. However, according to Kidney, Cummings, and Boehm (2007), documenting ways to assure the quality of e-learning is a critical endeavor. The authors explain that organizations such as the American Council on Education, the Institute for Higher Education Policy, the American Federation of Teachers and the Council for Higher Education Accreditation, have all circulated documents acknowledging online learning standards. However, they argue that these attempts (on behalf of these listed organizations) emphasize the significance of quality standards but lack a cohesive definition that can be recognized by all.

Consequently, according to Moore, Bourne, and Mayada (2005) the intent of the Sloan Consortium (Sloan-C) is to, “...help learning organizations continually advance and improve quality, scale, and breadth according to their own distinctive missions, so that education will become a part of everyday life, accessible and affordable for anyone, anywhere, at any time, in a wide variety of disciplines" (p. 1614). The authors also report 
that the Sloan-C maintains a catalog of degree and certificate programs offered by a variety of regionally accredited member institutions, consortia and industry partners. In addition, the Sloan-C provides speakers and consultants to help institutions learn about online methodologies and hosts conferences and workshops to help implement and improve online programs. The Sloan-C also conducts annual research studies (i.e. Online Education in the United States 2002-2011), surveys and forums to inform academic, government, and private sector organizations on new standards and initiatives necessary for improving the online learning industry (p. 1614). More importantly, according to Moore, Bourne, and Mayada (2005), the Sloan-C created a multi-perspective framework for all online programs to use as a guide for continuous quality improvement. This guide is based on the five pillars for employing quality online education at any institution.

Lorenzo and Moore (2002) maintain that quality in online education is commonly interchanged with learning effectiveness. While learning effectiveness is a critical element to achieving quality in online learning, it must be combined with a framework that also incorporates additional areas necessary for success. Below is a brief discussion highlighting each of the proposed five pillars.

Pillar I: Learning Effectiveness

The authors cite research claiming that there is overwhelming evidence to support the view that online learning can be just as effective as (and in some cases better than) traditional classroom learning. Lorenzo and Moore (2002) claim that the key to effective online learning is interaction. Online interaction can occur between student and instructor or student to student or student and content. The authors suggest incorporating active 
learning exercises into the course curriculum where students are placed in a position that requires them to reflect and respond to online course materials. A second critical component to effective online learning requires that educators understand how to create and nurture online learning environments that generate significant discourse and collaboration among students and faculty.

Pillar II: Student Satisfaction

According to Lorenzo and Moore (2002), online learners are very similar to customers when it comes to satisfaction. For example, any type of student learner (whether online or traditional) experiences a level of satisfaction when receiving timely, responsive, individual student support, and high-quality learning outcomes (p. 4). The authors suggest institutions employ a student survey as a tool to measure overall student satisfaction. Adjustments and improvements to the course or program can then be made accordingly. Additionally, the authors state that academic and administrative support services (i.e. registration, admissions, career counseling, tutoring, advising) are also critical components impacting overall student satisfaction. Further, Lorenzo and Moore (2002) report on the results of a survey conducted by the State University of New York Learning Network (SLN) which indicate the importance of productive interaction and discourse (i.e. student to student and student to faculty) in achieving student satisfaction. Finally, the authors point out that one of the best indicators of student satisfaction can be determined though an examination of online graduation and retention rates. Clearly, institutions have a vested interest in student persistence and graduation rates for a variety of reasons (i.e. institutional rankings, future alumni support, tuition dollars etc.). Ultimately, successful programs equal successful students—at graduation or beyond. 


\section{Pillar III. Faculty Satisfaction}

Simply put, quality in online education cannot be achieved without a solid faculty foundation. Initially, the authors cite several studies reporting on positive faculty reactions to online instruction. For example, according to Lorenzo and Moore (2002), several studies claim that faculty members are excited to find that electronic communication offers an opportunity for more classroom interaction (i.e. student to student and student to faculty). However, it is vital that online faculty members receive adequate institutional support. Whether the support comes in the form of technology, administrative, ministerial, or moral support, providing adequate assistance will allow faculty more time and dedication for developing quality online instruction and delivery. The authors also observe that there has been a resistance in the academy to online education. Indeed, some faculty consider online learning as a lesser form of education. Moreover, according to a report by Allen and Seaman (2011), one-third of all academic leaders continue to believe that the learning outcomes for online education are inferior to those of face-to-face instruction. Additionally, this study reveals that less than one-third of chief academic officers believe that their faculty accept the value and legitimacy of online education. This percent has changed little over the last eight years.

Pillar IV: Cost Effectiveness

Moore, Bourne, and Mayada (2005) explain that building effective forms of educational technology and infrastructure can be a very expensive undertaking when implementing any type of online course or program. The authors recommend the following guidelines for improving services while reducing cost:

1. Cost effectiveness models are turned to institutional goals. 
2. Tuition and fees reflect cost of services delivery.

3. Scalability, if an institutional objective, can be accommodated.

4. Partnering and resource sharing are institutional strategies for reducing costs.

5. Mission-based strategies for cost reduction are continuously formulated and tested.

6. Intellectual property policies encourage cost-effective strategies.

Pillar V: Access

Lorenzo and Moore (2002) argue that regardless of all the scholarly research indicating the effectiveness, flexibility, and economic feasibility associated with online education, prospective students must be able to access the medium with ease. This includes students with diverse learning abilities and disabilities. Further, Moore, Bourne, and Mayada (2005) indicate the importance of monitoring and evaluating the reliability and functionality of delivery mechanisms. Student demand for specific courses should also be made available and open at flexible and convenient times. Additionally, feedback from student learners should be taken very seriously and applied for continuous program and course improvement.

\section{Theory to Practice: Building Quality and Effective Online Courses and Programs}

While accrediting agencies assess standards of quality at the institutional level, there are countless "best practices" and "guidelines" for designing and implementing successful online learning strategies in the classroom environment. For example, selected literature focuses primarily on effective technological practices in the online classroom, while others place heavy emphasis on the role of the instructor/facilitator. Regardless of motivation, online course standardization is often questioned among the variety of 
stakeholders such as: student, instructor, administrator, and employer. Therefore, in the absence of face-to-face interaction, the design and strategy of an online program or course becomes a critical element in creating of an effective learning environment. Accordingly, Wildflower (2010) provides suggestions for teaching professionals on how to become successful online instructors in Teaching Professionals to Be Effective Online Facilitators and Instructors. Moreover, the author argues that success online requires an instructor to provide a clear understanding of course goals and learning experiences. Additionally, it is important to inform participating students of the pace, attitude, and behavioral expectations for academic success.

Next, the author lists several elements necessary for effective course design and structure. For example, Wildflower (2010) highlights the importance of employing the appropriate software. Further, software that is too complex may distract participants from a rich discussion. However, software that allows an instructor to divide the classroom "space" is essential for effective learning. The author explains that chat rooms or break out rooms allow for different discussion threads to take place. In essence, this gives course participants and the instructor a forum to respond to one another in a group or individual capacity.

Additionally, the author recommends that successful online instructors promote optimal participation and provide several examples to encourage learner participation which include:

1. Students organize to write collective papers.

2. Students are encouraged to collectively determine functional guidelines for the course. 
3. Students take turns introducing each new topic, facilitating the discussion, or summarizing what has been said (Wildflower, 2010, p. 390).

The author also advocates that instructors in an online environment clearly articulate expectations and boundaries enabling students to transition through a course as a cohesive unit. More specifically, Wildflower (2010) shares an example from her own personal teaching experience in online teaching and facilitating group discussions. She explains that she did not provide any guidelines, boundaries or expectations to students in her own course with regard to group discussion. Essentially:

'I had students complaining about other students' postings. Other students shut down completely. I am sure that many dropped the course as a result of the discussions" (Wildflower, 2010, p. 391).

Therefore, the author suggest instructors be as clear as possible about participation, grading criteria, assessment and procedure from the beginning. Next, Wildflower urges teaching professionals to establish an atmosphere where students know that confidentiality is respected and maintained. Confidentiality ensures that what is said online will not be shared beyond the virtual classroom walls, thereby contributing to a more stimulating and open course environment.

Due to the differences between online learning and traditional face-to-face instruction, Barrett (2010) argues that online learning instructors must possess a different type of skill set in order to be effective in the virtual classroom. From a human resource and hiring perspective, the author proposes that institutions create and implement different processes and procedures for determining the best possible instructor for an online teaching position. The author discusses that while many traditional instructors enjoy teaching in a physical classroom, there has been new interest among traditional faculty with regard to transitioning to the virtual classroom space. The author assumes 
that the motivation behind the transition from traditional classroom instruction to online teaching includes new part-time and adjunct teaching opportunities. This provokes one to consider whether or not traditional faculty consider online instruction an easy alternative to making additional compensation or spending less time in the classroom.

Initially, the author points out that a new type of online student population has emerged as Internet and online learning technologies continue to advance. More specifically, he indicates that many instructors have noted an increase in a more diverse population of online learners. This evolution has prompted instructors to update and improve their teaching skills, practices, and strategies in an effort to accommodate the changing study body. Consequently, instructor demand for new online teaching skills has prompted educational departments to develop learning and training programs for their faculty. Further, in an effort to assist institutions, Barrett identifies three major areas that universities must consider in the area of online instructor recruitment and hiring:

1. Reconsider recruitment approach to focus on online instruction

2. Examine best practices of other leading educational institutions with regard to their recruitment and training of online instructors

3. Update technological and skill requirement for online instructors (p. 17)

Barrett (2010) also emphasizes the importance of hiring quality online faculty with regard to maintaining academic and program quality. Additionally, the author acknowledges a current challenge often associated with online instruction:

"While some teaching tools may be effective in one learning environment, they may not be as successful in another. Therefore, as each environment is unique, as well as the learners in it, the teacher needs to assess their virtual environment and determine if change is necessary. However not all educators may be as flexible in their teaching method, and they may not be willing to change" (Barrett, 2010, p. 19). 
Undoubtedly, the issue of what constitutes educational quality in the virtual world is an evolving benchmark. Accrediting agencies cannot act alone in setting quality standards. Rather, the research clearly points out that determining quality is a collaborative effort among all stakeholders. Therefore, examining stakeholder arguments for and against the value and outcomes of online education as documented in past research is vital to understanding the value of an online degree from any postsecondary institution.

\section{Stakeholder Overview}

Before examining past research on stakeholder arguments for and against the value and outcomes of online education, it is important to identify the major actors/stakeholders, namely: academic institutions, students, faculty, and employers. Additionally, there are other stakeholders who are rarely mentioned in scholarly research but play a powerful "behind the scene" role in promoting online education. These stakeholders are largely comprised of software and hardware vendors and developers, who enormously benefit in an economic sense from the proliferation of online education.

This analysis will be limited to an examination of the former stakeholders mentioned.

\section{Arguments For and Against Online Education}

It is instructive to begin a review of the scholarly research by examining the work of Appana (2008), as he highlights many of the benefits and limitations often associated with online learning. The author describes each beneficial outcome and limitation from a student, instructor, tenured faculty, and institutional stakeholder perspective. Essentially, 
Appana's (2008) review intends to provide additional knowledge to educators and practitioners about the processes and outcomes of online learning as compared to traditional classroom instruction. Initially, the author discusses the benefits of online education and poses the question to all stakeholders: Why invest in online learning? $\mathrm{He}$ then provides a description of the following beneficial outcomes associated with online instruction:

1. New Markets

2. Economic Benefits

3. International Partnerships

4. Reduced Time to Market

5. Educational Benefits

6. Anonymity

7. Student Interaction and Satisfaction

8. Growth in Faculty Learning Curve

9. "Rich" Feedback and Evaluation (pp. 7-10)

Explanations of some of these beneficial outcomes are described in adequate detail. However, others appear to lack substance and support. For example, Appana (2008) provides a cogent argument that online learning has the potential to, "tap into markets, both national and international, that cannot be easily accessed with other more traditional forms of course or program delivery" (p. 7). He maintains that academic programs located in certain regions or countries can now open their virtual doors to students on a global scale. Additionally, individuals who are unable to attend an institution on a full-time basis are also a new marketable group of students, thereby 
providing the academic institution with the potential for additional economic benefits and positive outcomes. The author also cites research claiming that the cost benefits to online learning are very real. Moreover, institutional financial gain on the back end should outweigh any additional costs incurred on the front end. Of course, the recent success enjoyed by for-profit online institutions provides additional credibility for Appana's position.

Appana (2008) emphasizes student anonymity as a beneficial outcome of online learning. While the author does not define the term with reference to online learning, he does state:

"Another benefit of the online delivery method is that the associated anonymity can result in greater participation from all students, including 'shy' ones. The lack of visual cues allows the instructor to treat all student in the same manner" (Appana, 2008, p. 9).

Rapid feedback and evaluation was another beneficial outcome of online learning discussed in this article. For example, Blackboard and WebCT technologies enable students to view on a more immediate basis the results of their tests, quizzes, assignment etc. This process allows a student to also solicit quick instructor feedback, advice, and suggestions for help, clearly a positive outcome for the student.

While Appana (2008) believes the potential outcomes of online learning are very promising, he also identifies several of the limitations evident in the virtual environment. In fact, many of the limitations are directly related to the previously mentioned benefits. For example, while the author argues that the economic/financial benefits for institutions that invest in online programs are numerous, the need for start-up funding and capital is a substantial limitation on the medium. Additionally, the author references costs, 
challenges, and potential negative outcomes associated with technology, instructor and learner readiness, organizational preparedness, and program or system upgrades.

Access is another limiting outcome. For example, Appana (2008) points out that some students, based on geography or socio-economic status, will have limited access to the technology required in online instruction. Further, he revisits the idea of feedback and evaluation and explains, "Online learning systems may make it difficult to control participation of the students. The instructor must have a way of checking that each student is actively participating" (p. 16). Several of the other limiting outcomes mentioned in this study include: assessment, crisis management, and differing stages of group development.

Institutional and student stakeholders will find this review beneficial as they navigate both the positive and negative outcomes as well as the opportunity costs associated with online instruction. Clearly, administrators need to consider the challenges faculty and students may face with regard to technology, access, and overall learner/instructor readiness. Despite these challenges and potential negative outcomes, Appana (2008) articulates that online education is here to stay. More specifically, in order for an online course or program to be successful he recommends that:

“...benefits and limitations to the organization and to the student should be appropriately balanced. It is important not only to focus on the costs of developing and delivering an online course or program, but also to focus on potential performance and value added benefits to both the institution and more importantly the student" (Appana, 2008, p. 19). 


\section{Student Learning and Program Outcomes Obtained Through Online Instruction}

How do student learning outcomes in the online classroom compare with those in a traditional classroom environment? This is a critical inquiry and has enormous pedagogical and economic consequences for both bricks and mortar and virtual institutions. Kirtman (2009) launched a study comparing three online courses to three traditional face-to-face courses in an effort to explore issues of learning outcomes associated with each classroom approach. The author explains the study was designed to address the issue of "level of student learning" in both an online and traditional course format.

First, Kirtman (2009) points out several gaps in the research which provide her study with relevance and contextual support. For example, the author explains that a considerable amount of the research in the area of online teaching and learning is not directed toward academic achievement or learning centered outcomes. Rather, much of the research in online education is focused on challenges associated with online learning (i.e., social issues, advantages and disadvantages) and "how-to" manuals and guides. Additionally, the author found that many studies describe issues in online instruction and examples of failed teaching experiences. Also helpful, the author examined several studies and noted limitation with samples size and subject matter unrelated to higher education. For example, "Faculty concerns, small sample sizes, and the lack of focus on the field of education coupled with the growing number of online programs in the area of education lead to a growing need for more research in this area" (Kirtman, 2009, p. 105). Accordingly, Kirtman's study was designed to address some of the gaps and limitations found in the area of online learning research. 
The author's research drew from a sample of students from three online courses and three face-to-face courses. The courses were taught over a two-year time period, and 71 students were enrolled in the online classes and 69 participated in the face-to-face classroom environment. Additionally, the author points out that instruction in both types of courses was equivalent in every capacity except the fact that students were required to complete their work online or in a class. All study participants were enrolled in a public institution in the Southwest. It is important to note that each participant had previously completed a bachelor's degree and was working toward a Master's degree. The author highlights which data sources were used for analysis. First, exam grades were compared (both groups were administered the same midterm and final exams). Second, participant papers were also analyzed which were based on the same topics. Finally, student participants in both groups were asked to complete an end-of-course anonymous survey regarding course satisfaction.

This study's methodology was unique for several reasons. First, it employed several different data collection procedures and analyses. For example, the technique of document analysis (i.e., student written submissions) was used. Further, the author states that data was analyzed using descriptive and inferential statistics to determine significance when comparing scores on the exams and written work. Additionally, survey data was used to emphasize and clarify the numeric findings. Ultimately, the author reports that results of the study were mixed. For example, in paper grade analysis, no significant difference was found between the two groups of students (online vs. traditional). However, in analyzing the results from the exams, a significant difference was discovered between the online and traditional student learner groups with regard to 
the midterm exam. In fact, the traditional students scored 2 points higher than the online student group (statistically significant). The author indicates the final exam scores were less conclusive. Finally, survey data revealed only positive results in terms of comments related to online classes. More specifically, (when asked if there was a difference in learning when completing an online course session vs. an in-class session) the majority of students stated there was no perceived difference in their learning. Further, one student stated:

"With an online class I have been able to focus more on the information of the class and less on the stuff that has nothing to do with the class, such as traveling time to get to class, gas, and parking. Now all of my school effort can be focused on learning the material" (Kirtman, 2009, p. 110).

In a results summary, the author indicates from survey data that students do value online classes. Further, she links "value" to a high level of student satisfaction and makes the assumption that high satisfaction could essentially lead to increased learning outcomes. However, there is no solid data in this study connecting high levels of student satisfaction with increased learning outcomes. Additionally, mixed data results make it difficult to conclude if online or face-to-face instruction produces a higher "level" of student learning outcomes.

It is important to disclose that there are a number of limitations associated with Kirtman's (2009) study. For example, in the area of instruction it is possible, “... since the students of the traditional group met together, some of the students formed study groups that met before and/or after class. Study groups were not likely to be formed with the online students because of issues with proximity" (Kirtman, 2009, p. 111). Further, the author describes a self-selection bias that could have potentially influenced study 
results. For example, students self-selected the course method of their choice. Therefore, it is possible that stronger students could have all self-selected into one course over another which could essentially account for the higher midterm grades achieved for inclass student participants.

Ultimately, based on study findings, there is evidence to suggest comparable learning outcomes in both the traditional and online course format. Therefore, institutional, student, and employer stakeholders (skeptical of or convinced of online learning effectiveness) may find the results of this study valuable.

In a similar study comparing learning outcomes in traditionally instructed courses with those in online courses, Ary and Brune (2011) examine student learning outcomes in online environments. The authors tested the relationship among learning outcomes (i.e. as measured by the percentage of total points earned over the course of the semester) and other variables (i.e. American College Testing scores (ACT), pre-course grade point average, gender etc.) in a finance course. Study results indicate that the instructional delivery method made little difference in student performance.

While smaller studies examining learning outcomes (i.e. in one classroom environment) are very valuable to all stakeholders, broadly based, systemic reviews are critical in providing statistically significant results to a more general population. For example, in a 2010 meta-analysis, the U.S. Department of Education conducted a systematic search of the research literature from 1996 through July 2008 that identified more than a thousand empirical studies of online learning. Moreover, analysts assessed these studies to locate those that: 
1. Compared online instruction to a face-to-face learning environment

2. Measured student learning outcomes

3. Applied a thorough research design

4. Provided sufficient information to calculate an effect size

Results of the meta-analysis included 43 studies which were mined from research with

older learners and 7 studies focusing on K-12 online students. The meta-analysis

revealed:

"On average, students in online learning conditions performed modestly better than those receiving face-to-face instruction. The difference between student outcomes for online and face-to-face classes - measured as the difference between treatment and control means, divided by the pooled standard deviationwas larger in those studies contrasting conditions that blended elements of online and face-to-face instruction with conditions taught entirely face-to-face (U.S. Department of Education, 2010, p. xi).

However, the report cautions that these blended conditions often integrated supplementary learning time and instructional elements that were not received by students in control conditions. Therefore, the advantages observed in online learning environments may be a result of the additional treatment conditions and not necessarily the delivery medium. Additionally, the report maintains that the existing research suggests that promoting self-reflection, self-regulation and self-monitoring leads to more positive online learning outcomes. Exercises such as prompts for reflection, selfexplanation and self-monitoring strategies have also demonstrated potential for improving online learning outcomes. 


\section{Employer Perceptions of Student Online Learning Outcomes and Performance}

Roussas (2006) compared the overall learning outcomes and performance levels of employees with college degrees earned from accredited online institutions with the performance level of employees with college degrees earned from accredited traditional classroom institutions. Roussas (2006) used INTEL Corporation as a case study example since INTEL employs thousands of employees at all levels who have received education from both a traditional classroom environment and from an online environment.

In order to compare the performance of Intel employees who obtained education from a traditional classroom environment with Intel employees who obtained education from an online environment, Roussas (2006) applied ANOVA and t-tests to the data. Results indicated that no statistically significant differences exist in organizational productivity and overall skillset between traditional classroom-educated employees versus online-educated employees. Roussas (2006) suggests his findings contradicted the generally held perception that graduates from traditional higher education institutions are better performers than graduates from online institutions. The author assumes this perception has led companies to preferentially recruit and retain employees because they have graduated from or have continued their education through traditional educational institutions.

In a similar study, Metrejean and Noland (2011) examined the perceptions of CPA firm recruiters on whether learning outcomes achieved in an online Master of Accounting (MACC) degree is comparable to that of a traditional MACC. Study results demonstrated that recruiters do not perceive a difference in a candidate who receives an online MCAA and a candidate who receives a MCAA from a traditional classroom-based 
accounting program. Instead, results reveal that having passed or passed part of the CPA exam is a positive outcome and most highly rated attribute of a new accounting graduate from a recruiter perspective. Interestingly, the authors report that a strong GPA is another factor important to firm recruiters. However, it was inconsequential to the recruiter as to whether a high GPA was achieved in an online or traditional program. Indicative, of this type of study, GPA achievement in an online course environment as compared to a traditional course setting appears to be a notable gap in the literature.

\section{Institutional and Faculty Arguments For and Against Online Education}

In an effort to apply several of the lessons learned during the evolution of distance education, Lorenzo (2010) suggests critical elements for practitioners and institutions to consider as they strategically plan for the future of online education. Moreover, the author maintains, “...while academics will continue to debate the equivalency of online course work, no one can dispute the personal empowerment that has resulted" (p. 95). Further, the author explains that the purpose of this discussion is to help bridge a gap in information regarding online strategy and effective procedure for both institutions and participating faculty.

Initially, Lorenzo (2010) provides a brief discussion on the historical lessons associated with online learning. For example, he first explains that throughout the history of distance education there have been shared purposes and practices among users and facilitators. More specifically, the idea of providing greater flexibility in learning, allowing for asynchronous and independent learning, and requiring a different degree of educational pedagogy are essential. However, the author states that while the technical 
elements of online learning have evolved, often institutions become distracted with technical aspects associated with the medium. Further, Lorenzo explains that history serves as an important reminder with regard to product life cycles. He notes that except for correspondence programs, all previous distance education delivery mediums have had fairly short "life spans." Therefore, he recommends that institutional planners consider "life spans/cycles" even if technology (i.e. the Internet) appears to exhibit long-term potential. The author speculates that technologies such as interactive holographs, personalized learning devices, and genetic biomedical implants are possible mediums for one day displacing the Internet in distance education. However, he does not ground this speculation in any research or literature.

Next, Lorenzo (2010) entertains several of “today's lessons” which institutions can apply to online learning planning strategies. He notes three lessons that include: increasing demand, finding faculty, and continuing skepticism. Similar to many other current studies focusing on online learning, in this analysis, the author states that the extraordinary demand for online learning opportunities has created a major challenge for institutions with regard to properly trained faculty. Interestingly, the author cites a study indicating that student demand exceeded their online offerings in a large percentage of colleges surveyed. An additional study also exposed that 96 percent of community colleges (participating in the study) reported offering specific distance education training for their faculty. The author argues that despite institutional efforts, educational planners should anticipate that the demand for online learning is likely to create a deficit in faculty or instructors. 
Faculty and employer skepticism is another challenge for institutional

programmers and planners. Moreover:

"More than ten thousand faculty members at sixty-seven public four-year campuses responded to a survey regarding online instruction...Although 30 percent felt that online courses provided superior or equivalent learning when compared to face-to-face classes, 70 percent felt that learning outcomes were inferior..." (Lorenzo, 2010, p. 97).

Further, the author indicates that studies including employer perceptions of online education also reveal a level of skepticism, but less so than university faculty. For example, the author quotes a study conducted by Zogby International indicating that a majority of employers who are familiar with online colleges believe online programs to be just as credible as traditional learning. Moreover, Lorenzo states that improvement in employer regard for online learning has been attributed to the number of well-established schools offering such options.

Lorenzo's (2010) work is especially valuable with respect to presenting a broad overview of several of the major outcomes, challenges, and recommendations that institutions and faculty should consider when planning and incorporating online learning into their strategic planning process.

When viewing the scholarly research in a holistic sense, several conclusions and observations can be articulated:

1. While stakeholders can debate the positive and negative externalities of online education, it is difficult to dispute its rapid ascent and powerful foothold in the educational paradigm.

2. Student online learners perceive value and positive outcomes in this delivery model, which include but are not limited to: geographic and economic access, rapid feedback and evaluation, student satisfaction, similar performance outcomes in comparison to traditional classroom students, and growing acceptance by employers of online degree programs as a bonafide entry credential. 
3. While institutional stakeholders must navigate a myriad of challenges and potential negative outcomes (i.e. economic development and startup costs, technology choice and programming, instructor and learner readiness, faculty skepticism, competition from both for-profit and non-profit institutions, etc.) nevertheless to ignore the potential benefits of an online delivery model would be risky at best and potentially devastating at worst.

4. The direct and perceived quality of online educational offerings and degree programs will be driven not only by faculty and students but also by employer demands for degree programs which serve as an entry credential.

Clearly, the value and quality associated with online learning from the institutional stakeholder perspective (i.e., students, administrators, faculty) is a topic of continual debate throughout the academy. However, in an effort to provide online degree seekers with the ability to protect themselves from making a poor financial decision, it is critical to examine the views regarding the legitimacy of online programs as an entry credential for employment from the perspective of hiring gatekeepers and employers.

\section{Credentialing versus Educating}

A substantial number of scholars have researched the question: How do hiring gatekeepers and employers view the legitimacy of online programs and online degrees as a sufficient, entry credential for employment? This inquiry is especially relevant in today's global economy, which is characterized by fierce competition for employability in any field and profession. In fact, the entry level job search is further complicated by the post-recession U.S. economy and the continued contraction of several Western European economies. For example, as reported by the Associated Press (2012), “The percentage of Americans in the workforce dropped to its lowest level in 31 years" (p.1). Moreover, the U.S. economy remains mired in the painful aftermath of the deepest 
recession since the 1930's. Further, the U.S. Department of Labor reported that the hourly pay rate for American workers fell in August (Associated Press, 2012, p.1). Especially problematic, U.S. manufacturers cut more than 15,000 jobs last month-a further signal of a shrinking manufacturing base. In light of the employment outlook, it is vitally important that educators understand the subtle differences and impacts of merely credentialing our students as opposed to educating a viable workforce. Thus, any scholarly review of the literature on entry level credentials for employment must begin with a thorough understanding of credentialing versus educating.

According to Rao et. al. (2011), employability is defined as acquiring, creating, and fulfilling work through the use of competencies. This often requires a specific set of credentials or skills held on behalf of the potential employee. Obviously, institutions and faculty should be well aware of market conditions in order to enhance their students' potential of finding employment upon graduation.

In a challenging critique of American culture, Jacobs (2004) explores the concept of credentialing versus educating in higher education. Jacobs argues:

"Credentialing, not educating, has become the primary business of North American universities. This is not in the interest of employers in the long run. But in the short run, it is beneficial for corporations' departments of human resources, the current name for personnel departments. People with the task of selecting successful job applicants want them to have desirable qualities such as persistence, ambition, and ability to cooperate and conform, to be a 'team player'... From the viewpoint of a government agency's or corporation's department of human resources, the institution of higher learning has done the tedious first winnowing or screening of applicants" (p. 45).

While Jacobs' assumption may be challenged by traditional degree granting institutions, do Jacobs' indictments hold true for degrees obtained in an online capacity? Essentially, which factors legitimize and bestow value on a college degree? If employers are only 
seeking the credential (degree), then the institutional and educational approach toward learning is certainly of lesser importance. Indeed, one could speculate that this is one reason why participation in a distance education program was most common among undergraduates attending for-profit institutions at a rate of 12 percent in 2008 (U.S. Department of Education, 2011, p. 3). Jacobs proceeds with her argument against the academy (in its entirety) by stating that students today have simply succumbed to the system that allows credentialing to be the normal primary business of higher education institutions. Moreover, she exposes the economic imperative that university education has become a growth industry. Further, in an effort to manage issues of scale, traditional institutions have adopted strategies for profit making organizations, “...that turn expanded markets to advantage by cutting costs. Increased output of product can be measured more easily as numbers of credentialed graduates than as numbers of educated graduates. Quantity trumps quality" (Jacobs, 2004, p. 49). If Jacobs' arguments are valid, then one must conclude that educational institutions will increase and embrace the online delivery model not only because it makes economic sense but also employers are not grasping the essential difference between credentialing and educating.

\section{Hiring Gatekeeper and Employer Perceptions}

Most relevant to the proposed study, and before one can examine the scholarship, it is necessary to define terms. Columbaro and Monaghan (2009), discuss the definition of a hiring gatekeeper in their examination of the literature. According to the authors, a hiring gatekeeper is defined as, “... anyone who stands between you and the person who 
might want to hire you. Gatekeepers come in many forms, including receptionists, HR recruiters, and resume screeners" (p. 2).

What is considered to be a "quality" education among employers? In other words, is there a difference between credentialing and educating? Adams (2008) exposes the thoughts and perceptions of hiring gatekeepers (i.e. those who make hiring decisions) in a comprehensive study designed to understand the factors limiting the acceptability of online courses and degrees. Herein below (see Table 1), the author provides a comprehensive, summary table illustrating gatekeeper acceptability of candidates, who earned their degree online or partially online in multiple industries and professions. The data was obtained from four different studies that Adams had previously conducted and co authored.

\section{Table 1}

Gatekeeper Acceptability of Candidates

\begin{tabular}{l|l|l|l}
\hline $\begin{array}{c}\text { Focus of } \\
\text { Acceptability }\end{array}$ & Residential Campus & $\begin{array}{c}\text { Combination } \\
\text { Online/Traditional }\end{array}$ & Online Only \\
\hline Graduate School & $96 \%$ & $48 \%$ & $9 \%$ \\
\hline Academic Professions & $98 \%$ & $16 \%$ & $1 \%$ \\
\hline Business Professions & $96 \%$ & $27 \%$ & $4 \%$ \\
\hline Health Professions & $93 \%$ & $29 \%$ & $5 \%$ \\
\hline Mean & & & $5 \%$ \\
\hline
\end{tabular}

Note. Adapted from Adams, J. (2008). Understanding the factors limiting the acceptability of online courses and degrees, International Journal on ELearning, 7(4), 573-587. 
In summary, the mean acceptability level of online degree candidates was very low, essentially 5 percent. This compares and contrasts with the mean acceptability level of traditional degree candidates at 96 percent. Also, the mean acceptability level of candidates whose degree was a combination of online/traditional approximated 30 percent. Interestingly enough, the lowest acceptability of an online degree candidate occurred among academic professionals.

Additionally, using results from four national surveys, Adams (2008) conducted a study to assess the degree of objections among academic search committee chairs to hiring job candidates with online degrees. Adams (2008) stresses that the focus of his study is unique, as it was not designed to assess the social value of distance learning programs or to make comparative evaluations with regard to educational outcomes received in either learning environment. Instead, the goal is to foster research which examines the employer and gatekeeper preferences concerning candidates who have obtained a degree either entirely or partially online. In other words, the specific aim of this study was to assess gatekeeper perceptions that appear to impact the acceptability of online degrees as a sufficient condition for employment. In an effort to understand the priorities of search committee chairs, the methodology of the study examined results of a questionnaire and written comments. The study's rationale was grounded in data from the U.S. Department of Education stating that the number of doctoral degrees conferred will increase by 21 percent by 2015. Moreover, Adams maintained that half of all new doctoral graduates are expected to seek employment. Consequently, "to fill this growing need, many institutions are moving to mirror residential coursework with online versions, or to create new degree programs that are offered entirely online" (p. 575). 
The study sample included university search committee chairs in institutions advertising open faculty positions (which typically require a doctoral degree). Additionally, Adams notes that online degree programs are now being recognized in publications such as U.S. News and World Report. However, the author explains that while none of the for-profit distance education programs offered by virtual institutions are accredited by the National Council for Accreditation of Teacher Education, each retains a type of accreditation that allows these for-profits to promote their programs in direct competition with traditional higher education institutions. Further, Adams uses Capella University as an example of a for-profit institution providing a wide range of online doctoral degrees and maintaining a healthy enrollment of 6,000 doctoral students. The author makes the assumption that the previously mentioned figures from the U.S. Education Department would suggest at least one half of Capella's 6,000 doctoral students would seek employment in the academy upon graduation. Therefore, combined with other online degree seekers from major for-profit institutions (e.g. University of Phoenix), the number of doctoral candidates from online degree programs will continue to increase substantially. Essentially, it is imperative for all institutional stakeholders to more clearly understand employer acceptability of these online degree candidates.

Research questions in the Adams study were designed to provide understanding as to what counts (as acceptable) and also to learn which instructional elements affect the acceptability of online degrees. More specifically, Adams (2008) summarizes the study findings:

"While the reputation of a university for academic rigor is also associated with acceptability, traditional classroom experiences are perceived to offer something more. It may be suggested that online programs, even those offered by institutions 
noted for excellent academic standards, may always be regarded as 'missing' key elements" (p. 583).

He further notes that the missing key elements are face-to-face communication with students and faculty, mentored research, intellectual rigor and program reputation.

In a second study examining employer perceptions of online degree candidates, the Society for Human Resource Management (2010) conducted research from 449 organizations and employers which included: privately owned for-profit, publically owned for-profit, non-profit, and government sector organizations. The study revealed several significant findings. For example, more than one-third of the organizations (34\%) reported that job candidates who have obtained their degrees online were viewed as favorably as job applicants with traditional degrees. Additionally, 55 percent of the organizations indicated that if two job applicants with the same job experience were applying for a job, it would not make a difference whether the job candidate's degree was obtained through an online or traditional (i.e., brick-and-mortar) degree program. However, it was observed that the higher the position in the organization, the less acceptable the online degree credential was valued. More specifically, 43 percent of the organizations indicated that an online degree credential is acceptable for a job applicant seeking an entry-level position, but only 15 percent of organizations indicated that an online degree is acceptable for a job applicant seeking an executive-level position. In other words, employers became more cognizant of and sensitive to the educational background of applicants (traditional vs. online degree candidates), as the applicant moves up the job pyramid. 
Perhaps the most interesting statistic in this study was that only 11 percent of organizations reported that applicants frequently or always identified on their resumes whether their degrees were obtained virtually. Clearly, there is a possible issue of disclosure now associated with online degree applicants and should be an area of focus for expanded study. However, 79 percent of organizations indicated that they had hired a job applicant with an online degree in the last 12 months. This study presented solid data indicating favorable hiring tendencies among employers toward online degree candidates for entry-level positions.

Next, in a study assessing the value of online education, Adams and DeFleur, (2006) examine the acceptability of a bachelor's degree earned online (or partially online) as a pre-condition for obtaining employment among hiring executives. This study is the first of many similar studies conducted by the authors to explore employer perceptions of online degrees. In this investigation, Adams and DeFleur (2006) launched a national survey of hiring executives from a variety of industries to determine whether a significant difference existed between the hiring rate of applicants with online degrees and those with traditional degrees. Essentially, survey respondents were asked to compare their attitudes and preferences with regard to making a hiring decision based upon degree type (i.e., online, partially online, or traditional). Survey respondents were mined from national newspaper employer job listings. Additionally, the authors report that the employers were seeking managers or entry-level employees in industries such as accounting, business, engineering, and information technology. Quantitative survey results reveal that applicants with a traditional degree were overwhelmingly preferred 
over applicants possessing a degree obtained online or partially online. This result was consistent across both industry and professions.

Exploring administrator attitudes toward online teacher preparation programs, Huss (2007) conducted a study among school principals to investigate the attitudes and reaction of principals toward online degree programs and the legitimacy of a pre-service teacher preparation program conducted wholly or almost wholly online. More specifically, Huss (2007) maintains that the frequency of online courses in the field of education has been rather predominant at the masters level. However, there remains an increasing enthusiasm to develop online undergraduate teacher preparation programs as institutions strive to ease issues with classroom capacity, profit from market opportunities, and expand educational access. Additionally, Huss implies that determining the credibility of an online degree has generally been restricted to the business industry and cites several studies examining employer perceptions of online degrees that this author has also previously examined such as those conducted by Adams and DeFleur (2008; 2006). Study results indicated that principal perception of an online degree in teacher preparation was overwhelmingly negative.

\section{Factors Affecting the Acceptability of Online Courses and Degrees}

In a related study, Adams and DeFleur (2007) explore the attitudes and perceptions of academic administrators with reference to the merits of a doctoral degree earned online (or partially online). Study participants were asked to compare their attitudes and preferences with regard to making a hiring decision based upon degree type (online, partially online, or traditional). Results of the study indicated that the applicant 
with a traditional degree was preferred in two different hiring scenarios (i.e., online or partially online). Additionally, according to Adams and Defleur (2007), respondents' open-ended comments highlighted five factors which impact the hiring decision: experiences, institutional quality, face-to-face interaction, socialization, and mentoring. The authors note that the employers question whether these factors are present in an online learning or degree program.

Across the globe, in an effort to explore employer perceptions of distance learning graduates, Dailin, Fengyan, Shaungxu, and Fenglong (2008) conducted a follow up survey among graduates from China Central Radio and TV University (CCRTVU) and their respective employers. CCRTVU is an established distance education institution that provides students with courses through print, television, audio-visual materials, computer-assisted learning courseware and online delivery via the Internet. Study results revealed that 58 percent of graduates' employers thought that CCRTVU's graduates were excellent on a scale from one to five (i.e. five indicates excellent and one indicates poor). Further, the authors note that 37 percent of employers thought graduates were "fairly good". Interestingly, graduate morality and professional ethics were major factors influencing the employment decision. Work performance, knowledge and ability were secondary factors behind morality and professional ethics.

Finally, in a study describing the perceptions of human resources (HR) professionals regarding the value of an online MBA from a for-profit university compared to that of an MBA from a traditional higher education institution, Lamer (2006) found that HR professionals preferred to hire a job candidate with a traditional MBA earned from a recognizable or familiar university. Further, Lamer (2006) found that 
HR professionals placed greater emphasis on a candidate's experience and critical thinking skills than where the applicant had earned an MBA. Interestingly, the author also shares findings suggesting that those HR professionals 40 years old and under view for-profit universities more favorability than those in the $41-50+$ age group. It is possible that professionals from the younger age group have more experience (positive or negative) with technology and online learning and are consequently more comfortable with the educational medium.

The study also suggests that in spite of concerns regarding the quality of online MBA degrees from for-profit universities, many companies offer employee tuition reimbursement for these types of degrees. It would be interesting to further explore the topic of corporate employee education development/advancement through online learning opportunities. For example, according to Bolliger and Halupa (2012), at Atlantic International University (a university offering online undergraduate and graduate degrees) the average age of their bachelor to doctoral degree seeking student is 42 years old. Bolliger and Halupa also note that most students in online doctoral programs are nontraditional students ranging in age from 45 to 60 . Given the age demographic it is reasonable to assume that many of these online students are also working full or part time while obtaining their degree online. Understanding and examining corporate policy and perceptions regarding employee pursuit of an online degree (i.e. bachelor, maters or doctoral) is another area in need of further research. Ultimately, Lamer concludes that HR professionals view online MBA degrees from traditional universities equivalent with an MBA earned at a traditional higher education institution. 
A careful examination of these three studies leads one to the conclusion that there are multiple factors affecting the acceptability of online course and degree candidates for hire. They include candidate factors such as previous work performance, professional ethics, breadth of experience, and critical thinking skills. Other factors affecting the hiring decision include: age of gatekeeper; familiarity with degree granting institution; knowledge of technology and delivery mediums; perceived institutional and academic quality of the program.

Essentially, all of the studies addressed are valuable to institutional, employer and student stakeholders. More specifically, a student contemplating investing in an online degree should consider future hiring implications and challenges. Additionally, institutions must also exercise caution when advertising the merits of their online degree programs. Moreover, institutions as well as employers must be mindful of the implications of credentialing versus educating students. Finally, institutions of higher education can use the information to better structure the design and implementation of online degree programs, while simultaneously considering other factors affecting employer acceptance of online candidates.

Exploring the theories that have been used to explain stakeholder reactions to online learning and especially the acceptability of an online degree as a credential for employment is a critical element toward supporting the medium. The following theoretical review is intended to update practitioners, platform designers and other vested stakeholders who wish to critically explore or develop a greater understanding of the marriage between theory and practice in online education. 


\section{Challenges: Promulgating an Acceptable Theory of Distance Education and Online Learning}

Learning is rooted in many different theoretical frameworks and pedagogies. According to Juwah (2006), learners must, “...construct their concepts through active and personal experimentation and observation" (p. 14). The question of whether learning can successfully be accomplished in an online environment can be examined through several different learning theories. However, according to Schlosser and Anderson (1994), distance education has historically lacked an accepted theoretical base. Although, several authors have proposed theoretical frameworks and lenses to define and describe the distance education process, "Lack of accepted theory has weakened distance education...A firmly based theory of distance education will be one which can provide the touchstone against which decisions - political, financial, education, social, when they have to be taken, can be taken with confidence" (Schlosser and Anderson, 1994, p. 5-6). A review of the literature depicts several formal theories that partially explain stakeholder

reactions to the development and growth of online learning. For example, Tesone, Severt, and Carpenter (2008) maintain that most commonly applied modern theories (that are considered to connect well to the epistemologies associated with distance and online learning approaches) all fall within the domain of Learning Constructivism. Meyer (2002) also names the theory of Constructivism as one that guided the study of online education. Constructivism is grounded in the idea that learners actively create knowledge in an effort to make sense of their environment (p. 24). Meyer (2002) further points out that the theory of Constructivism is appropriate to apply to adults and traditional college 
age students, since Constructivism helps students make a connection to learning and application. Constructivism can also be applied to multiple delivery designs including online or asynchronous approaches to learning.

\section{History: Theoretical Framework of Distance Education}

In a critical discussion reflecting and analyzing theory development in the distance education field, Birochi and Pozzebon (2011) discuss five influential distance education theories and their respective foundations. The authors' theory comparisons can essentially be used to determine the extent of compatibility among practical pedagogical applications as well as provide a foundation and guide for interested stakeholders.

Moreover, in an effort to make a contribution to the advancement of theory development in distance education, the authors organize each theory's principles and tenets into three categories in order to examine core concepts and theoretical underpinnings.

Similar to Schlosser and Anderson (1994), Birochi and Pozzebon (2011) indicate that research in distance education often lacks solid foundations to support theoretical advances in the field. Therefore, Birochi and Pozzebon (2011) recognize five theorists that they identify as having provided the most notable contributions to the study of distance education. In addition, the authors highlight each author's theory, central concepts, and primary focus in a table adapted from Amundsen (1993). 


\section{Table 2}

Influential Distance Education Theories and Theorists

\begin{tabular}{|c|c|c|c|}
\hline Authors & Theory & Central Concepts & $\begin{array}{l}\text { Primary } \\
\text { Focus }\end{array}$ \\
\hline Otto Peters (1983) & $\begin{array}{l}\text { Theory of distance } \\
\text { education as the most } \\
\text { industrialized form of } \\
\text { education }\end{array}$ & Industrial and post-industrial & $\begin{array}{l}\text { Industrialized } \\
\text { education }\end{array}$ \\
\hline $\begin{array}{l}\text { Michael Graham } \\
\text { Moore (1973) }\end{array}$ & $\begin{array}{l}\text { Theory of transactional } \\
\text { distance and learner } \\
\text { autonomy }\end{array}$ & $\begin{array}{l}\text { Transactional distance (dialogue } \\
\text { and structure); learner autonomy }\end{array}$ & Distance \\
\hline $\begin{array}{l}\text { Börje Holmberg } \\
\text { (1983) }\end{array}$ & $\begin{array}{l}\text { Guided didactic } \\
\text { conversation theory }\end{array}$ & $\begin{array}{l}\text { Motivation; empathy; non- } \\
\text { contiguous communication; } \\
\text { learner autonomy; interpersonal } \\
\text { communication }\end{array}$ & Distance \\
\hline $\begin{array}{l}\text { Desmond Keegan } \\
\text { (1986) }\end{array}$ & $\begin{array}{l}\text { Theory of reintegration of } \\
\text { the teaching and learning } \\
\text { acts }\end{array}$ & $\begin{array}{l}\text { Reintegration; intersubjectivity; } \\
\text { two- way communication }\end{array}$ & $\begin{array}{l}\text { Communicatio } \\
\mathrm{n}\end{array}$ \\
\hline $\begin{array}{l}\text { Randy Garrison } \\
(1985 ; 1987)\end{array}$ & $\begin{array}{l}\text { Theory of communication } \\
\text { and learner control }\end{array}$ & $\begin{array}{l}\text { Inseparability of technology - } \\
\text { collaborative; educational } \\
\text { transaction; self- directed } \\
\text { learning; adult education }\end{array}$ & $\begin{array}{l}\text { Communicatio } \\
\mathrm{n}\end{array}$ \\
\hline
\end{tabular}

Note. Adapted from Birochi, R., \& Pozzebon, M. ( 2011). Theorizing in distance education: The critical quest for conceptual foundations, Journal of Online Teaching and Learning, 7(4), 562-575.

After review and analysis, Birochi and Pozzebon (2011) identify two central themes shared among each theorist: distance and communication. Further, the authors also articulate a third theme of industrialized education and link it to the seminal works on distance education theory. The authors maintain that Peters was the first to highlight the impact of industrial practices on education. More specifically, according to Keegan (1996), Otto Peters emerged as one of the most influential contributors to distance education research and theory in the 1960's. In fact, Peters believes the conventional 
categories for educational research were insufficient to provide stakeholders and scholars with an instructive examination of distance learning systems. Therefore, Peters takes the industrial production process model and linked it with teaching and learning processes associated with distance education. Essentially, Birochi and Pozzebon (2011) summarize:

"All theories being analyzed here hold that distance education should be treated as a phenomenon arising from socio-economic conditions typical of the $20^{\text {th }}$ century. In this sense, central elements of industrial society are also present in the educational sphere, such as extensive use of technology, mass production, rationalization of organizational processes, standardization of production, division of labor, and creation of large-scale economies" (p.563).

The authors also examine the meaning and key elements of distance education in a postindustrial or post-modern theoretical approach. For example, distance education has undergone complex and dynamic changes in structure and values over the course of its history. Moreover, Birochi and Pozzebon (2011) state that as new information and communication technologies have created innovative forms of education (i.e. flexible learning, open campus or virtual campus), the industrialized model of education has progressed into a post-industrial model. It is important to note that distance education theorists used the term "post-modern" interchangeably with the term "post-industrial" (p. 564).

Therefore, one must ask if these previously mentioned theories do indeed meet the needs of today's stakeholders such as student learners and faculty? It seems reasonable to assume that a new theory, one that encompasses new developments in software, web-based technology, and asynchronous learning modules, would be more appropriate to explain stakeholder reactions to online learning. The following section presents several theoretical developments that further accommodate the current generation of distance and online learners. 


\section{Theory: Emerging Learning Theories in Online Education}

According to Falloon (2011), Moore's seminal Theory of Transactional Distance is repeatedly cited and frequently applied to many different distance and online educational pedagogies. The theory suggests that in a distance learning situation, separation between instructor and students can "...lead to communication gaps, a psychological space of potential misunderstandings between the behaviors of instructors and those of the learners" (p. 187). Further, Falloon (2011) explains that the type of transaction established between instructors and students (in distance learning scenarios) requires three factors: dialogue, structure, and learner autonomy. Falloon (2011) reports that a number of studies have been conducted to determine the pragmatic significance of Moore's theory. He notes that while it is not unanimously accepted, most studies do confirm its value as a conceptual framework to evaluate and apply distance education practice. Falloon (2011) uses Moore's theory as a lens to assess the value of using the technology in online instruction in order to promote quality dialogues and reduce transactional distance. For example, dialogue considers all forms of communication and interaction. Essentially, this study intends to explore if and how an online learner's experience may have been enhanced through dialogue, and ultimately if effective dialogue helped to lesson their perception of transactional distance.

In an effort to further clarify Moore's theory, Falloon (2011) expands on the three factors required in transactional distance learning. According to Falloon (2011), Moore's theory maintains that in a distance learning transaction, it is not only the frequency of dialogue exchanged, but essentially the quality and the extent to which the dialogue is 
effective in the resolution of learning challenges one may be encountering (p. 190). Next, course structure (the second factor in Moore's theory) includes the extent to which course goals and objectives are articulated, instructional pedagogy, course assessment practices, and the ability of the course to adjust to individual student needs. Additionally, learning autonomy (the third factor) is contingent upon both dialogue and course structure. For example, Falloon (2011) states that learner autonomy is closely tied to a student's sense of self-motivation/direction. Moreover, the direction of course dialogue and the level of flexibility integrated into course format and organization can drastically impact a learner's self-determination. Consequently, Falloon (2011) argues that Moore's theory actually alleges that an inverse relationship exists between all three factors. In other words, “.... course with an inflexible structure can lead to a decrease in the quality of dialogue and sense of learner autonomy, thereby increasing the students' perception of transactional distance" (p. 190).

Moore's theory of Transactional Distance is very applicable to the virtual classroom pedagogy. For example, the theory provides a lens and theoretical frame of reference for researchers to explore the process of improving course dialogue and structure to positively impact students in a virtual learning environment. Essentially, Moore's formal theory of transactional distance has created opportunities for researchers (especially in online education) to branch out and develop substantive theories related to online epistemologies.

Using a different theoretical approach to online learning, Berg (2005) argues that group work conducted in online learning environments has become a rapidly growing method of instruction. Therefore, using social or group learning theories for support, the 
author provides suggestions for software design for computer-based instruction in Social or Group Learning Theories. According to Berg (2005), collaborative or group learning methods have been adopted by many of the prominent distance education institutions. Therefore, the author notes the significance of understanding social or group learning theories. Next, Berg (2005) cites several authors who have contributed extensively to the "social-learning-theory perspective" such as, Bruner, Lave, Piaget, and Vygotsky. The author maintains that cooperative and collaborative learning strategies are presently considered to be among several of the most studied approaches to learning in both online and traditional education. Before Berg (2005) provides a definition for each learning approach, he points out that each method:

“...represents opposing ends of constructivist teaching and learning, ranging from an approach that is highly structured by the teacher (cooperative) to one that gives the responsibility for learning primarily to the student (collaborative)" (Berg, 2005, p. 1630).

Further, Berg (2005) explains that cooperative learning is categorized as a set of processes designed to help individuals working together in a group capacity. In comparison, collaborative learning is structured on the establishment of a systematic application of arrangements pertaining to the organization of social interaction in the classroom. Moreover, the author states that in terms of learner motivation, social theory assumes that group cooperation efforts, “....are based on intrinsic motivation generated by a joint aspiration to achieve personally significant goals" (p. 1630).

Berg (2005) posits that computers may provide a system to handle the "awkwardness" often associated with group work and allow for greater equity in representing each participant's thoughts. For example, according to Berg (2005), Rourke, 
Anderson, Garrison and Archer (1999), describe this difference in a notion of "social presence" in online courses, defined as the ability of learners to project themselves socially into a community of inquiry. Additionally, the author highlights the concept of "grounding" in social or group learning theory literature. For instance, Berg (2005) defines grounding as the shared understanding of problems and tasks for a group of learners. Berg (2005) argues that a high degree of grounding is critical for collaborative learning to take place. Additionally, he states that collaborative learning requires students to also understand shared meanings and symbolic tools for successful group communication.

Finally, Berg (2005) offers several recommendations for success in online group learning. For example, he cites research from Spector (1999) recommending that supporting active participation and reflection requires: the support of collaborative analysis of problems, providing tools for collaboration, and facilitating divisions of labor (p. 1632). These examples of active participation would certainly require a strong facilitator/instructor presence. Therefore, it is reasonable to conclude that social or group learning theory can also be closely linked to qualities and characteristics of effective online instruction.

\section{Applying Theory to Practice: Online Learning}

Similar to the Berg's (2005) theoretical framework for achieving positive educational outcomes through group or social learning approaches, Cho (2011) argues that interaction is a critical factor for student success. According to Cho (2011), "In both traditional and online learning environments, students learn best when they interact with 
an instructor, other students, and subject content...Interaction is regarded as the key to effective learning and information exchange" (p. 109-110). Therefore, the purpose of Cho's (2011) study was to identify the relationship among different forms of interaction and student satisfaction in an online learning environment. The author explains the foundation for his study is grounded in Moore's (1998) theories of interaction, which focus on three different types of interaction in a learning environment: learner-content, learner-instructor, and learner-learner interaction. However, Cho (2011) has identified a fourth interaction that he calls the learner-interface. The learner-interface describes the relationships among the various types of interaction in online instruction and learner satisfaction. This study is unique because it draws a comparison strictly between online courses. For example, Cho (2011) acknowledges that many studies have been conducted that compare online courses to traditional face-to-face courses.

Cho (2011) argues that increasing levels of interaction can provoke more student motivation, positive attitudes toward learning, higher satisfaction with instruction, deeper levels of learning, and encourage higher achievement (p. 110). Additionally, he defines learner or student satisfaction as, “...the student's contentment and fulfillment of the expectations and experiences of the subject and/or course" (p. 114). Essentially, Cho (2011) maintains that as online education continues to expand, it is necessary to examine new practices and theoretical approaches associated with learner satisfaction in a purely virtual environment.

Study results indicate that learner-content, learner-instructor, and learner-learner interactions had a significant positive impact on learner satisfaction. The author reports that there was no statistically significant evidence that a relationship between the learner- 
interface interaction and learner satisfaction existed. Ultimately, Cho (2011) concludes that among the four different types of interaction, learner-content interaction was acknowledged as the most influential in predicting learner satisfaction in the online learning environment, followed by learner-instructor interaction and learner-learner satisfaction.

\section{Theory: Determining the Value of an Online Degree as a Credential for Employment}

Since a majority of institutions are turning to online delivery of courses and programs, it is imperative to know from an employer stakeholder perspective whether online degree candidates are in fact gaining knowledge and skills equivalent to face-to-face instruction. Therefore, in an effort to link theory to degree value and as a credential for employment, several substantive theories associated with perceptions of online education can be examined. Determining the value and quality of a degree from an employer or hiring gatekeeper perspective can be linked to legitimacy theory, screening theory, and equivalency theory. These theories provide concepts, terms, definitions, models, and ideas grounded in the online learning discipline. For example, according to Brown (2006), rooted in the conceptual framework of educational screening theory (and/or legitimacy theory) is the idea of credentialism and institutionalization. Credentialism encourages discourse on degree standardization and quality by debating which factors legitimize and bestow value on a college degree. According to Stiglitz (1975), "One of the most important kinds of information concerns the qualities of a factor or a commodity" (p. 283). Essentially, the concept of "quality" provides the theoretical framework for educational screening theory and legitimacy theory and offers logically 
consistent ideas to establish functional relationships between online learning, value, and quality. Further, according to Keller (2011), with the arrival of online education, a new institutional form is taking place in the context of higher education with regard to online degree programs. Therefore, in order for institutional and employer stakeholders to view online learning as legitimate, it must become institutionalized. Based on the institutional perspective, Keller (2011) argues that traditional academic degree programs are an existing or established institutional form, and online degree programs are considered to be a new or emerging institutional form (p. 2). Essentially, new emerging institutional practices (i.e. online education) must disrupt the well-established institutional practice of traditional classroom learning and become institutionalized. Online education must be perceived by key stakeholders as academically and socially legitimate as traditional learning.

Additionally, Lapsley, Kulik, Moody and Arbaugh (2008) discuss the constructs of equivalency theory and apply them to the learning experiences and outcomes for student and employer stakeholders. The authors indicate that equivalency theory maintains that courses should provide equivalent learning experience for all students, regardless of the method of delivery (i.e. online, traditional) and should be determined based upon demonstrated learner achievement instead of instructional time-based standards. Further, the authors explain that equivalency theory was developed, “.... as a means to integrate previous theories of distance education into a uniquely American perspective in light of recent advances in telecommunication technologies. The theory is intended to ensure that distance education does not become an inferior form of education, and in fact may not even be a distinct field of education" (Lapsley, Kulik, Moody and 
Arbaugh, 2008, p. 3). Essentially, if both online and traditional courses included the same rigor, curriculum, and learning experience, then one could claim equivalency in practice. Achieving "equivalency" would allow student, institutional and employer stakeholders to more accurately assess online programs and course quality.

To date, no single theory can entirely explain stakeholder reactions and response to online learning. However, a substantial number of theories have been discussed. These existing theories can serve as a basis for articulating a more comprehensive theory that would integrate educational, financial, political, and social concerns and reactions of all stakeholders.

\section{Gap Analysis}

\section{Current Research Directions}

Online education is a multifaceted industry, providing the scholar with extensive research opportunities. Throughout the past decade, there have been countless studies conducted which compare online and traditional classroom instruction with respect to student learning outcomes and student learning satisfaction. Examples include Norton and Hathaway's (2006) research comparing learner perceptions of two online courses using two different design models (i.e. Blackboard and one-on-one/mentor-learner) and Ary and Brune's (2011) discussion comparing learning results over several different semesters in an online and traditional finance course. Additionally, there is extensive literature available that examines the various pedagogical approaches to effective online course instruction and design. Further, authors Kidney, Cummings, and Boehm (2007), and organizations such as the Sloan Consortium provide volumes of research on quality 
assurance approaches to online learning. In other words, research to date has largely focused on learning outcomes, student satisfaction, effective online coursework and design, and educational quality.

\section{Research Gaps}

In spite of scholarly efforts, there remain serious gaps in the literature. For example, there is limited research previously conducted on the issue of employer acceptance of online degree job candidates and credentials required for entry employment. Additionally, there is an absence of comparative research on the key issues of post-graduate career success for those students who completed a degree (or classes online) as compared to those students enrolled in traditional classroom learning. Locating specific research comparing the salaries of online graduates to those of their traditional degree holding counterparts also remains a significant challenge. Similarly, data on online degree holders with reference to student retention/persistence and job placement rates after graduation is almost non-existent. For example, according to the Kaplan University website (2012), Kaplan University Online does not even calculate placement rates of their online students. Lack of disclosure may well be linked to an institution's strategy to only release positive statistics on its student retention and graduate placement rates.

Many studies have compared the quality of online education with the quality of traditional classroom education; however, there are few studies to date that compare the effects of the two educational institutions on organizational productivity. Further, there is a paucity of research regarding employer perceptions of online degrees from traditional higher education institutions (i.e. Harvard). This is clearly a major gap in the literature 
and of particular interest to this researcher.

Another research gap worthy of study can be posited in question form: what are the relationships between online learning, plagiarism, and impact on stakeholders? According to the Pew Research Center (2011), 55 percent of college presidents indicated that plagiarism in students' papers has increased over the past ten years. Additionally, 89 percent of those presidents who noted this increase in plagiarism place the blame squarely on computer technology and the Internet. Obviously, online learning and its relationship to plagiarism is certainly a critical issue for institutional stakeholders to consider and address when designing online programs and student codes of conduct. This represents a serious gap in the literature. For example, online learning often includes group activities and assignments. Therefore, it is imperative for all online instructors to clearly articulate which assignments, discussions, or projects are to be individual or can be worked on collectively. Clearly, there is no instructor monitoring an online student during an online examination or completion of a written assignment. In an effort to eliminate instances of academic dishonesty, appropriate rules and mechanisms for assessment should be weaved into any online program or course.

The Pew Research Center (2011) has preliminarily raised serious issues concerning institutional perception of online course work across institutional lines:

"Aside from the differences among public, private, two-year and for-profit institutions, there are clear divisions across other dimensions. The presidents of liberal arts colleges and highly selective institutions are less likely than other college presidents to report that their schools offer online classes. And at highly selective schools, fewer students are taking online classes when they are offered" (p. 6). 
Therefore, one may speculate that online education at more selective institutions is viewed in a more negative light as compared to less selective institutions. Additionally, the Pew Research Center (2011) suggests that individuals who have personally experienced online learning also demonstrate a more positive assessment of its value. Moreover, 39 percent of those have participated in an online course maintain that online classes (in general) provide an equivalent experience as compared to traditional classroom instruction. Therefore, an additional fruitful area of research would be to compare employer attitudes toward online education based upon the individual opinions and beliefs of employers/hiring gatekeepers who have personal experience with online learning and those who do not.

\section{Research Questions}

Based on the identified research gaps, the following three research questions are especially worthy of future research:

1. What are the current perceptions of academic hiring gatekeepers regarding online education in general?

2. Do academic hiring gatekeepers' perceptions toward online education differ from the perceptions they hold toward traditional higher education?

3. Do academic hiring gatekeepers' perceptions toward online education differ by their institution type?

4. To what extent do academic hiring gatekeeper perceptions toward online education influence their hiring decisions?

These questions provide the scholar with fertile areas of research, and they raise important issues for all stakeholders. Moreover, these research questions have not really been addressed in a rigorous and systematic manner, particularly with respect to 
comparing and contrasting the employer viewpoints of corporate America and the academy. Further, since the academy is the major delivery apparatus for online degree programs, it is especially important to determine whether or not academic gatekeepers are just as willing to hire online degree candidates as traditional degree candidates. 


\section{CHAPTER III}

\section{METHODOLOGY}

According to Creswell (2009), there is an opportunity to gain new insight, "...from the combination of both qualitative and quantitative research than either form by itself. Their combined use provides an expanded understanding of research problems" ( $p$. 203). Essentially, by combining the comprehensive, contextualized, and natural insight of qualitative data with the predictive power of quantitative data, this study's methodology is grounded in a mixed methods approach to data collection and analysis. More specifically, data for this study will be collected through two sources: 1) in-depth interviews and 2) online survey questionnaire.

\section{Rationale for Mixed Method Design}

Creswell (2008) maintains that a mixed methods design involves the "...merging, integrating, linking, or embedding the two 'strands' (of data)" (p. 552). Further, quantitative data is used to examine trends in the sample population while the qualitative data can provide a complex and rich illustration of the research problem. For the purpose of this study, the researcher believes that only one type of research design (quantitative or qualitative) is not enough to effectively address and answer the proposed research 
questions. Rather both quantitative and qualitative data will be collected simultaneously in a concurrent triangulation design (Creswell, 2009). The strategy behind this methodology allows data from one source to enhance and expand upon data from another source to better explore the research question. Essentially, data will be combined during the analysis and interpretation of the study and compared in a side-by-side discussion. Additionally, quantitative and qualitative data will be treated with equal weight.

Creswell (2009) also maintains that the concurrent triangulation strategy is advantageous because it is a familiar and accepted method to most researchers, and it can result in well-validated and authenticated findings. However, Creswell also indicates several limitations to the strategy that include an extensive effort and expertise, difficulty with results comparisons, and discrepancies in data.

Data analysis and interpretation for this study will use Creswell's (2008) example of qualifying quantitative data that maintains: "Quantitative data from questionnaires are factor analyzed. Their factors then become themes that are analyzed from qualitative data" (p. 565). Given that the results from past research have suggested that members of the academy do not always consider an online degree as a credential for employment (Adams and DeFleur, 2005; DePriest, 2009), the experiences shared and collected through both quantitative and qualitative methods may provide a unique opportunity for academic hiring gatekeepers to engage in honest and productive discussions regarding the online degree debate.

Clearly, (as with any type of methodology) there are always advantages and disadvantages associated with conducting a mixed methods study. Ayiro (2012) lists three advantages to the mixed methods approach: 
1. Incorporates the strengths of both qualitative and quantitative approaches

2. Provides a more comprehensive view of the phenomena being studied

3. Does not limit the data being collected (p. 496).

Additionally, Ayiro (2012) also argues that the disadvantages of a mixed methods study are that it requires expertise in both methods (qualitative and quantitative) and requires extensive data collection and subsequent resources. Understanding both the advantages and limitations of a mixed method study will help for better navigation during the data collection and analysis process.

\section{Sample}

Data from several studies (Allen \& Seaman, 2011, Pew Research Center 2011) reveal a continued growth and increase in student enrollment in online courses as well as expansion in online course and program offerings among higher education institutions. Therefore, if higher education institutions continue to embrace the online learning modality, it is important to examine whether or not administrator and faculty acceptance of online teaching and learning as evidenced through hiring online degree candidates has also changed with trends of online education growth and development. After all, if institutions of higher education are using methods of online learning to educate future faculty members and administrators, it would appear counterintuitive for academic hiring gatekeepers to exclude these online degree holders from obtaining academic and administrative positions within the academy.

According to Allen and Seaman (2011), while the number of online programs and courses continue to grow, the acceptance of this learning mechanism by faculty has been 
relatively constant since first measured in 2003. More specifically, "Less than one-third of chief academic officers believe that their faculty accept the value and legitimacy of online education" (p. 5). Therefore, the objective of this study is to answer the proposed research questions by interviewing and surveying those academic hiring gatekeepers who are directly involved in the hiring process of faculty members and administrators. Essentially, interviews and an online survey instrument will be administered to academic deans, division/department chairs, and various members of faculty hiring committees where appropriate. Academic hiring gatekeepers included in the study are employed in a variety of academic departments and colleges. These departments have been broken down by discipline categories that include: arts, business/management, communications, education, health/medicine, humanities, professional fields, science/technology/ mathematics, social/behavioral sciences, vocational/technical fields, and other.

The academic hiring gatekeepers examined in this study will represent a sample of several two-year, four-year, and doctoral public and private colleges and universities in the Midwest region of the United States. Specifically, the states included in this study are Illinois, Indiana, Wisconsin, Minnesota, Ohio, Iowa, Missouri, Kansas and Michigan. Institutions included in this study are not limited to only "Big Ten" institutions, but will also include other state and private academic institutions in the mid-west region of the United States. Surveys will be administered to academic hiring gatekeepers at selected universities within these state jurisdictions. Similar to Thomas A. DePriest, Jr.'s (2009) dissertation study, this particular sample population of academic hiring gatekeepers was chosen based on the idea that one may find a representation of these academic 
colleges/schools at the majority of institutions of higher learning regardless of the institution's size or location.

Participants selected for in-depth interviews will be identified through a sample selection process referred to as purposeful sampling. According to Merriam (2009), there are several types of purposeful samples. For the purposes of this study, participants will be initially identified through a typical sample. More specifically, "A typical sample would be one that is selected because it reflects the average person, situation, or instance of the phenomenon of interest" (p. 79). The contributors invited to participate in the indepth interview process were recruited based on their individual experiences in an effort to provide meaningful data to this study's topic and essentially address the study's research questions. Similar to this study's survey participant selection, interview participants will represent a sample of two-year, four-year, and doctoral public and private colleges and universities in the Midwest region of the United States.

The participants that were invited to participate in the in-depth interview process had to meet the following criteria:

- Presently be employed as:

1. An academic administrator (i.e. Dean or Department Head or Chair)

2. A faculty member who has served on a faculty or administrative hiring or search committee in the last two years

3. Any member of the academy who has faculty or administrative hiring responsibilities. 


\section{Survey Instrument}

The survey instrument was designed using SurveyMonkey, which is a tool used for survey programming, creation deployment, and results analysis. The survey apparatus that was used in this study was an adapted instrument based on two previous studies. The first was a pilot study previously conducted by this researcher between 2011-2012. However, the pilot survey study was not designed and directed specifically at academic hiring gatekeepers. Instead, the pilot survey examined the perceptions of a wide-ranging sample of hiring gatekeepers in a variety of businesses and industries (including academia). According to Dillman, Smyth, and Christian (2009), conducting a pilot study with a subsample of the population allows the researcher to evaluate interconnections among questions, the questionnaire, and implementation procedures (p. 228). More specifically, the pilot study provided a foundation for the researcher to develop and experiment with different question types and word phrasing options in an effort to yield significant data. For example, one pilot survey participant noted his confusion with the following statement (on the pilot survey): When presented with two candidates, the institution from which they earned their degree is important if the degree is a traditional degree. Therefore, in an effort to avoid further confusion, this researcher re-wrote the statement to be clearer in the final survey apparatus.

Additionally, participants were surveyed utilizing an adapted apparatus from DePriest's (2009) dissertation: Perceptions of academic administrators regarding the acceptability of online doctoral degrees for faculty members. In his study, DePriest (2009) demonstrated that academic administrators, “...do exhibit negative inclinations 
regarding Web-based degrees. Specifically, academic administrators expressed a slightly negative view of online degrees" ( $p$. iv-v). Therefore, this researcher assumed a connection existed between DePriest's (2009) study and the focus of this proposal, thereby justifying the use of his survey apparatus as a starting point for the development of this author's survey. Although similarities exist between studies, this research differs from DePriest's (2009) study by employing a mixed methods approach to data collection. DePriest's (2009) study was purely quantitative in nature and only included academic deans and division/department chairs as study participants. However, this study was expanded to include all academic hiring gatekeepers such as faculty hiring committee members.

DePriest's (2009) survey instrument was designed using both demographic and Likert-type questions. DePriest's survey instrument included five demographic questions, forty Likert-type questions, and ten multiple-choice questions related to a participant's division or department. This researcher sought and received permission to make adjustments to the survey instrument from DePriest. Modifications were made to the survey instrument by removing questions that were not directly related to the perceptions/acceptability of online degrees. For example DePriest's (2009) question, "Basic Web-based technologies (e.g. chat rooms, discussion boards, posting of online course content, grades, and assignments, and e-mail) can be used by the faculty members to effectively supplement face-to-face instruction in my department" is certainly a valuable question for research purposes. However, it is not relevant to this particular study. Additionally, DePriest explains that after initial development, a panel of experts 
(who were experienced in research methods and measurement) reviewed the survey apparatus for instrument validity.

Ultimately, the final survey design (for this study) consisted of twenty-five demographic, multiple choice, and Likert-type questions concerning the perceptions and acceptability of online degrees from the academic hiring gatekeeper perspective (see Appendix A). The Likert-type questions were designed to allow participants to choose between different responses on a 5-point scale such as strongly disagree, disagree, neutral, agree, and strongly agree. More specifically, this survey contained fifteen demographic questions. While several of the demographic questions have been adopted from DePriest's (2009) survey, this survey also asked participants to include their gender, age, and highest level of degree each participant has earned. Other demographic questions included items such as number of online vs. traditional/blended/asynchronous courses offered in a participant's institution/department, number of online degree programs offered in a participant's institution/department, and what type of institution would best describe a participant's school (i.e. public, private, research, etc.).

Moreover, this survey contained two additional sections. The first section addressed participant perceptions of online education, and the second section asked participants to share their perceptions when making faculty/administrative hiring decisions. Both sections use Likert-type and open-ended questions to determine participant perceptions. Also there is another key difference between this survey and DePriest's (2009). This survey included several opportunities for participants to provide feedback regarding their perceptions of online degrees and also related hiring practices 
(toward online degree candidates) through open-ended structured questions.

According to Dillman, Smyth, and Christian (2009), in self-administered surveys, more participants skip over open-ended question formats than close-ended formats because open-ended questions required more time and work to answer (p. 72). Therefore, in an effort to avoid a non-response bias from participants, this survey was designed for respondents to provide an answer after considering or evaluating a set of answer choices. More specifically, questions 11-19 (see appendix A) are designed using an ordinal scale or Likert-type style inquiry. Further, Dillman, Smyth, and Christian (2009) maintain that respondents are more likely to select question answer options that are provided to them rather than writing or typing their own responses. Therefore, most questions have also included key items of interest; however, care has been taken to ensure that participants will not be persuaded to draw bias conclusions about the explicitly provided volunteered categories.

In an effort to maintain instrument validity and credibility, this researcher obtained content validity from institutional faculty members who have experience in statistical research methods and design. More specifically, these faculty members possessed expertise in educational research methodology. Further, these faculty members evaluated each survey question for content and transparency. Appropriate changes and revisions were then applied to the survey instrument to help facilitate appropriate instrument validity. 


\section{Interview Protocol}

An additional source of data for this study were collected through in-depth interviews using a semi-structured interview guide. To provide perspective and integrity to the interview process, this researcher previously conducted a qualitative pilot study that included a series of four in-depth interviews. The interview structure was guided using a framework proposed by Merriam (2009). For example, Merriam (2009) maintains that semi-structured interviews include a combination of more and less structured interview questions. Further, all questions must use flexibility where the major segment of the interview is simply guided by a list of questions or issues to be explored. The interview guide for this study was derived by this researcher and consisted of 22 items (see Appendix B) that were assessed for content validity using a group of higher education administration faculty. Questions 1-9 were designed to collect background information on the participant's educational and academic employment history. Questions 10-15 were designed to explore the current hiring practices each participant actively engages in at his/her respective company/organization. Finally, questions 16-22 were constructed to solicit current perceptions and attitudes participants held with regard to online degrees, online degree granting institutions, and the value of an online degree.

\section{Procedures: Survey and Interview}

Upon receiving approval (from the Institutional Review Board) to move forward with this proposed study, this researcher distributed a recruitment letter through email to identify and recruit potential study participants for in-depth interviews and surveys. 
Individuals invited to participate in the study must have been or currently are fully or partially responsible for making hiring decisions for administrative or academic faculty positions.

After identifying a sample of possible study participants through various social media networking sites, blogs, and institutional websites, an email was sent inviting the individual to partake in the survey. Initially, the email introduced the participant to the nature of the research. Next, if the participant was interested, the email provided a hyperlink for the individual to be directly routed to the survey. In an effort to prevent multiple surveys from being submitted by the same individual, the survey was formatted so that no more than one survey can be accepted from an e-mail address. The survey was available and open for participants to complete for a time period of four calendar months. During this time, several follow-up or reminder emails were sent to survey participants in an effort to achieve maximum survey participation. After four calendar months had passed, the survey was closed for inspection and analysis. On average, the survey took participants between ten and fifteen minutes to complete.

In addition to completing the survey, participants were invited to submit to an hour-long interview with the researcher using a semi-structured interview protocol. Merriam states that semi-structured interviews do not follow any predetermined wording or order, but specific data is typically required from all participants. Essentially, the semistructured interview format allowed this researcher to respond to the emerging ideas and perceptions of the respondent. According to Merriam (2009), "Less structured formats assume that individual respondents define the world in unique ways" (p. 90). Merriam 
(2009) also maintains that interviews allow participants an opportunity to clarify their own thoughts and experiences. Additionally, he highlights three variables that can determine the nature of the interview interaction:

1. The personality and skill of the interviewer

2. The attitudes and orientation of the interviewee

3. The definition of both (and often by significant other) of the situation (p. 107).

Clearly, the interaction between the interviewer and the participant is a complex process. Therefore, it is critical to understand that both parties hold certain beliefs, bias, and attitudes that can ultimately impact data collection. For the purposes of this study, this researcher accounted for these factors in order to effectively evaluate the data being collected.

From a technical perspective, interviews were digitally recorded and transcribed verbatim. Each interviewee was assigned a pseudonym to protect anonymity. This researcher also documented her personal observations and reflections before and after conducting each interview.

Finally, Creswell (2008) articulates that using interviews in qualitative research have both advantages and limitations. For example, interviews:

“...provide useful information when you cannot directly observe participants, and they permit participants to describe detailed personal information...Some disadvantages are that interviews provide only information 'filtered' though the views of the interviewers...interview data may be deceptive and provide the perspective the interviewee want the researcher to hear" (p. 226).

Therefore, it was extremely important that this researcher demonstrated a deep knowledge regarding the topics of administrator or faculty perceptions of online degrees 
to provide a foundation for significant dialogue to take place during the interview process. However, it was even more significant for this researcher to disclose any personal biases with participants in an effort to avoid guiding the conversation in a particular direction (in order to obtain certain responses).

\section{Ethical Considerations}

A research protocol for this study was submitted for approval from the Illinois State University Internal Review Board (IRB). The IRB approved this research protocol following an expedited review procedure. In order to maintain ethical practices within this study, participation remained completely voluntary, and participants were informed they could discontinue participation at any time without penalty. Additionally, there were no incentives for participation. Participants were also informed that any data and information collected throughout the study will not be used in any way to impact their relationship with their institution. Further, respondent anonymity (for the survey) and confidentiality (for the interview process) were protected at all times.

\section{Reliability and Validity}

\section{Quantitative Data Analysis}

In an effort to establish authority for this study, prior to administering any survey or conducting any interviews, current research in the field was examined and explored in depth. According to Edmonson and Irby (2008), establishing authority requires the researcher to have a degree of familiarity and knowledge base with the topic.

In quantitative research, establishing validity and reliability of the data collection instrument is critical for minimizing errors that could occur from measurement 
complications. According to Creswell (2008), reliability occurs when accuracy and consistency on repeated administration of an instrument is achieved. Additionally, Creswell lists several factors that can result in unreliable data. Two of these factors include: questions on instruments that are ambiguous and unclear; and procedures of test administration vary and are not standardized (p. 169). To ensure reliability of the survey instrument used in this study, a pilot study was conducted to eliminate survey questions that were ambiguous and unclear. The pilot study also allowed this researcher to assess whether or not the survey instrument produced internally consistent results. According to Creswell, scores from an instrument are reliable and accurate if participants' scores are internally consistent across all of the questions on the study instrument. Therefore, the pilot allowed this researcher to study and examine whether or not participants revealed consistent answers to similar questions (i.e. perceptions of online degrees). The same process for achieving reliability and internal consistency that was used in the pilot study were applied to this study's survey instrument.

Validity is achieved when a study accurately examines and reflects a specific idea or construct from scores about a sample or population (Creswell, 2008). There are three types of validity of the survey instrument that were established in this study: content, criterion-related, and construct validity. According to Creswell, content validity will demonstrate the extent to which the survey questions and the corresponding scores (from these questions) are representative of all the possible questions that could be asked about academic hiring gatekeepers perceptions of online degrees. In an effort to achieve content validity, the wording of the survey questions were assessed by several higher education 
administration faculty members in order to determine whether survey items are relevant to the subject it is intended to measure. Criterion-related validity is achieved when scores from an instrument are a solid predictor of some type of outcome they are expected to predict. Further, there are two types of criterion-related validity: predictive and concurrent (Creswell, 2008, p. 172). For the purpose of this study, concurrent validity was tested by comparing the consistency of scores on the survey instrument with the results of other existing instruments such as the one used in DePriest's (2009) study. Similar to concurrent validity, Creswell refers to construct validity as a determination of the significance, meaning, purpose, and use of scores from an instrument. Construct validity also seeks significance between a theoretical construct and a measuring instrument or apparatus. In other words, it can be used to test this study's theory. Therefore, the results of this study were examined and compared with the results from other similar studies measuring related ideas and constructs (i.e. academic employer and hiring gatekeeper perceptions of online degrees).

\section{Qualitative Data Analysis}

The measures for assessing reliability and validity in a quantitative study differ from qualitative research studies. For example, according to Merriam (2009), qualitative research is grounded in how people interpret their experiences, how they construct their worlds, and what meaning they attribute to their experiences (p. 5). More specifically, Merriam explains that reliability in quantitative research is based on causal relationships and the assumption that there is a single reality. Further, there is the belief that studying a 
central concept continuously will reveal the same results. However, qualitative studies “...seek to describe and explain the world as those in the world experience it. Since there are many interpretations of what is happening, there is no benchmark by which to take repeated measures and establish reliability in the traditional sense" (p. 220). Therefore, in an effort to ensure this study's qualitative data is reliable and valid, several strategies were implemented to enhance trustworthiness and credibility. First, the researcher implemented a peer review strategy. For example, interview questions were assessed and evaluated by other education professionals in an effort to determine and guarantee relevance. In addition, according to Edmonson and Irby (2008), maintaining interpretive validity in one's study requires participant feedback. Therefore, this researcher asked participants to check the accuracy of the transcriptions. This member checking approach provided an opportunity for study participants to provide additional feedback following their interview. Further, this researcher provided participants with a copy of the interview questions (prior to the interview taking place). This strategy was intended to reduce some elements of the facilitator-bias phenomenon. A third strategy designed to help ensure study trustworthiness is data triangulation. Data triangulation for this study included the use of documents such as curriculum vitae and department/employee documents (i.e. hiring manuals/guidelines).

\section{Researchers Subjectivity and Reflexivity}

Online degree programs have become increasingly popular in the past decade as they offer students a flexible option and alternative to a traditional degree. In fact, I entered the Education Administration and Foundations doctoral program at Illinois State 
University as a member of the first blended learning and weekend cohort program.

Essentially, this degree program included many online/asynchronous learning activities. I found the course work and online component of the program to be very challenging and valuable with regard to developing new communication and organizational skills. Further, I believe that my experience and overall positive attitude toward the program was also shared among many of my colleagues. For example, I found value in the online course discussions. Moreover, due to its nature and format, all students were required to post in the online discussion forum. This learner exercise allowed all participating students to have a "voice". In other words, I have often found traditional classroom environments intimidating for some students and not every student will feel comfortable participating in a discussion. Essentially, I believe working in an online capacity removes the intimidation factor and creates an equal discussion field.

Further, I believe that my online learning experience was one of quality and also quite demanding at times with reference to course workload and content. While I cannot speak for all online learning and degree programs, I do believe online learning courses and programs can be just as rigorous and valuable as traditional classroom instruction. Therefore, I assume that if I were in a position to make a hiring decision, I would not judge an online degree candidate based on the nature of his/her degree type. However, I must disclose a potential and favorable bias I may have toward online degree programs at traditional higher education institution versus online degree programs at for-profit colleges and universities. I can attribute this bias to my personal experience with online learning at a traditional higher education institution. More specifically, I do not have prior experience with students, instructors, and courses from for-profit online education 
programs. Further, it is also important to note that my experience with online learning is also at the Master's and Doctoral levels.

\section{Data Analysis}

\section{Quantitative Data Analysis}

Answers from the completed surveys were recorded in Microsoft Excel to allow easy transferability of data to the Statistical Package for the Social Sciences (SPSS). The SPSS software allowed for generating frequencies and descriptive statistics to determine academic hiring gatekeepers perceptions of online degrees. More specifically, SPSS was used to calculate frequency distributions, means, modes and standard deviations.

To determine differences or discover similarities in the perceptions of academic hiring gatekeepers among various university or academic demographics (i.e. position type, institution type) SPSS was used to calculate an Analysis of Variance (ANOVA) and a test of association using Fisher's Exact Test.

\section{Qualitative Data Analysis}

Each participant interview was recorded and transcribed by the researcher. This process enabled the researcher to maintain a firsthand account of the interview dialogue and simultaneously allowed one to accurately recall particular points of interest or participant responses that occurred throughout the interview. In addition, participant responses were reviewed multiple times by both the researcher and interviewee in an effort to ensure reliability and validity. Responses among all participants were assessed, coded and analyzed in order to generate themes and subthemes or sub categories that demonstrate commonality and differences in the participant data. Finally, a compare and 
contrast method of data analysis was employed as suggested by Coffey and Atkinson (1996). This type of data exploration falls in line with the definition of data analysis applied by Huberman and Miles (1994) and Dey (1993). For example, in this approach, data are summarized, coded and broken down into themes. Essentially, data analysis methods (such as those proposed by Huberman, Miles, Dey in Coffey and Atkinson, 1996) use codes to summarize, synthesize, and sort many interpretations of the data. Further, Huberman and Miles and Dey also utilize methods of comparing and contrasting data, exploring themes, patterns, and common occurrences. This researcher believes that one can effectively document consistencies and inconsistencies in the data by using a form of comparing and contrasting method. Additionally, "Dey also breaks qualitative data analysis into three related processes: describing, classifying, and connecting... Dey suggests that categorized or coded data can be analyzed in terms of the patterns and connection that emerge" (as cited in Coffey \& Atkinson, 1996, p.8). Ultimately, based on the strategic compare and contrast method of data analysis, this researcher connected each data set in a meaningful and effective manner. Finally, to avoid erroneously drawn conclusions, the interpretations were peer-reviewed by other educational professionals in the field.

\section{Summary}

When examining academic employer perceptions of online degrees, many of the studies conducted are quantitative in nature. A combination of both qualitative and quantitative data methods can extend this research to a larger sample population. For example, a quantitative survey apparatus was used in this study in order to obtain a larger 
sample of opinions and perspectives of academic hiring gatekeepers and employers from several different states within the selected region. From the qualitative perspective, indepth interviews allow participants a greater degree of freedom to explain their thoughts and to highlight areas of particular interest and expertise. Essentially, a study grounded in both qualitative and quantitative data (mixed-methods approach) can provide a rich source of information exploring the preferences, prejudices or misconceptions held by employers regarding candidates possessing online degrees. Further, by employing both research methods, the current gap in the literature was more comprehensibly addressed: namely, understanding academic hiring gatekeepers' perceptions of online degrees and their hiring practices using both a qualitative and quantitative approach. 


\section{CHAPTER IV}

\section{RESULTS}

The purpose of this study is to examine academic employers' beliefs regarding whether online degree programs have the same level of quality and excellence as traditional programs. Furthermore, the study seeks to explore employer perceptions regarding hiring online degree holders for faculty and administrator positions. It is critical from a conceptual perspective to examine the value of an online degree especially as it is perceived by hiring gatekeepers and employers, and more particularly, those in academic institutions as online education and degree programs continue to grow and expand exponentially. In this chapter, study results are presented in two sections: first, participants' demographics and profiles are presented and second the findings are discussed in line with the research questions posed in the study.

\section{Section 1: Participant Descriptions}

For the purpose of this study both quantitative and qualitative data were collected and analyzed. Quantitative data was gathered by way of an online survey. A total of 102 faculty and administrators responded to the survey. Table 3 provides information on the survey participants' demographics. This information includes position type, institution type, institution size, and the number of fully online degree programs offered by the institution. 


\section{Table 3}

Distribution of Survey Participants by Position Type, Institution Type, Institution Size, and Number of Online Degree Offerings

\begin{tabular}{|c|c|c|}
\hline Demographics & $\mathbf{N}$ & Percent \\
\hline \multicolumn{3}{|l|}{ Position Type } \\
\hline Faculty & 14 & 13.7 \\
\hline Administrator & 10 & 9.8 \\
\hline Dean & 25 & 24.5 \\
\hline Department Chair & 53 & 52.0 \\
\hline Total & 102 & 100.0 \\
\hline \multicolumn{3}{|l|}{ Institution Type } \\
\hline Liberal Arts & 42 & 42.9 \\
\hline Religious & 16 & 16.3 \\
\hline Research & 31 & 31.6 \\
\hline Comprehensive & 7 & 7.1 \\
\hline Community College & 1 & 1.0 \\
\hline NA & 1 & 1.0 \\
\hline Total & 98 & 100 \\
\hline \multicolumn{3}{|l|}{ Public vs. Private } \\
\hline Public & 53 & 52.0 \\
\hline Private & 49 & 48.0 \\
\hline Total & 102 & 100.0 \\
\hline \multicolumn{3}{|l|}{ Institution Size } \\
\hline $1-1,000$ & 3 & 3.0 \\
\hline $1,001-5,000$ & 29 & 28.7 \\
\hline $5,001-10,000$ & 25 & 24.8 \\
\hline $10,001-15,000$ & 18 & 17.8 \\
\hline $15,001-20,000$ & 6 & 5.9 \\
\hline $20,000+$ & 20 & 19.8 \\
\hline Total & 101 & 100.0 \\
\hline \multicolumn{3}{|l|}{$\begin{array}{l}\text { Number of Fully Online } \\
\text { Offerings at Institution }\end{array}$} \\
\hline None & 24 & 23.5 \\
\hline Less than 5 & 20 & 19.6 \\
\hline Between 5 and 10 & 13 & 12.7 \\
\hline Between 11 and 20 & 10 & 9.8 \\
\hline $20+$ & 28 & 27.5 \\
\hline I don't know & 7 & 6.8 \\
\hline Total & 102 & 100.0 \\
\hline
\end{tabular}

The majority of individuals who participated in this study $(52 \%)$ were employed as department chairs at their respective institutions. Less than 10 percent of participants were administrators (i.e. program and department coordinators, vice chancellors) and approximately 25 percent were deans. Additionally, the majority of participants (42 
percent) indicated that their school was categorized as a liberal arts institution, followed by 31 percent of participants who were employed at research institutions. Participants employed at either a public or private institution were basically split evenly, with a slight majority of individuals (52 percent) employed at public colleges and universities.

When it comes to the size of the institution, only 3 percent of participants were employed at institutions with student enrollment populations smaller than 1,000 , and the largest percentage of participants (28.7 percent) worked at institutions with student enrollments between 1,001-5,000. Finally, almost 24 percent of participants were employed at institutions that did not offer any fully online degree programs. However, excluding the 6.8 percent of participants indicating that they did not know how many fully online degree programs existed at their school, the remaining participants did come from institutions offering at least one or more fully online degree program.

\section{Interview Participants' Profiles}

A series of open-ended interviews were conducted with six higher education administrators in various positions. Table 4 below displays a summary of participant backgrounds. Pseudonyms are used to represent all participant names and to ensure confidentiality.

As illustrated, all individuals who participated in the interviews held high level administrative or dean positions at their respective institutions. Each participant had been serving in his or her current role for at least 2 years or more. Participants were selected from various academic disciplines such as business, education, and the arts. Further, all 
Table 4

Participant Profiles

\begin{tabular}{l|l|l|l|l}
\hline $\begin{array}{c}\text { Participant Name } \\
\text { (pseudonym) }\end{array}$ & \multicolumn{1}{|c|}{ Position } & \multicolumn{1}{|c|}{$\begin{array}{c}\text { Institutional } \\
\text { Type }\end{array}$} & $\begin{array}{c}\text { College/Area of } \\
\text { Study }\end{array}$ & \multicolumn{1}{c}{$\begin{array}{c}\text { Years in } \\
\text { Position }\end{array}$} \\
\hline John & $\begin{array}{l}\text { Director of the } \\
\text { Master, Science, } \\
\text { and Finance } \\
\text { Program }\end{array}$ & $\begin{array}{l}\text { Public, Research } \\
\text { One }\end{array}$ & Business & $\begin{array}{l}\text { Approximately } \\
3 \text { years }\end{array}$ \\
\hline Dean Ron & $\begin{array}{l}\text { Associate Dean for } \\
\text { Academic } \\
\text { Programs }\end{array}$ & $\begin{array}{l}\text { Public, Research } \\
\text { One }\end{array}$ & Education & $\begin{array}{l}\text { Approximately } \\
3 \text { years }\end{array}$ \\
\hline Dean Sarah & $\begin{array}{l}\text { Associate Dean of } \\
\text { Instruction }\end{array}$ & $\begin{array}{l}\text { Community } \\
\text { College }\end{array}$ & $\begin{array}{l}\text { Interdisciplinary } \\
\text { Studies }\end{array}$ & $\begin{array}{l}\text { Approximately } \\
2 \text { years }\end{array}$ \\
\hline Dean Jane & Associate Dean & $\begin{array}{l}\text { Public, Research } \\
\text { One }\end{array}$ & Education & $\begin{array}{l}\text { Approximately } \\
2 \text { years }\end{array}$ \\
\hline Dean Alan & $\begin{array}{l}\text { Executive } \\
\text { Associate Dean }\end{array}$ & $\begin{array}{l}\text { Public, State } \\
\text { Institution }\end{array}$ & $\begin{array}{l}\text { College of Fine } \\
\text { Arts }\end{array}$ & $\begin{array}{l}\text { Approximately } \\
13 \text { years }\end{array}$ \\
\hline Dean Wilson & $\begin{array}{l}\text { Dean College of } \\
\text { Business }\end{array}$ & $\begin{array}{l}\text { Public, Research } \\
\text { One }\end{array}$ & Business & $\begin{array}{l}\text { Approximately } \\
6 \text { years }\end{array}$ \\
\hline
\end{tabular}

participants were from state colleges and public universities. Dean Sarah was the only participant who was employed at a community college, and Dean Alan had served the longest tenure of all participants. Finally, all participants had previous positions and experiences in higher education that had led to their current role. Many of the participants had been employed in different roles at their institutions for many years prior to their current positions that included positions such as department chairs and faculty who had sat on faculty and administrator hiring committees. All participants indicated that they had served on various hiring committees throughout their tenures.

\section{Section 2: Presentation of Findings by Research Questions}

What are the current perceptions of academic hiring gatekeepers and employers regarding online education in general? Do perceptions differ from the perceptions held 
toward traditional higher education? And to what extent do academic hiring gatekeeper perceptions toward online education influence their hiring decisions?

Participant perceptions, with respect to the questions raised above are highlighted in Table 5. A total of twenty-four questions were asked in order to ascertain the academic hiring gatekeeper perceptions of online learning, online degrees and online education in general. A number of the items produced interesting patterns in participant perceptions. For example, 90 percent of participants believe that online degrees do have some value, while only 8 percent agree that institutions of higher learning should not be offering online education. Additionally, 86 percent of participants agree that the institution from which a candidate earns their degree is very important when considering the hiring of a potential employee. In fact, 47 percent of academic employers agreed that an online degree is okay provided the candidate earned the degree from a highly respected institution. Essentially, this high percentage demonstrates the importance employers place on institutional reputation. This number also demonstrates a positive shift in perceptions toward the legitimacy of online learning as suggested by Allen and Seaman (2013).

Moreover, only 8 percent of academic employers agree that institutions should not be offering online degrees to students since that depreciates their reputation or credibility. Of the total number of participants who responded to the online survey, 66 percent agree that online education does provide a useful role in educating candidates in one's field. When asked about the quality of an online degree, the participant feedback was mixed. For example, 40 percent agreed that an online degree is of lesser quality than a traditional 
degree, while 36 percent disagree. Further, it is critical to note that a majority of

participants (59 percent) believe online degrees are not as credible as traditional degrees

when considering a potential job candidate. This data appears consistent with current

literature. For example, according to the Kresge Foundation (2013), most employers

would prefer a job applicant with a traditional degree from an average school over one

with an online degree from a top university. Namely, among academic employers, there

continues to be a debate as to the overall quality and value of online degrees.

\section{Table 5}

\section{Hiring Gatekeeper and Employer Perceptions of Online Education}

\begin{tabular}{|c|c|c|c|c|}
\hline Items & $\begin{array}{l}\text { Disagree } \\
\%\end{array}$ & $\begin{array}{l}\text { Agree } \\
\%\end{array}$ & $\begin{array}{c}\text { Neutral } \\
\%\end{array}$ & $\mathbf{N}$ \\
\hline $\begin{array}{l}\text { Online education provides a useful role in educating } \\
\text { candidates for our field. }\end{array}$ & 24 & 66 & $` 10$ & 100 \\
\hline $\begin{array}{l}\text { Online degrees have a place in preparing faculty and/or } \\
\text { administrators for their careers. }\end{array}$ & 39 & 45 & 16 & 100 \\
\hline $\begin{array}{l}\text { Online degrees are not rigorous enough for anyone to gain } \\
\text { any knowledge from such a program. }\end{array}$ & 55 & 22 & 16 & 99 \\
\hline $\begin{array}{l}\text { Students from online programs are weaker than candidates } \\
\text { from traditional programs. }\end{array}$ & 33 & 49 & 18 & 99 \\
\hline $\begin{array}{l}\text { Traditional institutions should not be offering online } \\
\text { degrees since that goes against their reputation or } \\
\text { credibility. }\end{array}$ & 71 & 8 & 21 & 100 \\
\hline $\begin{array}{l}\text { Institutions of higher learning should not be offering } \\
\text { online education in an online mode. }\end{array}$ & 90 & 3 & 7 & 99 \\
\hline Online degrees are of less quality than traditional degrees. & 36 & 40 & 24 & 97 \\
\hline $\begin{array}{l}\text { If one has the opportunity to take either an online course } \\
\text { or a traditional course, they should go for the online } \\
\text { course. }\end{array}$ & 66 & 6 & 28 & 100 \\
\hline $\begin{array}{l}\text { Students benefit from online courses in a similar way like } \\
\text { they do from traditional courses. }\end{array}$ & 54 & 31 & 15 & 100 \\
\hline Online degrees have no value at all. & 90 & 4 & 6 & 100 \\
\hline $\begin{array}{l}\text { The institution from which a candidate earns their degree } \\
\text { is a very important consideration when making hiring } \\
\text { decisions in our institution. }\end{array}$ & 9 & 86 & 5 & 100 \\
\hline $\begin{array}{l}\text { It is irrelevant if the degree is online so far as the } \\
\text { candidate has the necessary experience. }\end{array}$ & 64 & 28 & 8 & 99 \\
\hline $\begin{array}{l}\text { Our institution generally believes that an online-degree is } \\
\text { not as credible as a traditional degree when considering } \\
\text { potential job candidates. }\end{array}$ & 23 & 59 & 18 & 100 \\
\hline $\begin{array}{l}\text { Our institution generally believes that an online degree is } \\
\text { okay provided the candidate earned the degree from a }\end{array}$ & 35 & 47 & 18 & 98 \\
\hline
\end{tabular}




\begin{tabular}{|c|c|c|c|c|}
\hline Items & $\begin{array}{c}\text { Disagree } \\
\%\end{array}$ & $\underset{\%}{\text { Agree }}$ & $\begin{array}{c}\text { Neutral } \\
\%\end{array}$ & $\mathbf{N}$ \\
\hline \multicolumn{5}{|l|}{ highly respected traditional institution. } \\
\hline $\begin{array}{l}\text { Our institution generally believes that a potential job } \\
\text { candidate possessing an online degree from a traditional } \\
\text { higher educational institution has received a similar } \\
\text { educational experience as a candidate with a traditional } \\
\text { degree from the same traditional higher education } \\
\text { institution. }\end{array}$ & 56 & 31 & 13 & 98 \\
\hline $\begin{array}{l}\text { I (or my institution) believe that there is a clear difference } \\
\text { between a degree obtained online and a degree obtained } \\
\text { traditionally. }\end{array}$ & 19 & 68 & 12 & 96 \\
\hline $\begin{array}{l}\text { Our institution places heavy emphasis on the reputation of } \\
\text { a specific college or university when considering the } \\
\text { potential hire of a faculty member or administrator. }\end{array}$ & 19 & 76 & 5 & 99 \\
\hline $\begin{array}{l}\text { Our institution believes it is ok to take a portion of the } \\
\text { course required toward obtaining a traditional degree } \\
\text { online, but not have the entire degree obtained online. }\end{array}$ & 17 & 55 & 28 & 98 \\
\hline $\begin{array}{l}\text { The higher the position in the institution (i.e. tenured } \\
\text { faculty, dean, etc.) the less acceptable an online degree } \\
\text { credential becomes. }\end{array}$ & 28 & 55 & 17 & 99 \\
\hline $\begin{array}{l}\text { Our organization has different pay scales for online degree } \\
\text { holders and traditional degree holders. }\end{array}$ & 77 & 0 & 23 & 96 \\
\hline $\begin{array}{l}\text { I believe fully online education will play a significant role } \\
\text { in my college/school's strategic plan over the next } 3-5 \\
\text { years. }\end{array}$ & 25 & 63 & 12 & 98 \\
\hline $\begin{array}{l}\text { The advantages of using online instruction exceed the } \\
\text { disadvantages. }\end{array}$ & 26 & 37 & 38 & 98 \\
\hline $\begin{array}{l}\text { Online instruction is not appropriate for educating and } \\
\text { training future faculty members and educational } \\
\text { administrators. }\end{array}$ & 51 & 33 & 16 & 98 \\
\hline $\begin{array}{l}\text { Online education contributes to the de-professionalization } \\
\text { of faculty. }\end{array}$ & 44 & 32 & 24 & 98 \\
\hline
\end{tabular}

In Table 6, participant hiring practices are highlighted. First, it is notable to report that a majority of respondents (64 percent) agree that they would more likely hire a doctoral candidate who completed a degree in a traditional education setting rather than a candidate with an online doctoral degree from a traditional higher education institution. Next, over 80 percent of participants indicated they would choose a candidate with a doctoral degree completed in a traditional program from a traditional higher education institution rather than a candidate with a doctoral degree from an online only higher education institution. Additionally, a large majority (71 percent) of academic hiring 
gatekeepers agreed that when hiring for a faculty/administrator position, they would

choose a candidate with a degree completed in an online program from a traditional

higher education institution rather than a candidate with a doctoral degree earned from an

online only higher education institution. Finally, more than half of the participants (61

percent) disagreed with the statement: I would never consider hiring a faculty member or

administrator who completed an online degree (regardless of the institution or program).

\section{Table 6}

Hiring Gatekeeper and Administrator Hiring Practices

\begin{tabular}{|c|c|c|c|c|}
\hline Items & $\begin{array}{c}\text { Disagree } \\
\% \\
\end{array}$ & $\begin{array}{c}\text { Agree } \\
\%\end{array}$ & $\begin{array}{c}\text { Neutral } \\
\%\end{array}$ & $\mathbf{N}$ \\
\hline $\begin{array}{l}\text { When hiring for a faculty/administrator position, I would } \\
\text { choose a candidate with a degree completed in a } \\
\text { traditional program from a traditional higher education } \\
\text { institution over a candidate with an online doctoral degree } \\
\text { from a traditional higher education institution. }\end{array}$ & 21 & 64 & 15 & 99 \\
\hline $\begin{array}{l}\text { When hiring for a faculty/administrator position, I would } \\
\text { choose a candidate with a degree completed in a } \\
\text { traditional program from a traditional higher education } \\
\text { institution over a candidate with a blended/asynchronous } \\
\text { doctoral degree from a traditional higher education } \\
\text { institution. }\end{array}$ & 34 & 48 & 18 & 99 \\
\hline $\begin{array}{l}\text { When hiring for a faculty/administrator position, I would } \\
\text { choose a candidate with a degree completed in a } \\
\text { traditional program from a traditional higher education } \\
\text { institution over a candidate with a doctoral degree from an } \\
\text { online only higher education institution. }\end{array}$ & 8.2 & 83 & 9 & 98 \\
\hline $\begin{array}{l}\text { When hiring for a faculty/administrator position, I would } \\
\text { choose a candidate with a degree completed in an online } \\
\text { program from a traditional higher education institution } \\
\text { over a candidate with a doctoral degree earned from an } \\
\text { online only higher education institution. }\end{array}$ & 13 & 71 & 15 & 98 \\
\hline $\begin{array}{l}\text { I would never consider hiring a faculty member or } \\
\text { administrator who completed an online degree (regardless } \\
\text { of the institution or program). }\end{array}$ & 61 & 24 & 14 & 99 \\
\hline $\begin{array}{l}\text { The type of degree (online or traditional) would not make } \\
\text { any difference with regard to my hiring decision of a } \\
\text { faculty member or administrator. }\end{array}$ & 72 & 16 & 11 & 98 \\
\hline
\end{tabular}


A content analysis of the participants' written comments to the open-ended responses on the survey (provided by participants) was also conducted to provide support for the results gleaned from the quantitative data analysis. Participants were asked to respond to three open-ended questions that solicited more in-depth responses of their perceptions toward online education. For instance, the first open-ended question asked participants to describe their personal perceptions regarding online education (see Appendix A). A total of 89 participants provided responses to this particular question. Reoccurring words or phrases used by the participants in their responses included: quality, rigor, flexibility, standardization, mixed feelings, specific disciplines, positive, and negative. The following main ideas were gathered from the participants' responses:

1. Online education can offer a flexible alternative for those individuals unable to pursue a higher education in a traditional environment.

2. There appears to be a place or niche for online education. However, there are certain fields and disciplines that require hands-on learning and online education is not the appropriate educational medium.

3. The quality and rigor of traditional classroom learning is not present in online education environments.

4. There is no standardization in online education.

5. The value associated with online learning is entirely dependent on faculty/instructor quality and experience.

6. Skepticism toward online education exists and many individuals remain "on the fence" with regard to its effectiveness.

7. Those individuals who hold the most positive views toward online education are those who often had first-hand experience teaching or working with the medium.

Overall the participants articulated negative reactions, mixed-feelings, or positive perceptions in their responses to the open-ended survey items. In terms of negative perceptions, the following statements were presented: 
"[Online education] inadequately prepares faculty for higher education teaching activities."

"It is inferior to traditional education."

"I think it is a huge waste of money and predatory."

"I think that graduate online degrees are problematic for future faculty as they don't have sufficient scholarly hands-on training nor working in collaborations with graduate and undergraduates."

The following statements expressed the mixed-feeling reactions toward online education:

"I have mixed feelings. I think it is appropriate in some fields and difficult to duplicate the brick and mortar experience in others."

"Wait and see. Okay for a professional master's. No way a person can prepare themselves to be a faculty member at a research institution by studying online."

"I am trying to remain open but skeptical."

"I have mixed beliefs. I can see the value in online education but for my field, education, it is hard for me to understand how an on-line program can effectively prepare future teachers and leaders."

The following statements reflect positive views of online education:

"I graduated from a hybrid doctoral program and found it to be an excellent learning experience. This experience shapes my view of online-education."

"I get to know students better in online courses and have deep discussion and they work harder but I have higher standards. We fight to be competitive with the paper-mill online programs."

"I believe many students can benefit from online education, especially if their schedules, responsibilities, and commitments prevent them from attending traditional courses."

"I am in favor of blended learning, especially useful for an urban university."

The second open-ended question asked participants to discuss their organization's hiring policy regarding online degree holders. Again, a total of 89 participants provided 
written responses to this question. Yet again, several reoccurring word phrases emerged from the data gathered through the use of this question. The reoccurring words and phrases included words such as: no formal policy, reputable, accredited, and would not hire. Of these reoccurring words and phrases, the following main ideas were generated:

1. $[\mathrm{My}]$ institution does not have a formal hiring policy in effect for online degree candidates.

2. Any applicant must have received a degree from a reputable or accredited institution.

3. An online degree candidate would not be hired under any circumstance at our institution.

In addition, the following statements were gleaned from respondents' comments regarding their organization's hiring policy:

"As long as the degree is from an accredited institution they are considered equal candidates in the pool."

"No formal policy, but strong bias in favor of in-person education for students and faculty."

"As far as I know, there is no official policy and what determines how "terminal degree' is defined is left up to each academic unit/department."

"We have no such policy. However, we have never hired a person with a terminal online degree. Almost all of our faculty hold Ph.D.'s. I'm not sure if online Ph.D. programs even exist, but if they did, they'd be viewed with extreme skepticism at my university."

"Because we hire nursing faculty, we do not hire online degree (holders) because they do not include clinical (hands on) preparation at a graduate level."

"As far as I know, we have never hired one- there is no respected online $\mathrm{PhD}$ or MFA in English."

"They are viewed equal to a traditional degree holder."

"Online is fine for bachelors and some Masters - not so much for doctoral positions." 
The final survey question asked participants to share any additional thoughts, comments, insights, and perceptions they had regarding online education and/or the hiring of potential job candidates who had online degrees. Forty-five participants responded to this open-ended question. The following statements are some of the direct quotes culled from respondents written comments:

"Everybody I know would prefer candidates with traditional degrees. However, when a current faculty member (with masters) in a tenure earning position pursues an online doctorate - this seems to be more acceptable. Probably because that person is known/liked and the department wants to keep him or her."

"Prestige trumps degree. Same degree (say MBA or a PhD) from a more prestigious institution carries more weight than from a less prestigious institution irrespective of how the degree is earned (online or face to face)."

"Bias and discrimination of hiring practices can occur because of how others will perceive the faculty/administrator in your department/university. I may be more ok with it (online degrees), but I don't want others to think I have a weaker department or university because they are totally against it. So, in essence, I am discriminating over it in practice."

Additional qualitative data was collected through semi-structured interviews with six administrators to determine whether participant patterns of perception persisted and also to obtain an in-depth understanding of the participant perceptions. Each of the interviews lasted approximately one hour and were conducted with higher education administrators in various positions. In the qualitative data analysis portion of this research, four a priori themes emerged. According to Ryan and Bernard (2003), a priori themes originate from the characteristic of the phenomenon being studied and from a researcher's values, theoretical orientation, and personal experiences. Identifying repetition of ideas, phrases, and words was one of the primary methods for identifying themes in this analysis. 
Additionally, the use of metaphors and analogies (by interviewees) were also used to isolate emerging themes. The following themes are noted and discussed in line with each participant's profile: Faculty/Administrator Experience with Online Education; Institutional Hiring Practices and Experience with Online Degree Recipients; Quality of Online Education and its Relation to Institutional Type and Institutional Reputation; Institutional Reputation and the Future of Online Education in Relation to Traditional Education. The data collected from each interviewee's interview were coded and analyzed for themes and were mostly based on the previously stated apriori themes.

\section{Director John}

Applying his previous experience and knowledge from both the private sector and academia, John currently serves as the Director of the Master of Science Finance program for the College of Business at a public, research one institution in the Midwest region of the United States. John's college is nationally ranked as one of the top twenty business schools in the nation. The total enrollment at John's university is approximately 45,000 students, and his college enrolls over 3,000 undergraduates and graduates annually. John has been in his director position for approximately three years. Before his appointment to program director, John had spent almost thirty years in the private business sector. $\mathrm{He}$ served as a President and CEO in his professional tenure for a major insurance company. After retiring from private industry, John decided to join academia and was hired as a professor of finance at his current institution in 2004.

Experience/Familiarity with Online Education. John's unique combination of work and career experience produced an interesting and focused discussion on online education and faculty hiring practices. First, John noted that while he did not have 
personal experience with online education, he watched his daughter complete an online Master's program. He said it was a very positive experience for her, and he thought it was a terrific way for individuals working full-time (or with other life obligations) to pursue a degree.

Quality of Online Education and its Relation to Institutional Type and

Institutional Reputation. John mentioned that his particular college was starting to look and consider online learning/degrees as a very viable option for students. In fact, he stated that while some faculty at the college remain skeptical of online education, he believes that ensuring the same quality of education in both the traditional and online environment is critical. However, John did indicate that while online education at his college has come a long way in terms of quality, there is still room for growth. More specifically, John noted that, "I would say in general, when you have a (reputable) university on your diploma and if you have a few online courses, I think people look at it (the online program component) as the same level of excellence that we would get in a classroom experience. I think the broader issue will be, will we ever get to the point where we offer a full opportunity to have a master's program online?"

While John may be open to hiring faculty members who have online degrees, he did disclose that institutional reputation is very important when making a faculty hiring decision. For example, John specifically mentioned the Big Ten institutions, Ivy League schools and pre-eminent research institutions would all be considered highly reputable; and, he would hire faculty with degrees from these types of colleges and universities. Further, John stated, 
"...the ones (institutions) that we'll probably stay away from are those that, at least for now, that we don't know that well. If we don't know the school well that probably says we're going to steer away, whether it's online or otherwise. I think we're still trying to keep the caliber of the institution at a high level. If online is part of that, and we trust the institution, then I think we'll feel comfortable with it."

Essentially, John argued that if a faculty candidate did have an online degree from a reputable institution and the necessary experience etc., that person would be considered for employment. However, an individual with an online degree from a not-so-reputable institution or even from a for-profit institution would not be considered for a faculty position.

John also mentioned that he believes individuals with $\mathrm{PhDs}$ from for-profit online institutions are probably not looking for faculty positions. Instead, he believes these degree holders are nestled in institutional administration. Next, John stated his major concern with hiring a faculty member with an online degree: "Now I think the biggest worry I would have is why that student doing it (online degree). Is it because they won't want to have the social interaction? Is it because there are more economic reasons? There's a social interaction piece that's probably important. I would think about that...I would say there's nothing like sitting across from people and talking to them and finding how they handle themselves."

Hiring Practices and Experience with Online Degree Recipients. In our discussion regarding hiring practices, John initially stated that his college looks for a combination of skills and expertise when it comes to future faculty hires. He indicated that he received about fifty applications for a recent faculty position. He said these applicants possessed a combination of education obtained from both the United States 
and international institutions. In general, John remarked that there are not any specific "rules" regarding those applicants who have an online degree credential. In fact, John stated, "More and more students want to have professors that have experience in the classroom. I think when I look at online education, what it says to me is many times, they're (the professor with the online degree) going to be working professionals that are having to do things in what might be considered a non-traditional way. Frankly, it probably fits the model for what we're trying to do in terms of thinking about a way to fill spots that might help our students understand more about business.”

The Future of Online Education in Relation to Traditional Education. John indicated that he perceives many faculty and administrators remain very cautious of institutions such as the University of Phoenix. However, he stated that the negative perception may change over the next ten years as online education continues to grow and institutionalize on a global scale. He also suggested that the next generation of college students would find online education a natural alternative to a traditional college experience.

Next, John suggested that there is certainly a place for online education and he remains a big believer in the educational medium. He also stated that he believes executive education is certainly moving in an online direction. In fact, he has taken notice that companies are starting to utilize executive education opportunities for their employees. More specifically, he stated that more and more companies are starting to realize that sending people away for a year or for two years of coursework has many benefits for employee growth and development. However, he suggested that giving these individuals the opportunity to do part of their coursework online, so they could still work 
full or part time, would be very enticing for organizations. He strongly believes that business education will be moving in that blended/online direction.

Finally, John suggested that at many institutions of higher education, traditional classroom education will never be replaced with online education despite the medium's rapid growth. In fact, John believes that there will always be a demand for a traditional education and in traditional classrooms especially in certain educational fields such as the medical sciences that require "hands on learning" and lab experience. John also believes that the tradition of college education (a tradition that includes a residential type component) will always be a staple of American higher education.

\section{Dean Ron}

Dean Ron currently serves as an Associate Dean for academic programs in the College of Education at a public, research one institution in the Midwest region of the United States. The total enrollment at Dean Ron's university is approximately 45,000 students and his specific college enrolls over 1,200 undergraduate and graduate students annually. Dean Ron has been in his position for approximately three years. Before his appointment to associate dean, he had spent a decade teaching education at various institutions.

Experience/Familiarity with Online Education. While Dean Ron has not personally enrolled in any online courses, he carefully articulated how his college had effectively incorporated online education and online degrees despite the university's failure to follow the same path. In fact, Dean Ron's college currently offers twelve fully online degree programs. Many of the students enrolled in these online degrees have never 
actually stepped foot on the university or college campus. They have completed their education solely online. While the college does not offer an online PhD, Dean Ron indicated that there were talks of exploring the possibility of offering an online EdD (Doctor of Education) in an effort to remain competitive with other peer institutions. Dean Ron firmly stated that in his particular college, online degree programs were of equal quality and value as compared to the traditional degree programs offered.

Quality of Online Education and its Relation to Institutional Type and Institutional Reputation. Dean Ron believes that if highly reputable institutions offer online degree programs, the typical student will essentially forgo a traditional education to "finish the degree quickly and with less expense". It is important to note that Dean Ron is only referring to institutions which he considers "peer institutions" (i.e. similar in position, scope, mission, and benchmarking data analytics and/or rankings). Moreover, this category of online degrees does not include for-profit institutions such as those identified by Dean Ron as University of Phoenix, Kaplan University, etc. However, Dean Ron did specifically mention an online degree program from a highly reputable Midwest institution that offers both Masters and PhD level credentials in their school of education. He believes that if reputable institutions can effectively administer these types of online degree programs, students will abandon traditional notions of education and pursue an online degree.

Further, Dean Ron believes students will pursue online credentials if the degree is being granted from a reputable institution and meets all state standards for teaching etc. In fact, Dean Ron articulated that the only "saving grace" for his institution (with regard to the competition) was state specific standards. More specifically, if a student wants to 
be certified to teach in a particular state, he or she must meet the appropriate state credentials, which generally requires a traditional classroom component.

Hiring Practices and Experience with Online Degree Recipients. As an associate dean, Dean Ron has made numerous faculty hiring decisions in the past several years. I was curious to learn what credentials, experience, and expertise a potential faculty job candidate must possess for that individual to be considered for a faculty position in the college. Dean Ron stated that his college would only consider hiring a faculty member who had received his or her degree from a peer institution. However, I posed the question: what if a candidate received an online degree from a peer institution? Dean Ron surprised me and said an individual with an online degree from a peer institution (only) would be considered for hire if he or she also held other critical qualifications for a faculty member such as publications, research, teaching experience etc. Dean Ron was clear that a faculty applicant with a degree from a for-profit institution (such as University of Phoenix) would not be considered for employment as these types of institutions are not considered to be peer institutions. Finally, when asked if he had ever encountered online degree candidates, Dean Ron indicated a low occurrence, but wouldn't be surprised if the number of online degree applicants would steadily increase. He also mentioned that at his college there is no distinction indicating whether or not the degree was obtained online. Therefore, he said it is very possible that other faculty applicants also achieved their degree online (from peer institutions) but one would not necessarily be aware of how that degree was obtained.

More surprisingly, Dean Ron stated that any faculty candidate would have to agree to teach in some online capacity in order for them to ever be considered for a 
position within his college. For example, he explained that a majority of the faculty in his college were comfortable with the technology of online education. Additionally, some of the faculty were more "on board" than others, but the overall consensus was positive toward teaching in the online course and programs. He stated that most of the current college faculty had previously taught a course online. While Dean Ron's college has built a strong culture and foundation for online learning, he also mentioned the importance of "faculty buy-in". For example, we discussed the failure of his university's attempt to launch a campus wide online education initiative. Dean Ron argued that for several reasons faculty members were skeptical to extend the university's traditional higher education brand to also encompass online degrees. These reasons included issues concerning institutional reputation, negative prejudices and stigmas associated with the online learning medium.

\section{The Future of Online Education in Relation to Traditional Education. When} addressing the future of online education, Dean Ron assertively stated that online education would be the future of education in some capacity. For example, he explained that online degree programs have started threatening the sustainability of face-to-face degree programs (especially in smaller colleges or degree programs like his). More specifically, Dean Ron suggested that within the next ten years, it is his prediction that online education will institutionalize at traditional education institutions and consequently will legitimize the educational medium for the academy. However, it is critical to note that Dean Ron did not think that online education would replace traditional education in all areas. For example, he believes that degrees in the hard sciences, engineering, law, and medical fields will not be replaced with an online learning 
medium due to their complex subject material. Additionally, Dean Ron stated, "There will always be a Harvard, but some of the other smaller and liberal arts institutions will suffer when online education is legitimized."

\section{Dean Sarah}

Dean Sarah serves as the Associate Dean of Instruction at a public community college in a major city in the Midwestern United States. The approximate enrollment of Dean Sarah's college is 12,000 students. Dean Sarah holds a bachelor's degree in both Communications and Spanish from a public Midwestern university, and a Master's degree in Linguistics. Dean Sarah has worked at her institution for five and a half years, and she has been in her current position for almost two years.

Experience/Familiarity with Online Education. Initially, Dean Sarah discussed her experience with online education. While she explained that she had never taken an online course, she had taught several online courses at a for-profit college. She indicated that as an instructor, she was familiar with the online teaching platform. Therefore, she did not have difficulty using the technology but found several of her students did. She explained that acclimating adult students, who were new to the technology of online education, was a challenge.

Quality of Online Education and its Relation to Institutional Type and Institutional Reputation. In terms of content, rigor, and quality, Dean Sarah said she believes her courses are equivalent to that of her traditionally taught classes. In fact, Dean Sarah articulated that it is the instructor that determines the quality of a class - online or traditional. For example, according to Dean Sarah, "It could have been so easy for me to just put grades in and just pass people through, but I actually did take the time to read the 
papers and give them (the students) revisions and notes...I didn't need to do that. Whereas on a physical (traditional) campus they (students) are expecting it."

Next, when asked the number (if any) of online degree applicants Dean Sarah had encountered while making a hiring decision she indicated that she was not certain. Dean Sarah stated that she may have come across some candidates with online certifications but could not recall seeing applicants who possessed any major online degree (Bachelor, Master, etc.). However, she did mention that one of the top administrators at her college had received an online $\mathrm{PhD}$ from a well-known for-profit online institution. She also mentioned that while she would love to pursue an $\mathrm{EdD}$ or $\mathrm{PhD}$ in the future, the traditional degree route may not be feasible for her due to her work and family obligations. Instead, she would consider completing her doctoral degree online.

Based on her comments, I asked Dean Sarah to consider the following hypothetical scenario: Would an individual still be considered for hire if the candidate had obtained a Master's degree online, but also possessed the relevant experience and qualities necessary for successful teaching? Dean Sarah replied, "If you had just that online degree from University of Phoenix and you came in with nothing except that online degree, I'd be like okay, not going to work." However, she did say if the individual did have relevant teaching and instructional experience she would consider that person for hire if the online degree was obtained from an accredited institution. She proceeded to argue that traditional classroom learning gives future faculty members a solid learning model to draw from with regard to classroom instruction. If that candidate did not have the classroom experience (i.e. includes presentations and face-to-face group projects), then that individual may struggle as an instructor. Further, Dean Sarah also 
mentioned that she believes for-profit online institution such as the University of Phoenix, DeVry University, and Kaplan University were much more willing to hire faculty with less prestigious credentials than more reputable institutions. She also mentioned that a current faculty member or administrator (currently employed at her institution), who decided to enroll in an online $\mathrm{PhD}$ program from an online institution, would probably be well received or accepted. Essentially, Dean Sarah argued that once an individual has earned respect in her institution, then the degree type would be less of an issue.

Hiring Practices and Experience with Online Degree Recipients. Dean Sarah explained her college's policy with regard to online instruction. She indicated that the college has a pretty rigorous and intensive training process for those instructors who wanted to teach online. However, Dean Sarah stated, "I am hesitant about students who get online degrees at lower levels like undergrad levels. I think there's so much value in the face-to-face and the social aspect of being in college, even if it's a community college". Dean Sarah added that the first credential required of future faculty hires is a Master's degree in the appropriate discipline. A degree obtained from an accredited college or university is another critical credential required of a faculty applicant. A third component for consideration is the amount of actual classroom teaching experience a candidate has. For example, Dean Sarah states, “...a lot of times you can come in with a $\mathrm{PhD}$ in physics, but if you can't teach our students at this level the math that they need, a PhD doesn't do us any good". Dean Sarah discussed in further detail the importance of institutional reputation when considering a faculty candidate. For example, “...you're going through 50 different resumes and that's (institutional reputation) the first thing 
you're keyed into. I mean honestly, if I see something that's a state university or even a private college, or something that we know produces really solid students, I am going to pull that one out more, more often than when I see these ones (institutions) that I have to take the time to look up."

The Future of Online Education in Relation to Traditional Education. Finally, Dean Sarah and I concluded our interview with a discussion on how traditional higher education institutions can be successful at providing online education and online degrees. She noted that success for these institutions is due to the fact that, "They've been in existence for hundreds of years and their name is a brand and it's not something that started in 1981" (i.e. University of Phoenix).

\section{Dean Jane}

Dean Jane currently serves as the Associate Dean for the College of Education at her institution. Her college is part of a public, state institution located in the Midwestern region of the United States. Her institution enrolls approximately 21,000 students, and her college enrolls over 2,500 students annually. Dean Jane indicated that her position is associated with three major duties that include: international education, graduate education, and research and grants. Prior to her appointment as associate dean, Dean Jane also served as a faculty member and department chair for many years. She earned her $\mathrm{PhD}$ in Educational Administration from a traditional higher education institution.

Experience/Familiarity with Online Education. Dean Jane had a very unique experience to share regarding online education, and she also indicated a strong inclination toward online learning in general. In fact, she stated that she practiced some of the original forms of online education in her early years as a classroom instructor. For 
example, Dean Jane stated she would make VHS tapes of her lectures for adult nontraditional students. Additionally, she discussed her experience with teaching interactive TV classes; further, she notes that she was one of the first professors at her institution to use Internet based programs such as Web CT. Dean Jane said that part of her job was also to run the school's first computer lab. Therefore, she notes that she is self-taught when it comes to many computer-based technologies. Dean Jane also indicated that she had previously taken an online class from a reputable institution assessing online learning. She has also taken online supplemental courses from organizations such as Sloan-C and in the future would like to take a class via a MOOC (massively open online courses).

\section{Quality of Online Education and its Relation to Institutional Type and}

Institutional Reputation. When addressing the overall quality and value of online education, Dean Jane agreed that the online classroom instruction she has experienced has been of equal quality and value as compared to traditional classroom education. She referred to the process as "...this flip your classroom notion." More specifically, she indicated that online instruction requires more effort on the front end (i.e. before-class preparation). Further, she noted that the whole point of online education is to make individuals more independent. However, Dean Jane stated that the misconception of less work or less time involvement is often associated with online education.

Hiring Practices and Experience with Online Degree Recipients. Dean Jane's college is not currently offering fully online degree programs, but there are many online courses offered to students in the college. She did mention that the college was exploring the idea of implementing an online degree program. This discussion transitioned into faculty hiring practices within her college. She revealed that different departments in the 
college had slightly different hiring practices and requirements for faculty applicants. For example, she indicated that a department focusing on PK-12 education would require an individual to have not only the appropriate degree credentials, but also possess actual classroom teaching experience at that educational level. However, in the higher education department, there may be more of an emphasis on scholarly publications rather than actual classroom teaching experience. Further, Dean Jane stated that there is an expectation for future faculty members to use the Internet as a teaching tool or at least possess the willingness to learn to use it.

When asked about online degree faculty candidates, Dean Jane recalled one faculty candidate who possessed an online degree from a for-profit institution. She said it was about two years ago, and the for-profit nature of the degree was not well received by college hiring decision makers. However, Dean Jane articulated that it really came down to the for-profit nature of the degree instead of the "online" aspect of the degree. For example, she mentioned an online program at a not-for-profit traditional institution that is well respected among administrators of the college. More specifically, when referring to for-profit online degrees, Dean Jane stated, "You pay to get your degree as opposed to the quality...it's the for-profit that would make me think twice, more than the online part".

Essentially, when evaluating online degree programs, Dean Jane believes it comes down to the reputation (not-for-profit) and perceived level of excellence from that particular institution. She said she would feel comfortable hiring a faculty member who had obtained an online degree only if that individual had received the degree from a 
reputable institution and also had relevant experience, publications, etc. Additionally, Dean Jane discussed a situation where two students applied to the college for enrollment in a doctoral program, and both of these individuals possessed online Masters degrees. However, one of these students had an online degree from a reputable institution and the other from a for-profit. She revealed that there was no hesitation to admit the student with an online Master's degree from the traditional institution, but there was not consensus from college admissions administrators on whether to admit the student holding the forprofit degree. Eventually, the student with the online degree from the for-profit institution was admitted into the doctoral program; however, the academic progress of this individual was closely monitored. Additionally, Dean Jane mentioned that there were two students from her college's program who had actually left the program and enrolled in a for-profit to finish their doctoral degree. She argued that these student likely thought that the program at the not-for-profit could be completed much faster and was 100 percent online.

In our discussion regarding employment of students in her college's doctoral program, Dean Jane indicated that a majority of these students already had jobs when they entered the program. Therefore, she assumed that many of the students at online forprofit institutions would be in a similar circumstance regarding employment.

Finally, Dean Jane suggested that any individual or specific institution skeptical of another institution's online degree program or academic programs should examine the criteria set by the Sloan Consortium in an effort to effectively evaluate their online education. 
The Future of Online Education in Relation to Traditional Education. Dean Jane believes very strongly that online education will continue to grow and expand both inside and outside the academy. She indicated that due to time, money, and different learning styles, online education is a very attractive option for both students and the institution. Additionally, she referenced Massive Open Online Courses (MOOCs). She suggested that MOOCs will develop and multiply at many higher education institutions, essentially offering students even more flexibility and breadth in their education. However, Dean Jane did maintain that there remains a divide among supporters and non-supporters of online education. Further, Dean Jane was adamant that it would be impossible for the academy to do away with face-to-face communications. In fact, she states with regard to traditional education, “There's just something so valuable and again there's a social aspect...”

\section{Dean Alan}

For the past thirteen years, Dean Alan has served as the Executive Associate Dean for the College of Fine and Applied Arts at his institution. His college is part of a public, state institution located in the Midwestern region of the United States. His institution enrolls approximately 21,000 students, and his college enrolls approximately 1,200 students annually. Dean Alan's college educates students in art, art technology, music and theatre.

Experience with Online Education. Dean Alan stated that his college currently holds very strong convictions about completely online degrees in the arts. For example, he stated, "I can't imagine someone getting an MFA (master's in fine arts) in studio art, 
painting, or sculpture design or an MFA in directing theatre online. The idea is even difficult to comprehend because of the nature of those (online) degrees..."If you are going to get a master's or doctorate in conducting, you kind of have to be in front of an orchestra to do that." Dean Alan did indicate that some areas are more suitable for online education than others, such as history and general studies. In fact, Dean Alan's institution offers several online degree programs and many online courses. However, Dean Alan stated that a degree in art requires studio and hands-on learning experiences that cannot be accomplished in a completely online learning environment. Additionally, Dean Alan did note in the undergraduate area of the college, there are several courses offered in online versions to students. Further, the college is also looking to expand online course opportunities for students. Dean Alan stated that a majority of these courses are blended versions of the traditional course and are nestled in the general arts education and technology discipline. Dean Alan articulated that one of the things he has heard from other faculty teaching in the online capacity is how challenging the process is. For example, "I have found people that say it is so much harder than face-to-face because you can't make decisions on the fly. You can't change gears quickly. There is a sort of intuition in front of a class, particularly if you have been doing it for a long time that I think you lose and the technology becomes a different animal that you have to deal with." Additionally, Dean Alan discussed his involvement on his university's online education task force. He explained there was a lot of conversation among task force members regarding increasing student enrollment numbers and its correlation to online courses and programs. More specifically, Dean Alan said the task force tried to find the right mix of online classes to offer students throughout the summer months. Summer 
online courses would offer students flexibility to be at home and work, while increasing enrollment numbers for the university.

\section{Quality of Online education and its Relation to Institutional Reputation. Dean}

Alan expressed that in terms of quality, comparing online to traditional education was not "apples to apples". More specifically, he believes that there is a value and a quality associated with online education. However, he indicated that course content would be the deciding factor in overall quality and rigor. For example, he explained, "I could teach the same two classes at the same time... and have them different because one student is going to ask a question in one class that another student may not think of...those students who had me in the fall are not going to get the same experience as those students who had me in the spring." Essentially, he said content is always changing and it is up to the instructor to provide quality learning regardless of the educational medium. Dean Alan also suggested that institutional reputation plays a significant role in determining the value and quality of an online degree. For example, he explained that faculty hiring committees within the college comb through a wide variety of characteristics, experiences, and qualities of applicants. More specifically, "In music, there are very few large doctoral programs that tend to feed a lot of professors. In art, there are many more MFAs (master's in Fine Arts), so in art we get more of a range than music. If you look at the

music list of faculty, there are fewer institutions represented." Dean Alan proceeded to name several institutions that carry a significant amount of influence when making a faculty hiring decision, because those institutions produce doctoral students with a "certain type of thinking or a certain way of practice" aligned with his college. Additionally, Dean Alan explained that often in theatre and music, a faculty applicant 
will indicate under whom he or she has studied. Essentially, listing well-known and reputable individuals one has studied under carries a lot of weight in the faculty hiring process.

Dean Alan was not hesitant to express his views regarding for-profit institutions. First, he stated that he was very skeptical of for-profit institutions, naming the University of Phoenix Online. Next, he stated, "I know there have been some official rulings through the government about their cost and their reputation, but I don't know enough about it. I haven't had experience with graduates from there to be honest." Additionally, Dean Alan suggested that perhaps many of these for-profit institutions are offering degrees in areas such as education and not in the arts.

\section{Hiring Practices and Experience with Online Degree Recipients. Dean Alan} discussed the college's faculty hiring practices and disclosed that a key element to hiring in the arts is performance based. For example, he stated,

"When we hire someone in music let's say with a doctorate in music, and it is performance based, we are hiring them because they can teach one-on-one with students, or they have had enough experience doing that and playing and performing. Not that they know the theory of it; but, that they know the theory of it and can teach the practice and it can be applied."

Further, Dean Alan indicated that any potential faculty member in his college is required (during the interview process) to teach a class or series of lectures to students. Therefore, Dean Alan implied that it would be very difficult for a candidate who has learned solely online to teach and conduct a music, theatre, or art and design class without previous traditional classroom experience. Additionally, when discussing whether or not he would hire a faculty member who received an online degree from a traditional or reputable higher education institution, Dean Alan said it wasn't even an applicable question. More 
specifically, he indicated that to his knowledge there are no online master's or doctoral programs being offered at traditional higher education institutions in his field. Ultimately, Dean Alan stated he didn't believe he would ever hire a faculty member with an online degree from any institution.

The Future Online Education in Relation to Traditional Education. For Dean Alan, the future of online education in the arts is a blended form of education. More specifically, "I can see some blended ones (courses). I could see some blended degrees where some of the course work is online, but in an appropriate area". Dean Alan was adamant when he stated that he did not ever see a fully online degree coming out of his college. However, he did argue that he could see why an employer in the business world would want to utilize an online type of MBA program for its employees. More specifically, "If an employer can pay for someone to get an MBA and have them continue to work and not leave, it can be more convenient for the employer, and yet they are able to still have an employee with an MBA. I can see where there is a market for that".

\section{Dean Wilson}

Dean Wilson serves as Dean of the College of Business at a public, research one institution in the Midwest region of the United States. Dean Wilson's college is nationally ranked as one of the top twenty business schools in the nation. The total enrollment at Dean Wilson's university is approximately 45,000 students, and his college enrolls over 3,000 undergraduates and graduates annually. Dean Wilson's educational and professional background include an undergraduate, Master's, and $\mathrm{PhD}$ in Economics from various universities across the nation. Further, he started his career as an Associate 
Professor in his current college and was promoted to Full Professor, Associate Dean, and eventually Dean of the college.

Experience with Online Education. Dean Wilson was eager to discuss all of the online options that his college was currently offering. In fact, he stated that the college created a summer business minor program that is offered completely online. More specifically, he indicated that there continues to be a tremendous amount of demand on campus (and also other campuses) to offer non-business students an exposure to business courses. Dean Wilson mentioned that on his campus in particular, the engineering and life sciences programs are very eager to give their students business education exposure. Therefore, the college created an online summer business minor program that allows students from all colleges and majors on campus to enroll. The program cost is equivalent to the regular summer credit hour cost.

Dean Wilson mentioned that a majority of faculty members have been very receptive because, "...faculty are finally getting this idea that the flipped classroom (online classroom) is the future. Once they see how the flipped classroom works, and once they actually try it and read their reviews from the students, they realize that pedagogically, it's much stronger (of a learning experience)." Additionally, Dean Wilson explained that the college had built their own studios to videotape a course for online usage. However, he also indicated that while many faculty members appeared very receptive to the online classroom, there are faculty who have voiced skepticism. For example, Dean Wilson indicated that job security and stability was an issue for some faculty. More specifically, these faculty members were worried the online classroom would replace their position in the traditional classroom. 


\section{Quality of Online Education and its Relation to Institutional Type and}

Institutional Reputation. Dean Wilson was very adamant to convey that the online course offerings in his college were, “...not separate but equal...We don't want to make it seem like these are second-class citizens and that somehow these are crappy versions of what we really do pedagogically...I just think we're going to see that type of online learning working as a very, very, very, important compliment to brick and mortar education.”

Hiring Practices and Experience with Online Degree Recipients. Next, Dean

Wilson and I discussed faculty hiring practices. When I asked him if he would ever hire a candidate with an online masters or bachelor degree, he stated frankly:

"Well, if you are talking about faculty, the answer is, I could care less. Even if they don't even have an undergraduate degree. What I care about when I hire a faculty member is that he or she is finishing their $\mathrm{PhD}$ at a reputable place, and can demonstrate that they can write papers."

Dean Wilson proceeded to discuss that there is a faculty screening process that occurs which typically weeds out faculty candidates from institutions that are not considered reputable. In fact, Dean Wilson said that on his campus, a person with a $\mathrm{PhD}$ from an online institution would be eliminated immediately from any faculty search due to the selective nature of the College's screening process. For example, Dean Wilson explained, "When we hire people, we divide up the schools, and we call and we ask them to give us (his college) their top three names (of faculty candidates). So we'll get the top three from Cornell, the top three from Harvard etc."

Dean Wilson also mentioned that in his conversations discussing online degree candidates with faculty members at other schools, several had indicated a few online degree holders had "slipped through the cracks" and were hired. Essentially, the hiring of 
those particular faculty members caused some internal conflict at their respective institutions. Further, Dean Wilson speculated that online PhD holders from institutions such as the University of Phoenix graduate and then are hired to work or teach at the University of Phoenix. He also indicated it is possible these individuals are going to work in a private sector company.

While Dean Wilson's college is embracing online learning and education, he argued that institutional reputation and evidence of publication are the two essential ingredients of a faculty hire at his college. Therefore, candidates from any for-profit type of institution would immediately be disqualified from the college's initial screening process.

Based upon qualitative data results, it is appropriate to address the following research question: Do academic hiring gatekeepers' perceptions toward online education differ by position and institution type? In an effort to examine whether participant perceptions differ by position and institutional type an ANOVA (analysis of variance) was conducted on the participant responses to the survey items. The level of significance for the analyses was set at 0.05 . Institutional types such as comprehensive and community college were removed and two of the position types had to be combined (i.e. dean, administrator) to eliminate the issue of low counts. Results of the ANOVA did not indicate any significant differences between position types and institutional types (i.e. religious, liberal arts, and research).

Table 7 highlights the results from the ANOVA for both position and institution type. The analysis was not significant for either position type $(\mathrm{p}=0.582)$ and institution type $(\mathrm{p}=0.295)$. 


\section{Table 7}

ANOVA Outcomes for Comparison of Perceptions to Online and Traditional Education by Position Type and Institution Type

\begin{tabular}{l|c|c}
\hline Variable & F & Sig \\
\hline Institution Type & 1.239 & .295 \\
\hline Position Type & .544 & .582 \\
\hline
\end{tabular}

Moreover, a test of association was also conducted on selected survey items using

Fisher's Exact Test on five of the specific quantitative survey items that related to this issue. The level of significance for the analyses was set at 0.05. Fisher's Exact Tests were performed rather than Chi-square analyses due to the comparatively low frequencies of participants in the data sample. According to McDonald (2009), The Fisher's Exact Test is considerably more accurate that the Chi-square analyses in assessing the difference between groups when there are small numbers of expected observations. Results from Fisher's Exact Tests revealed statistical significance for five of the quantitative survey items, and three of the items are highlighted in Table 8 (Please see Appendix $\mathrm{C}$ for mean scores and standard deviation labeled comparisons by group).

Institutional types such as comprehensive and community college were removed and two of the position types had to be combined (i.e. Dean, Administrator) to eliminate the issue of low counts for the Fisher's Exact Test. Results demonstrate that faculty (76.9 percent) and department chairs (75 percent) disagree on a significantly higher level than deans and administrators (44.4 percent) with the statement: if one has the opportunity to take either an online course or a traditional course, they should go for the online course $(p=.007)$. Additionally, faculty (50 percent) and department chairs (22.9 percent) agree 


\section{Table 8}

A Comparison of Perceptions to Online and Traditional Education by Position and Institution Type

\begin{tabular}{|c|c|c|c|}
\hline \multirow[t]{2}{*}{ Groups } & \multicolumn{3}{|c|}{$\begin{array}{l}\text { If one has the opportunity to take either an online course or a } \\
\text { traditional course, they should go for the online course. }\end{array}$} \\
\hline & Disagree & Neutral & Agree \\
\hline Faculty & $76.9 \%$ & $7.7 \%$ & $15.4 \%$ \\
\hline Dean/Administrator & $44.4 \%$ & 51.9 & $3.7 \%$ \\
\hline Department Chair & $75 \%$ & $20.8 \%$ & $4.2 \%$ \\
\hline \multirow[t]{2}{*}{ Groups } & \multicolumn{3}{|c|}{$\begin{array}{l}\text { Online degrees are not rigorous enough for anyone to gain any } \\
\text { knowledge from such a program. }\end{array}$} \\
\hline & Disagree & Neutral & Agree \\
\hline Faculty & $33.3 \%$ & $16.7 \%$ & $50 \%$ \\
\hline Dean/Administrator & $70.4 \%$ & $25.9 \%$ & $3.7 \%$ \\
\hline Department Chair & $52.1 \%$ & $25 \%$ & $22.9 \%$ \\
\hline \multirow[t]{2}{*}{ Groups } & \multicolumn{3}{|c|}{$\begin{array}{l}\text { Traditional institutions should not be offering online degrees } \\
\text { since that goes against their reputation or credibility. }\end{array}$} \\
\hline & Disagree & Neutral & Agree \\
\hline Liberal Arts & $73.2 \%$ & $22 \%$ & $4.9 \%$ \\
\hline Religious & $43.8 \%$ & $43.8 \%$ & $12.5 \%$ \\
\hline Research & $80.6 \%$ & $9.7 \%$ & $9.7 \%$ \\
\hline
\end{tabular}

significantly more than deans and administrators (3.7 percent) with the statement: online degrees are not rigorous enough for anyone to gain any knowledge from such a program $(p=.020)$. Finally, deans and administrators (92.3 percent) disagree with the statement: our organization has different pay scales for online degree holders and traditional degree holders. While there were no groups who agreed with the above statement, faculty members (41.7 percent) and department chairs (30.4 percent) expressed a larger percentage of neutrality $(p=.025)$. 
Table 8 also highlighted significant findings between institutional groups. For example, a very low percentage of members from liberal arts (4.9 percent) and research institutions (9.7 percent) agreed that traditional institutions should not be offering online degrees since that goes against their reputation or credibility. However, members of religious institutions (43.8 percent) felt more neutral about the statement $(p=.048 *)$. On the other hand, 80 percent of members from research institutions disagreed with the statement. 


\section{CHAPTER V}

\section{SUMMARY, CONCLUSION, IMPLICATIONS, AND RECOMMENDATIONS}

The purpose of this study was to determine academic hiring gatekeepers and employers' views regarding online degree programs and to examine their hiring decisions when considering a candidate with an online degree. In this chapter, a summary of the results section will be presented while providing an interpretation of the results of the study. In the process, the discoveries obtained as a result of the application of both quantitative and qualitative methodologies and the extent to which these discoveries converge and/or conflict will be outlined. In order to accomplish these objectives, results from the individual methods are summarized in narrative form and findings are examined across methods for convergence, divergence and unique outcomes. Additionally, in this chapter, connections will be noted between the findings from this study and past research on academic hiring gatekeeper and employer perceptions of online degrees.

\section{Summary}

\section{Quantitative Findings}

It is important to note that over 60 percent of academic hiring gatekeepers agree that online education provides a useful role in educating potential faculty and administrator candidates irrespective of the field of study. Further, 90 percent of respondents disagreed with the statement: institutions of higher education should not 
be offering education in an online mode. These percentages indicate that a substantial majority of academic hiring gatekeepers share positive perceptions of online education. However, when asked whether an online degree was of lesser quality than a traditional degree, 36 percent disagreed but 40 percent agreed with the statement. Therefore, it is reasonable to conclude that there continues to be a robust debate among academic hiring gatekeepers in higher education regarding the quality and rigor associated with online degrees. Additionally, almost 90 percent of participants agreed that the institution from which a candidate obtains a degree is very important. Clearly, institutional reputation is a critical factor when making hiring decisions. Therefore, online degree seekers should heavily invest in a credible and reputable higher education institution.

Next, it is important to recognize a majority of respondents (64 percent) agreed that they would prefer to hire a candidate who completed a degree in a traditional education setting rather an online setting. Further, 83 percent of participants indicated they would choose a candidate with a degree completed in a traditional program from a traditional higher education institution rather than a candidate with a degree from an online only higher education institution. This data is consistent with a report conducted by Allen and Seaman (2013) that concludes that only 30.2 percent of chief academic officers believe their faculty accepts the value and legitimacy of online education. Additionally, 71 percent of academic hiring gatekeepers agreed that when hiring for a faculty/administrator position, they would prefer to hire a candidate with a degree completed in an online program from a traditional higher education institution as opposed to an online only educational institution. This finding supports and reaffirms the widely held belief examined in this study that institutional reputation plays a critical role in 
hiring preferences and practices of academic hiring gatekeepers. More specifically, according to Jaschik and Lederman's (2013) study on faculty attitudes about technology, 73 percent of faculty indicated that whether or not an online degree program was offered by an accredited institution was the most critical factor for determining degree quality. Finally, since over half of the participants (61 percent) disagreed that they would never consider hiring a faculty member or administrator who completed an online degree (regardless of the institution or program), it is reasonable to conclude that academic hiring gatekeepers are not entirely closed minded when it comes to online degree candidates. In fact, in their most current study, Allen and Seaman (2013) found that approximately 30 percent of chief academic officers believe their faculty accepts the legitimacy and value of online education.

Based on the results from the data there are two additional conclusions that can be mined. While initial perceptions of participants do not differ significantly based on institution and position type, further observation of responses to selected survey questions demonstrated that faculty and department chairs are much less willing to accept the legitimacy of online education as a credentialing element of the hiring decision. Possible explanations for this faculty unwillingness might include faculty hesitation to teach online, and the fact that almost all faculty have matriculated through a traditional educational experience. Secondly, and just as importantly, deans and administrators have a far more positive attitude toward online education in general and the consideration of online education as a credentialing element of the hiring decision making process. A possible explanation could include issues of revenue enhancement through the delivery of online courses. 
Results from the Fisher's Exact Test demonstrate that faculty and department chairs disagree on a significantly higher level than deans and administrators that if one has the opportunity to take either an online course or a traditional course, they should choose the online course. Additionally, Fisher's Exact Test revealed faculty and department chairs agree significantly more than deans and administrators that online degrees are not rigorous enough for anyone to gain any knowledge from such a program. Based on the data set, two possible explanations emerge. First, a possible explanation for this result could be related to the financial source of income deans and administrators associate with online courses and programs. Second a possible explanation may be related to the pressure deans and administrators face to promote online programs in order to remain competitive with other institutions offering similar online courses and degrees.

Significant findings were also observed among institutional groups and sizes. As previously stated, a very low percentage of members from liberal arts and research institutions agreed with the statement: traditional institutions should not be offering online degrees since that goes against their reputation or credibility. However, members of religious institutions felt more neutral about the statement. On the other hand, 80 percent of members from research institutions disagreed with the statement. Essentially, this positive shift in perceptions toward online degrees could be based on a variety of plausible explanations. First and foremost, the potential for financial gain and strategic positioning could be a driving factor for research institutions to expand and develop their online educational programs. According to LeBlanc (2013), more and more traditional higher education institutions are looking to expand their online programs as a way of 
extending their reach and compensating for lost revenue such as declining state support for public universities and shrinking net student revenue for private institutions.

Moreover, results of the Fisher's Exact Test reveal that members of institutions with larger enrollments (i.e. 10,001-20,000, 20,000+) agree more strongly that fully online education will play a significant role in their college/school's strategic plan over the next 3-5 years. In fact, according to Allen and Seaman (2013), the number of chief academic leaders that maintain online learning is critical to their long-term strategy is now at 69.1 percent. The authors state that this is the highest percentage recorded in a ten-year period. Allen and Seaman (2013) also report that just over sixty percent of those institutions with fully online programs say online education is significantly represented in their strategic plan. Therefore, it is reasonable to conclude that institutions with lower enrollments are also those institutions with limited online course and program offerings, which would essentially explain why participants from larger institutions (in this study) agree more strongly that fully online education will play a significant role in their institution's strategic plan over the next 3-5 years.

Finally, when examining the study results from the open-ended response questions, it is also important to re-emphasize that many participants recognize that online degree programs do have a place in higher education. However, most participants remain skeptical of the quality, credibility, and academic rigor of an online degree. In fact, according to Allen and Seaman (2013), the proportion of academic leaders who believe a lack of acceptance of online degrees by potential employers is a barrier has remained at just over 40 percent. This statistic complements results obtained in this study where only 31 percent of participants agree that an academic job candidate can possess an 
online degree and a similar educational experience as a candidate with a traditional degree. Further, it is important to note that these perceptions are more favorable for candidates who earned their degree from well-known or reputable traditional institutions.

\section{Qualitative Findings}

Regarding the findings from the qualitative data analysis, a cross-case analysis of the findings from all six administrators interviewed for the study are presented in relation to the themes generated from the data: Experience with Online Education; Quality of Online Education in Relation to Institutional Type and Institutional Reputation; Hiring Practice and Experience with Online Degree Recipients; and The Future of Online Education in Relation to Traditional Education.

\section{Quality of Online Education in Relation to Institutional Type and Institutional Reputation}

There was a general consensus among participants that the quality of any program or degree was directly related to the quality of the degree granting institution. For example, according to Dean Alan:

"I do think overall it (reputation) does help because people tend to know, I know someone at this school and I know it is a great school and schools do have reputations. I think you can, particularly in the Arts, often count on a certain type of thinking to come from a particular school or certain way of practice."

Further, when specifically discussing online degrees, four of the participants agreed that an online degree from a reputable institution would be considered as having the same quality and value as a traditional degree from that institution. For example, according to John, "Where it is going to hurt is if it's (institution) not thought to be a caliber of an 
institution that's at a high level". However, Dean Sarah and Dean Jane stated that quality of any online instruction is dependent on the instructor at any given institution. More specifically, Dean Jane indicated that in terms of quality, "I think there is still a divide. I think some people think a lot of it's impersonal and you can't do certain things... So there's trade offs but I think it depends on your teaching philosophy and some of the role of interaction."

Additionally, all participants were employed at institutions that currently offer some type of online education for students. Similarly, all participants agreed that specific online educational programs at their respective institutions (not necessarily in their college/department) were high quality educational courses and programs. Dean Jane and John stated that their peer institutions were also offering, in both quality and value, similar online programs and options to students. Therefore, it was critical for their institutions to continue expanding their online courses and programs to remain competitive in the academic marketplace.

Further, all participants agreed that the major shift and significant factor in determining and assessing the value and quality of an online degree was whether or not the institution was for-profit in nature. For instance, according to Dean Jane, "I would just say I would really have to interview a for-profit person. We'd probably be a lot more skeptical going in. Someone could convince us. I might not immediately eliminate them, but I bet there would be a very strong conversation.” Both Dean Alan and John specifically referenced the University of Phoenix Online when discussing for-profit institutions and online degrees. John expressed his uncertainty and stated, "I think people are still cautious about the University of Phoenix, and I know people who have done it 
and they're very successful. On the other hand, I don't think we're learning more about it.” Dean Alan suggested that for-profit institutions, “...certainly promote through national media all these things they are doing and where they are placing their students and I know I saw Phoenix, their ads are everywhere and they are listing all the corporations that hire them." However, Dean Alan was adamant that none of these graduates from for-profit institutions would be employed in his college (at least during his tenure).

\section{Hiring Practice and Experience with Online Degree Recipients}

All participants noted specific criteria for hiring at their respective colleges and institutions. However, institutional reputation was the critical hiring factor that was consistent across all participant hires and their colleges/universities hiring philosophies. For example, according to Dean Alan:

"If you went to 'No-Name University', it would be really hard for us to look at you....it almost sounds like discrimination...it's really a screening issue. Most people who went to 'No-Name University' are not somebody that we would think of as being the top-rate people. We know that everybody who went to University of Chicago or Cornell or Harvard are top-rate people."

Further, Dean Sarah, Dean Jane, Dean Ron, and John all agreed that an online degree candidate from a reputable institution (who also holds the necessary experience and various other required credentials) would be considered equally for a faculty position as compared with a candidate with a traditional degree. This finding represents a shift toward a positive perception of online degrees offered at traditional institutions of higher education among academic administrators and faculty. However, Dean Sarah expressed some hesitation toward those candidates who had an online degree and no teaching experience. More specifically she stated, "If you stand behind a computer for six years 
and you have a bachelors and masters (online) and you want to come teach in the classroom, it doesn't bode well.” Additionally Dean Jane and Dean Ron explained that any faculty candidate must also express willingness to teach online or use the Internet as a teaching tool; or consequently, they will not be considered for employment. Essentially, it is important to point out that other credentials (i.e. teaching experience, publications) are also critical factors in the faculty hiring process in addition to institutional reputation.

The lack of experience with online degree candidates and online degree faculty hires is another notable finding. In fact, none of the participants had ever hired a faculty member who had an online degree. Dean Sarah stated there was a top administrator at her college that had achieved his/her doctorate degree online at a for-profit university. However, according to Dean Sarah, that individual's personal history of success at the institution countered any negativity associated with the degree type. Therefore, personal reputation, in limited instances, may be another factor to consider when evaluating an online degree candidate.

\section{Experience/Familiarity with Online Education}

Additionally, participants did express their personal experience with online education. For example, Dean Sarah explained while she never took an online course in college, she had experience with online teaching. Dean Sarah believed strongly that the quality of online education is entirely dependent on the instructor. In fact, she described her experience as an online instructor:

"It could have been so easy I think for me to just put grades in there and just pass people through, but I actually did take the time to read the papers and give them revisions and notes and stuff like that. I didn't need to do that. Whereas on ...when you're on campus actually physically there they're expecting that. They ask you for it..." 
Dean Ron and Dean Jane have also experienced teaching an online course. Dean Jane discussed her personal history with online learning technologies:

"So I started a lot with making, before even the Internet, video tapes because with adult learners who are only coming once a week to campus, so I first started actually making VHS tapes back then. Showing how to do a lot of the computer applications at home because again, (students) coming to campus (once a week), I didn't want to waste everyone's time trying to teach how to run the technology. I really wanted the technology to be a tool."

Further, participants such as Dean Sarah, Dean Ron, and Dean Jane, who all discussed personal experiences with online education, also shared a positive view of the educational medium. Additionally, these participants agreed that an online degree candidate from a reputable institution (who also possesses other necessary credentials) would be considered equally with a candidate with a traditional degree. Essentially, it is reasonable to conclude that academic hiring gatekeepers who have prior experience with online education (in any capacity) are more likely to hold a positive perspective toward online education and online degree holders. More specifically, according to Allen and Seaman (2013), academic leaders at institutions with online offerings have a much more favorable opinion of the relative learning outcomes for online courses than do those at institutions with no online offerings.

\section{The Future of Online Education in Relation to Traditional Education}

Participants expressed a variety of views and perspectives about online education, and its current status at their institution, and the future of online education. Essentially, all participants agreed that online education was becoming a permanent fixture in higher education. However, participants did not believe that online education would replace traditional learning. Instead, online learning would supplement specific areas and 
disciplines in order to meet the growing demand for flexible student education.

Moreover, according to Dean Jane, “I still definitely don't think you can do away with the face to face communication. There's just something so valuable and again there's a social aspect..."

Further, all participants agreed it would be difficult for an institution to remain competitive without offering online degree and program options for students. For example, while Dean Wilson explained that he would not hire an online degree candidate for a faculty position, his college was currently offering a variety of online options for students. More specifically Dean Wilson stated:

"There was so much demand for it (business minor)...so what we've done is put them (the business minor classes) online...there is a lot of asynchronous and there's a lot of synchronous going on. And it's permitting us to scale up a bit."

Dean Wilson believed that online education options in his college would only continue to grow and expand to meet student demand. In addition, Dean Wilson noted the significant financial benefits (for the college) associated with offering online programs to students enrolled in the college and also outside the college. Clearly, the financial incentive is a strong force driving administrators to boost and expand their online education options. Similarly, John discussed an increased student demand (in his college) for flexible online options. For instance, he stated, "I have students, particularly those that are interested in a part time approach, have asked about online education or online courses to get them started. I think it's something we need to look at in terms of offering different opportunities." Additionally, John believed that certain fields will have a more difficult time transitioning into the online mode. In fact, he stated, "Medicine will be 
dead last for sure." He also postulated, "I don’t know how law schools are doing it. Are there online law programs or not?" However, he feels strongly that the new generation of students will continue demanding more and more online educational options. He stated:

"Kids, younger people that are coming right out of college and if they're in high school, they do everything online anyway. This will be a very natural way for them to seek out an education, a high level education. Whereas for our generation, it's not."

Comparably, Dean Alan suggested that at his particular institution, there remains more demand for some online programs than others. For example, he stated, "I believe that there will be online MBA programs. I think that as we get better at this (online education), as the technology gets better, I think we may have that offering.” Dean Alan also expressed his opinion regarding faculty responsiveness toward online education at his institution:

"Faculty buy-in, they're very receptive...but some are a little bit skeptical about online. Is this going to take my job away from me, and stuff like that...but I don't see this (online education) taking people's jobs away here."

Ultimately, qualitative findings reveal that while there are many institutions and administrators that are fully on board with online teaching and learning as an enhancement to traditional education, there is a general consensus that face-to-face instruction will never be replaced.

Finally, Table 9 represents a summary of the interview data in relation to the research questions. 
Table 9

Summary of Interview Data in Relation to the Research Questions

\begin{tabular}{|c|c|c|c|}
\hline Interviewee & $\begin{array}{c}\text { Perception } \\
\text { Online } \\
\text { Education } \\
\text { General } \\
\end{array}$ & $\begin{array}{c}\text { Perception } \\
\text { Online Degree } \\
\text { Candidates }\end{array}$ & $\begin{array}{l}\text { Perception Toward Hiring } \\
\text { Online Degree Candidates }\end{array}$ \\
\hline John & Positive & $\begin{array}{l}\text { Depends on Degree } \\
\text { Granting } \\
\text { Institution/Reputation }\end{array}$ & $\begin{array}{l}\text { Depends on Degree Granting } \\
\text { Institution/Reputation }\end{array}$ \\
\hline Dean Ron & Positive & $\begin{array}{l}\text { Depends on Degree } \\
\text { Granting } \\
\text { Institution/Reputation }\end{array}$ & $\begin{array}{l}\text { Depends on Degree Granting } \\
\text { Institution/Reputation }\end{array}$ \\
\hline Dean Sarah & Positive & $\begin{array}{l}\text { Depends on Degree } \\
\text { Granting } \\
\text { Institution/Reputation }\end{array}$ & $\begin{array}{l}\text { Depends on Degree Granting } \\
\text { Institution/Reputation }\end{array}$ \\
\hline Dean Jane & Positive & $\begin{array}{l}\text { Depends on Degree } \\
\text { Granting } \\
\text { Institution/Reputation }\end{array}$ & $\begin{array}{l}\text { Depends on Degree Granting } \\
\text { Institution/Reputation }\end{array}$ \\
\hline Dean Alan & Positive & Negative & $\begin{array}{l}\text { Would not Hire Online Degree } \\
\text { Candidate }\end{array}$ \\
\hline Dean Wilson & Mixed & $\begin{array}{l}\text { Mixed. Some } \\
\text { academic areas may } \\
\text { be suitable for online } \\
\text { degrees, others may } \\
\text { not. }\end{array}$ & $\begin{array}{l}\text { Would not Hire Online Degree } \\
\text { Candidate }\end{array}$ \\
\hline
\end{tabular}

Clearly, most participants indicated a positive perception of online education general.

Dean Wilson was the only participant who expressed a mix of both positive and negative perceptions toward the educational medium. Dean Wilson also stated that he believed some academic areas were more suitable for online degrees than others. However, perceptions shifted when participants discussed their thoughts toward online degree candidates and hiring online degree candidates. In fact, most participants agreed that their perception of online degree candidates would depend on the reputation of the degree granting institution. Although, Dean Alan and Dean Wilson stated that under no circumstance would they consider hiring an online degree candidate. 


\section{Connections Between the Study Findings and Past Research}

First, in regard to current administrator perceptions regarding online education in general, all the administrators who participated in the interviews (except Dean Alan) appeared to hold very positive perceptions and attitudes toward online education in general. In fact, all study participants indicated there was a need and demand for online education at their respective institutions. While Dean Alan expressed skepticism toward online education in the art discipline, he did agree that there was a place and demand for online education in other academic disciplines such as education. These findings differ with those of DePriest's (2009) and Levernier's (2005) that found administrators held slightly negative views of online instruction. However, DePriest (2009) indicated that many of his study participants expressed uncertainty with regard to their level of comfort when online instruction is a component of degree completion. This finding is consistent with Dean Wilson's perception of online education. Additionally, Allen and Seaman (2013) reported that academic leaders at institutions with online offerings now have a much more favorable opinion of the relative learning outcomes for online courses than those at institutions with no online offerings. This illustrates that the perceptions toward online education is shifting ever so slightly in a favorable direction. All of the administrators who were interviewed for this study indicated that their respective institutions did offer a variety of online options for students. Therefore, it may be reasonable to conclude that there was a positive bias toward online education as a result of the direction in which the administrators' colleges or institutions were headed in regard to online learning. In short, administrator perceptions may be shaped based on 
their personal and institutional experiences with online education. However, favorable administrative perceptions of online learning did not significantly influence their hiring practices. The study findings suggest that when faced with two types of job candidates, a traditional doctoral candidate and an online degree candidate (especially one who earned their degree from a for-profit institution), administrators are far more likely to choose the former. This finding ratifies DePriest's (2005) study that concludes that the majority of the time, administrators will choose the traditional doctorate over the candidate with a doctorate earned online. It is important to note however that administrators' decisions may change when faced with a candidate with an online degree from a traditional/ reputable institution of higher education. Some administrators clearly indicated that they would give consideration to candidates with an online degree from reputable institutions. Others went further to say that they would even give equal consideration to both candidates, whether the candidate obtained the degree traditionally or online, so long as the online degree candidate obtained his or her degree from a reputable institution. This finding may indicate a more recent shift in academic employer perceptions toward hiring candidates with online degrees. This shift in attitude and perception among academic employers may be due to a gradual increase in online degree programs in general or specifically due to the fact that more reputable institutions are now turning to online education. For example, schools such as Harvard are now providing course content online through the use of Massive Open Online Courses (MOOC).

Second, when considering whether or not academic hiring gatekeepers' perceptions toward online education differ from the perceptions they hold toward traditional higher education, it appears that a number of conclusions can be drawn from 
administrator hiring practices as well as the degree to which each administrator is willing to accept online education as indicated in the interviews. Clearly, all participants indicated that institutional reputation was critical when determining the value of both a traditional and online degree. In fact, many participants expressed outright skepticism associated with for-profit degrees, and most indicated that they would never consider hiring any faculty applicant with a degree from a for-profit online university. However, there were several interview participants who expressed that they would entertain the idea of hiring a faculty member who had received an online degree from a traditional/ reputable institution if that individual also met other essential requirements (i.e. relevant experience). Conclusions can be drawn from administrator statements in regard to the future of online education versus traditional education and its impact on faculty. For example, it will be critical for institutions and administrators to openly communicate with faculty in order to avoid additional skepticism and potential anxiety regarding job stability. More specifically, there should be sufficient information available to faculty explaining the developments and changes associated with online education at their institution and how it will directly impact faculty.

In their most current report on online education, Allen and Seaman (2013) reported that only 23 percent of academic leaders surveyed in their study continue to believe the learning outcomes for online education are inferior to those of face-to-face instruction. It is important to note that there has been an increase in this percentage from their first report in which 57.2 percent of academic leaders rated the learning outcomes in online education as the same or superior to those in face-to-face (Allen \& Seaman, 2003). Over the span of a ten-year period, there has been a 19.8 percent jump in academic 
administrator confidence in online education (Allen \& Seaman, 2003). While none of the administrators interviewed suggested that learning outcomes in online education were superior to those obtained from face-to-face settings, conclusions from the data gathered from four of the six administrators did suggest that the administrators perceived the quality of instruction provided in the online education offered at their respective institution/college was comparable to that offered in their traditional classrooms. In other words, administrators perceived that learning outcomes generated in both educational mediums were equivalent.

With respect to the question which expressed the extent to which academic hiring gatekeeper perceptions toward online education ultimately influenced their hiring decisions, the findings of the study suggest that while all participants except Dean Wilson expressed an overall positive perception of online education, two of the administrators (specifically Dean Wilson and Dean Alan) indicated that they would not likely hire a faculty candidate with an online degree (regardless of where that degree was earned). For example, Dean Alan said that his college had very specific institutional requirements and credentials for potential faculty members. Moreover, he explained that the screening process for new faculty would automatically "weed out" a candidate with an online degree. However, it was quite surprising that given these views, Dean Alan appeared extremely enthusiastic to discuss his college's online programs and opportunities during the course of his interview. Therefore, one can presumably conclude that for some administrators, positive perceptions of online education do not equate with positive perceptions toward hiring faculty candidates with online degrees. From a different perspective, Dean Wilson stated that it would be extremely difficult to find a qualified 
faculty candidate in the Arts who had never experienced or participated in hands-on, classroom, or studio learning. Consequently, it was almost impossible for Dean Wilson to fathom an individual (in the Arts) earning a degree online and/or hiring a faculty member with solely an online degree. It is important to note that Dean Wilson was the only interview participant who openly expressed a significant amount of skepticism toward online degrees and online learning. The remaining participants opined that they would consider hiring a faculty candidate with an online degree if that candidate was from a reputable institution and possessed the necessary credentials.

Finally, institution type or size did not seem to impact or drive perceptions regarding online education in one particular direction or another. In fact, perceptions seemed to be driven by department or college standards and personal experiences with online education.

\section{Convergence and Divergence in the Quantitative and Qualitative Findings}

The relationships between academic administrators and employers' perceptions of online degrees, institutional demographics, and administrator willingness to hire potential faculty candidates who earned an online doctorate were examined in order to answer the following research questions:

1. What are the current perceptions of academic hiring gatekeepers and employers regarding online education in general?

2. Do academic hiring gatekeepers' perceptions toward online education differ from the perceptions they hold toward traditional higher education?

3. Do academic hiring gatekeepers' perceptions toward online education differ by their position and institution type? 
4. To what extent do academic hiring gatekeeper perceptions toward online education influence their hiring decisions?

Both the quantitative and qualitative findings obtained in this study appear to converge. First, it is clear from both the quantitative and qualitative results that institutional reputation is the single most important factor academic hiring gatekeepers take into account when considering an online degree candidate for hire. In fact, demographic characteristics such as position type, institutional type, and institutional size do not significantly impact the decision making process of the hiring gatekeepers as compared to the overriding impact of institutional reputation. Second, participants in both data groups quickly distinguished between for-profit and non-accredited degree granting institutions, and not-for-profit online degrees when assessing overall quality and value. More specifically, online degrees from for-profit and/or non-accredited institutions were not considered nearly as valuable and credible as an online education from a traditional higher education institution. Essentially, almost all participants (in both data sets) agreed that they would not consider hiring an individual with an online degree from a for-profit institution/non-accredited. This data is consistent with recent literature from Jaschik and Lederman's (2013) Inside Higher Ed's 2013 Survey of Faculty Attitudes on Technology stating that when faculty members were asked to rate factors that contribute to quality in online education, whether an online program is offered by an accredited institution ranks highest at 73 percent. Additionally, Jaschik and Lederman (2013) indicate that about 6 in 10 faculty members agree that an online program that is offered by an institution that also offers traditional instruction is a critical indicator of quality. Essentially, quantitative and qualitative data from this study also demonstrated that an institution offering face-to-face 
learning is perceived to be more credible and reputable than an institution offering online learning only.

Third, in both data groups, participants did express several positive outcomes associated with online education. For example, the concept of flexibility linked to student demand was a benefit participants noted with regard to online degrees. Many participants agreed that hybrid and asynchronous degree programs can be very effective options for students with other full-time obligations. Additionally, many of the participants who expressed some positive perceptions of online education also had some type of previous experience with the medium. For example, some participants had actually taught online courses while others had instituted online degree programs at an administrative level. This finding corroborates data from the Allen and Seaman (2013) study that states chief academic officers at institutions with fully online programs have the most positive view of their faculty acceptance.

Finally, both quantitative and qualitative data in this study revealed that while online courses and degree programs are rapidly developing and expanding at most institutions, a certain level of skepticism does exist among faculty and administrators related to the overall value and quality of the learning modality. In fact, according to Allen and Seaman (2013), while the number of programs and courses online continue to grow nationwide, the perception of chief academic officers of the acceptance of online learning by faculty has decreased in the most recent year. This perception among administrators and faculty can be viewed with a slight twist of irony. More specifically, the acceptance level of online education by faculty may be on a slight decline, but the numbers of students enrolled in online courses and programs is on a constant incline. 
Clearly, in order to meet the student demand for online learning and degree opportunities, the attitudes and perceptions of administrators and faculty will need to continue to shift from skeptical to swayed.

\section{Conclusion}

Based on the findings of the study, while administrators' perception regarding online education and hiring candidates with online degrees may have undergone a positive shift, some of the negative perceptions still exist. The study exposed both negative and positive perceptions regarding online education and academic hiring gatekeeper hiring practices. Based upon the results of this study, the researcher suggests that when considering obtaining a doctoral degree, one should evaluate their options carefully regarding earning an education either online or through the traditional route. This study will help students understand the perceptions academic hiring gatekeepers hold regarding online degree legitimacy. The findings from this study also suggest that within higher education, academic hiring gatekeepers perceptions of online degrees do influence the hiring practices for positions. In other words, it could be argued that institutions of higher learning impose a double standard: that is to say that institutions are more than willing to offer online courses and degree programs but far less willing to hire the graduates of these programs for faculty positions. The results of this research study could encourage new guidelines for administrators and hiring committees on how to assess candidates for faculty positions regarding the candidate's educational and degree experiences. Further, this study may also confirm an institution's investment in online education courses and degree programs. Finally, this study may encourage colleges and 
universities contemplating establishing online degree programs to assess their institutional reputation as a factor for perceived legitimacy.

\section{Implications for Future Practice}

This study has major implications for academic candidates who are desirous of being hired at a traditional educational institution. As academic gatekeepers continue to embrace online degree programs at their own institutions, they may be more willing to hire candidates with online degrees despite internal faculty resistance. Second, if administrators and other academic hiring gatekeepers support online degree programs (and the students graduating from these programs), students will recognize the potential benefits of completing a degree online and ultimately demand for these programs will increase. Further, this study has implications for the higher education for-profit sector. As traditional higher education institutions expand their online degree offerings, the forprofit institutions will have to re-evaluate and potentially re-brand their online degree programs in order to remain competitive in terms of perceived quality and value.

There are additional implications to consider, which are based upon the construction of the study. The first implication to consider is the significance of neutrality. More specifically, a larger percentage of hiring gatekeepers indicated a neutral position when answering the questions in the quantitative data section. Therefore, it is important to consider what value a "neutral" position that is attributed to each question has. According to Dillman, Smyth, and Christian (2009), when offered as a choice, this option (neutral) made a significant difference in data with regard to placement. More specifically these authors state: 
"An experiment by Willits and Janota (1996) compared results from the placement of an 'undecided' category in the middle and at the end of the following scale... When the 'undecided' option was located in the middle of the scale, an average (across 13 questions) of $13 \%$ of respondents selected it compared to only $5 \%$ when it was located at the end of the scale" (p. 147).

Essentially, a participant's selection of neutrality could be attributed to a possible survey design bias. However, it is also possible that hiring gatekeepers are more neutral toward the perception of online degrees (and online degree applicants) due to the nature of their position and their overall investment and input toward organizational hiring decisions. It is also plausible that decision makers may hold less neutral positions due to the significant impact their hiring choices could ultimately have on the organization.

A second implication to consider when examining the findings of this study includes an online degree exposure bias. For example, according to Allen and Seaman (2013), academic leaders at institutions with online offerings have a much more favorable opinion of the relative learning outcomes for online courses than do those at institutions with no online offerings. In this study, approximately 80 percent of participants in the quantitative data segment were employed at institutions that offered at least one or more fully online degree programs and approximately 70 percent of participants worked at institutions that offered at least one or more asynchronous/blended learning degree programs. Further, all participants in the qualitative data segment were employed at institutions that offered some type of online degree program. Therefore, it is important to note that there may be a more favorable bias toward online degrees in this study as a majority of participants are employed at institutions with online offerings.

Additionally, many participants voiced concern regarding an online degree candidate's team building, interpersonal skills and overall social acumen. Therefore, it 
may be advantageous for online institutions to consider incorporating leadership and team building into the core/foundational curriculum.

\section{Recommendations for Future Research}

Although research regarding online education effectiveness is becoming a priority, there appear to be several re-occurring gaps present in the research. For example, much of the research does not examine post-graduate career success for those students who completed a doctoral degree online as compared with those in traditional classrooms. Areas of further research should include studies that address the perceptions and experiences held by online degree job seekers. Additionally, studies examining the impact of various other demographic variables such as age and gender on academic hiring gatekeeper perceptions toward online degrees would also provide valuable insight for all stakeholders. For example, the only formal participant selection requirement for this study included the individual's ability to make academic hiring decisions. More specifically, there was no consideration given to participant experience with online education or technology. Further, it is possible that an individual's age could impact one's perceptions of online degrees. For instance, those hiring gatekeepers who are younger and have more experience with technology (and quite possibly have some experience with online learning themselves) may hold more favorable attitudes toward online degrees than older individuals with less exposure to new educational technologies. Participant gender and race were not collected in this study. Examining these variables may produce different study outcomes in future research. 
This study examined online degree and doctoral degree programs in a general sense. Future research should consider various types of programs and in different academic disciplines. More specifically, future research might further examine the perceptual differences between undergraduate and graduate programs. For example, it is possible that online programs at the undergraduate level are considered more or less legitimate than online programs at the graduate and doctoral level.

A final recommendation is to conduct a nationwide study on the perception of online education and academic hiring practices. This study only included perceptions from the Midwest region of the United States. It is possible that rural areas may be more accepting of online degree candidates due to limited resources, and metropolitan areas less accepting due to a greater candidate pool.

As traditional universities look to the future of online education, educating the next generation of faculty through online doctoral programs may require more collaboration among institutions and accrediting bodies to establish standards for quality and legitimacy among the academic community. 


\section{REFERENCES}

Accrediting Council for Independent Colleges and Schools. (2010). Accreditation criteria policies, procedures, and standards. ACICS. Retrieved from: www.acics.org

Adams, J. (2008). Understanding the factors limiting the acceptability of online courses and degrees. International Journal on ELearning, 7(4), 573-587.

Adams, J., \& DeFleur, M. H. (2005). The acceptability of a doctoral degree earned online as a credential for obtaining a faculty position. American Journal of Distance Education, 19(2), 71-85. doi:10.1207/s15389286ajde1902_2

Adams, J., \& DeFleur, M. H. (2006). The acceptability of online degrees earned as a credential for obtaining employment. Communication Education, 55(1), 32-45. doi:10.1080/03634520500343376

Adams, J., DeFleur, M. H., \& Heald, G. R. (2007). The acceptability of credentials earned online for obtaining employment in the health care professions. Communication Education, 56(3), 292-307. doi:10.1080/03634520701344959

Allen, I. E., \& Seaman, J. (2011). Going the distance: Online education in the United States. Sloan Consortium. Retrieved from: http://www.sloanconsortium.org.

Allen, I. E., \& Seaman, J. (2013). Changing Course: Ten years of tracking online education in the United States. Sloan Consortium. Retrieved from: http://www.sloanconsortium.org

Anderson, M. L., \& Schlosser, C. A. (1994). Distance education: Review of the literature. Washington, DC: Association for Educational Communications and Technology.

Appana, S. (2008). A review of benefits and limitations of online learning in the context of the student, the instructor, and the tenured faculty. International Journal on ELearning, 7(1), pp. 5-22. 
Ary, E. J., \& Brune, C.W. (2011). A comparison of student learning outcomes in traditional and online personal finance courses. MERLOT Journal of Online Learning and Teaching, 7(4) 465-474. Retrieved from: http://jolt.merlot.org/vol7no4/brune_1211.pdf

Associated Press. (2012, September 8) Report crushes hopes for hiring. The NewsGazette, p. D-2.

Ayiro, L. P. (2012). A functional approach to educational research methods and statistics: qualitative, quantitative, and mixed methods approaches. Lewiston, NY: The Edwin Mellen Press.

Barrett, B. (2010). Virtual teaching and strategies: transitioning from teaching traditional classes to online classes. Contemporary Issues in Education Research, 3(12) pp. $17-20$.

Berg, G. A. (2005). Social of group learning theories. In The Encyclopedia of Distance Learning (Vol. 4, pp. 1630-1633). Hershey: PA Idea Group Inc.

Birochi, R., Pozzebon, M. (2011). Theorizing in distance education: The critical quest for conceptual foundations. Journal of Online Teaching and Learning, 7(4), 562-575.

Bolliger, D. U., Halupa, C. (2012). Student perceptions of satisfaction and anxiety in an online doctoral program. Distance Education, 33(1), 81-98. doi: $10.1080 / 01587919.2012 .667961$

Bramble, W. J., Panda, S. (2008). Organizational and cost structures for distance and online learning. In Bramble, W., J. and Panda, S, Economics of Distance and Online Learning. New York, NY: Routledge.

Branch, R. A. (2007). Keeping the ivy on the virtual ivy league walls: A study of the quality of online postsecondary education from the employers' perspective. Retrieved from: ProQuest Digital Dissertations. (AAT 3266267)

Brewer, E.W., DeJonge, J. O., \& Stout, V. J. (2001). Moving to online. Thousand Oaks, CA: Corwin Press, Inc.

Brown, G. M. (2006). Degree of doubt: legitimate, real and fake qualifications in a global market. Journal of Higher Education Policy and Management, 28(1), 71-79. doi: $10.1080 / 13600800500440789$

Capra, T. (2011). Online education: promise and problems. Journal of Online Learning and Teaching, 7(2) 288-291. Retrieved from:

http://jolt.merlot.org/vol7no2/capra_0611.pdf 
Chea, T. (2012, August 5). Elite colleges transform online higher education. Boston.com. Retrieved from: http://www.boston.com/news/education/2012/08/05/elitecolleges-transform-online-highereducation/OIdKcvdP35u1aHS9f7LAkL/story.html

Cho, T. (2011). The impact of types of interaction on student satisfaction in online courses. International Journal on E-Learning, 10(2), p.109-125.

Columbaro, N. L., \& Monaghan, C. H. (2009). Employer perceptions of online degrees: A literature review. Online Journal of Distance Learning Administration, 12(1). Retrieved from: http://www.westga.edu/ distance/ojdla/spring121/columbaro121.html

Creswell, J. W. (2008). Educational research: planning, conducting, and evaluating quantitative and qualitative research (3rd ed.). Upper Saddle River, NJ, Pearson Education Inc.

Dailin, L., Fengyan, C., Shaungxu, Y., and Fenglong, Z. (2008). Collecting feedback on the quality of distance education: a follow-up survey of China Central Radio and TV University graduates and their employers. Open Learning, 23(3), 215-229. doi: $10.1080 / 02680510802420118$

DePriest, T. A. (2009). Perceptions of academic administrators regarding the acceptability of online doctoral degrees for faculty members. Proquest Dissertations and Thesis: 376916

Dillman, D. A., Smyth, J.D., Christian, L. M. (2009). Internet, mail and mixed-mode surveys: The tailored design method. Hoboken, NJ: John Wiley \& Sons Inc.

Edmondson, S., \& Irby, B. (2008). Ten tips for producing a top qualitative research study. Boston, MA: Pearson Education.

elearners.com. (2012). What is accreditation? Retrieved from: http://www.elearners.com/online-education-resources/degrees-and programs/what-is-accreditation/

Falloon, G. (2011). Making the connection: Moore's Theory of Transactional Distance and its relevance to the use of a virtual classroom in postgraduate online teacher education. International Society for Technology in Education, 43(3), 187-209.

Garrison, R. D., Kanuka, H. (2008). Changing distance education and changing organizational issues. In Bramble, W., J. and Panda, S, Economics of Distance and Online Learning. New York, NY: Routledge.

Howell, S. L., Wilcken W. (2005). Student support services. In The Encyclopedia of Distance Learning (Vol. 4, pp. 1687-1692). Hershey: PA Idea Group Inc. 
Huss, J. A. (2007). A tri-state study: Administrator attitudes toward online teacher preparation programs: Are principals logging on - or logging off? International Electronic Journal for Leadership in Learning, 11. Retrieved from: http://www.ucalgary.ca/iejl1/vol111/huss

Inglis, A. (2008). Costs and quality of online learning. In Bramble, W., J. and Panda, S, Economics of Distance and Online Learning. New York, NY: Routledge.

Jacobs, J. (2004). Dark age ahead. New York: NY: Random House Publishing.

Kaplan University. (2012). Kaplan University Online. Retrieved from: http://getinfo.kaplan.edu/index.aspx

Keegan, D. (1996). Foundations of distance education (3rd ed.). New York: NY: Routledge.

Keller, R. H. (2011). Towards an understanding of an institution: The perceived legitimacy of online business degree programs. Retrieved from: ProQuest Digital Dissertations. (AAT 3498145)

Kirtman, L. (2009). Online versus in-class courses: An examination of differences in learning outcomes. Issues in Teacher Education, 18(2), 103-116. Retrieved from: http://ehis.ebscohost.com.proxy.lib.ilstu.edu/ehost/detail?sid=5c0d56b5-30634ccd-a5f1-e424f898f211\%40sessionmgr 10\&vid=1\&hid=23\&bdata $=$ JnNpdGU9ZWhvc3QtbG12ZSZzY29wZT1zaXRl\#db=eft\&AN=508101224

Lamer, M. (2007). A description of the perceptions of human resources professionals regarding MBA degrees from for-profit and traditional universities in term of Rogers' Diffusion of Innovations Theory. Retrieved from: ProQuest Digital Dissertations. (AAT 3297503)

Lapsley, R., Kulik, B., Moody, R., Arbaugh, J.B. (2008). Is identical really identical? An investigation of equivalency theory and online learning. Journal of Educators Online, 5(1), 1-19.

LeBlanc, P., J. (2013). The new for-profits. INSIDE HIGHER ED. Retrieved from: http://www.insidehighered.com/views/2013/05/31/nonprofit-colleges-should-bewary-new-breed-profit-players-essay

Levernier, E. (2005). An analysis of perceptions of online instruction by department chairs in the field of higher education administration. Unpublished doctoral dissertation, Georgia Southern University.

McDonald, J.,H. (2009). Handbook of biological statistics (2nd ed.). Baltimore: MD: Sparky House Publishing. 
McKeown, K.D. (2012). Can online learning reproduce the full college experience? Center For Policy Innovation. Retrieved from: http://report.heritage.org/cpi_dp03

Merriam, S. B. (2009). Qualitative research: A guide to design and implementation: revised and expanded from qualitative research and case study applications in education. San Francisco, CA: Jossey-Bass.

Metrejean, E., Noland, T. G. (2011). An analysis of CPA firm recruiters' perceptions of online masters of accounting degrees. Journal of Education for Business, 86, 2530. doi: $10.1080 / 08832321003713754$

Meyer, K. (2002). Quality in distance education: Focus on on-line learning. San Francisco, CA: Jossey-Bass.

Miller, B. (2010). Are you gainfully employed? Education Sector Reports. Retrieved from: www.educationsector.org

Moore, M., Kearsely, G. (2005). Distance education: A systems view. Belmont, CA: Thomson Wadsworth.

Morey, A. I. (2004). Globalization and the emergence of for-profit Higher Education. Higher Education, 48, 131-150.

Noel-Levitz. (2011). National online learners priorities report. Noel-Levitz, Inc. Retrieved from: www.noellevitz.com/Benchmark

Norton, P., \& Hathaway, D. (2008). Exploring two teacher education online learning designs: a classroom of one or many? International Society for Technology in Education, 40(4), 475-495.

Pew Research Center. (2011). The digital revolution and higher education: College presidents, public differ on value of online learning. Pew Social \& Demographic Trends. Retrieved from: www.pewsocialtrends.org

Rao et. al. (2011). Employability in MNCs: Challenge for graduates. Interdisciplinary Journal of Contemporary Research in Business, 3(4), 189-200.

Roussas, S. (2006). The effect of online education versus traditional education on employee productivity: A quantitative analysis within a high-tech company. Retrieved from: ProQuest Digital Dissertations. (AAT 3226229)

Rudestam, K. E., Schoenholtz-Read, J.S. (2010). The flourishing of adult education: An overview. In Rudestam, K. E., Schoenholtz-Read, J.S., Handbook of Online Learning 2nd Edition. Thousand Oaks, CA: Sage.

Seibold, K. (2007). Employers' perceptions of online education. Proquest Dissertations and Thesis: 3274545 
Society for Human Resource Management. (2010). SHRM poll: hiring practices and attitudes: Traditional vs. online degree credentials. Retrieved from: http://www.shrm.org/Research/SurveyFindings/Articles/Pages/HiringPracticesand Attitudes.aspx

Stiglitz, J. E. (1975). The theory of 'screening', education, and the distribution of income. American Economic Review, 65(3), 283. Retrieved from: http://www.jstor.org.proxy.lib.ilstu.edu/openurl?volume $=65 \&$ date $=1975 \&$ spage $=$ $283 \&$ issn $=00028282 \&$ issue $=3 \&$

Tesone, D.V., Severt, D., Carpenter, M. (2008). Modern learning theories provide application for distance learning practice. Journal of College Teaching \& Learning, 5(5), 17-24.

The College Blue Book. (2012). The college blue book, 39th edition volume 6. Farmington Hills, MI: Gale, Cengage Learning.

The Kresge Foundation. (2013). Not Yet Sold: What employers and community college students think about online education. Public Agenda. Retrieved from: http://www.publicagenda.org/pages/not-yet-sold

WJLA.com (2012, July 17). UVA to offer free online courses. WJLA.com. Retrieved from: http://www.wjla.com/articles/2012/07/uva-to-offer-free-online-courses77928.html

Wildflower, L. (2010). Teaching professionals to be effective online facilitators and instructors: Lessons from hard-won experience. In Rudestam, K. E., SchoenholtzRead, J.S., Handbook of Online Learning 2nd Edition. Thousand Oaks, CA: Sage.

Wolcott, L. L. (2003). Dynamics of faculty participation in distance education: Motivations, incentives, and rewards. In Moore, M. G., and Anderson, W. G, Handbook of Distance Education. Mahwah, NJ: Lawrence Erlbaum Associates, Publishers. 
APPENDIX A

SURVEY INSTRUMENT 


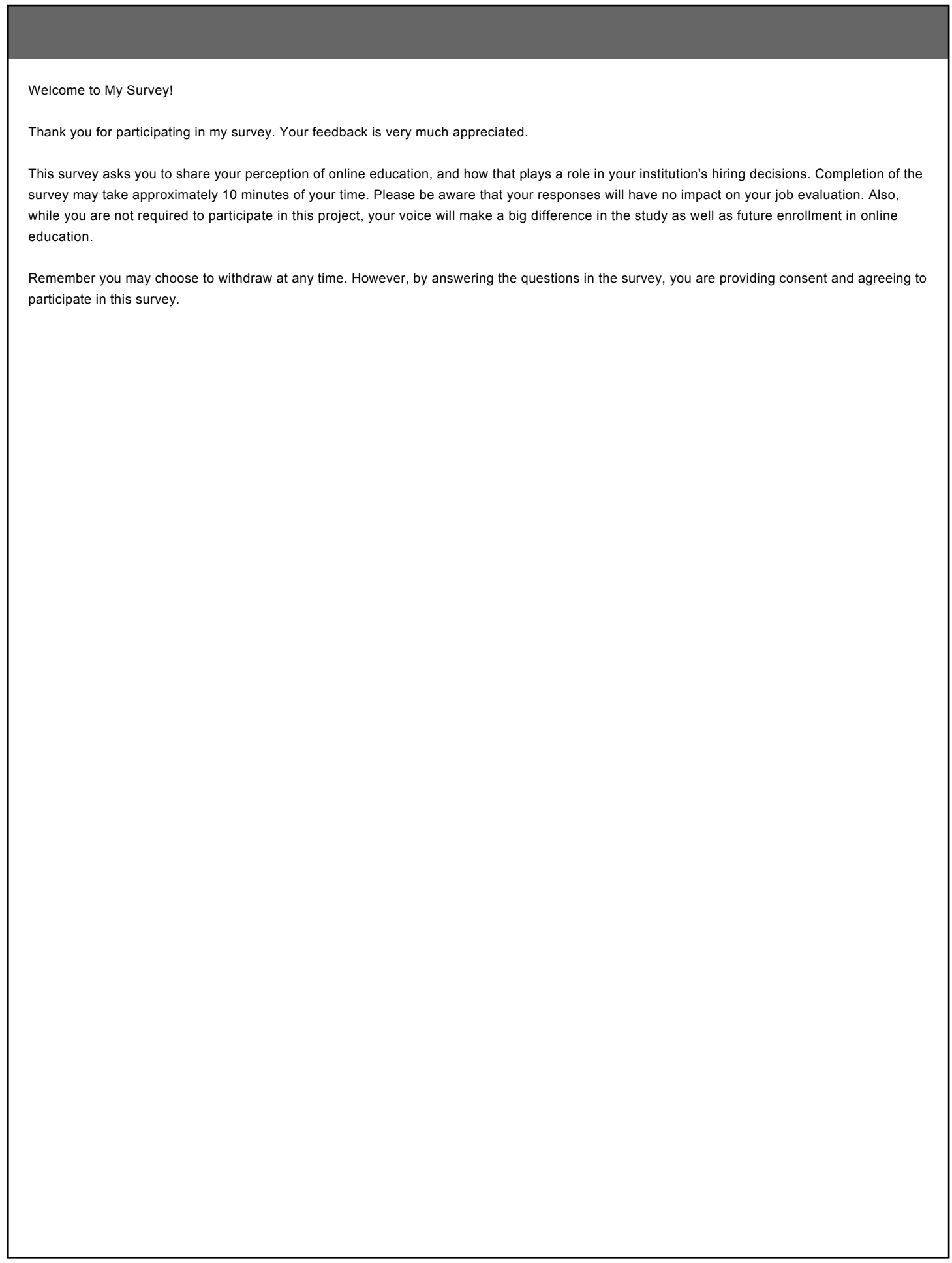


If you are a Dean or Administrator, please answer the questions regarding your college/school; however, if you are a Faculty Chair or Faculty member please answer the questions regarding your division/department.

1. Have you served on a faculty hiring committee or made a faculty hiring decision within the past two years?

Yes
No 


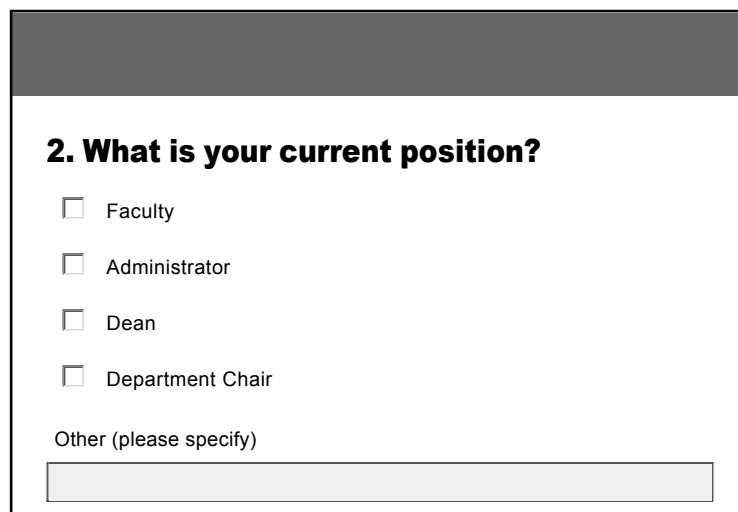

3. What department or program is your position associated with?
Arts
Business/management
Communications
Education
Health/medicine
Humanities
Professional fields
Science/technology/mathematics
Social/behavioral sciences
Vocational/technical fields
Other (please specify)

\section{How many years have you been working in your current position?}
0-1 year
1-5 years
5-10 years
10-15 years
15-20 years
$20+$ years

Other (please specify) 
5. How many fully online courses does your university/college/department offer?

Г none

ए less than five

ए between 5-10

Г between $11-20$

Г $20+$

Г I don't know but at least five or more

Other (please specify)

6. How many asynchronous or blended courses does your university/college/department offer?

Г none

Г less than five

$\lceil$ between 5-10

$\Gamma$ between $11-20$

Г 20+

Г I don't know but at least five or more

Other (please specify)

7. How may traditional courses does your university/college/department offer?

Г less than 20

Г between 20-30

$\Gamma$ between 31-40

Г between 41-50

Г 50+

Other (please specify)

8. Does your institution offer any fully online degree program(s)?

$\ulcorner$ Yes

№

Other (please specify) 
9. If your institution does offer a fully online degree program(s) please check all degree programs that apply

ए Associates Degree

『 Bachelors Degree

$\lceil$ Masters Degree

$\Gamma$ Doctoral Degree

Other (please specify)

10. Do you offer a blended/asynchronous degree program(s)?

$\Gamma$ Yes

ए No

Other (please specify)

11. If your institution does offer blended/asynchronous degree program(s), please indicate all degree programs that apply.

ए Associates Degree

ए Bachelor Degree

「Masters Degree

「 Doctoral Degree

Other (please specify)

12. Choose one which best describes your institution.

「 Public

$\lceil$ Private

Other (please specify)

13. Choose one which best describes your institution.

Religious Affiliated

Liberal Arts

Research

Other (please specify) 
14. What is your institutions approximate student enrollment size?

( ) $1-1,000$

( $1,001-5,000$

○ $5,001-10,000$

C $10,001-15,000$

C $15,001-20,000$

C $20,000+$

Other (please specify) 
Perceptions of Online Education

15.

Please rate your level of agreement with each of the following statements using a scale of 1= Strongly Disagree to 5=Strongly Agree

\begin{tabular}{|c|c|c|c|c|c|}
\hline & Strongly Disagree & Disagree & Agree & Strongly Agree & Neutral \\
\hline $\begin{array}{l}\text { Online education provides } \\
\text { a useful role in educating } \\
\text { candidates for our field. }\end{array}$ & 0 & 0 & 0 & 0 & 0 \\
\hline $\begin{array}{l}\text { Online degrees have a } \\
\text { place in preparing faculty } \\
\text { and/or administrators for }\end{array}$ & 0 & 0 & 0 & 0 & 0 \\
\hline
\end{tabular}

their careers.

Online degrees are not

rigorous enough for

anyone to gain any

knowledge from such a

program.

Students from online

programs are weaker than

candidates from traditional

programs.

Traditional institutions

should not be offering

online degrees since that

goes against their

reputation or credibility

Institutions of higher

c

learning should not be

offering education in an

online mode.

Online degrees are of less

quality than traditional

degrees

If one has the opportunity

to take either an online

course or a traditional

course, they should go for

the online course.

Students benefit from

online courses in a similar

way like they do from

traditional courses.

Online degrees have no

value at all.

The institution from which

a candidate earns their

degree is a very important

consideration when

making hiring decisions in

our institution.
C

6

C

O

C

C

O

c

C

o

$c$
0

o

O

C

O

C

0

C

C
0

0

0

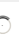




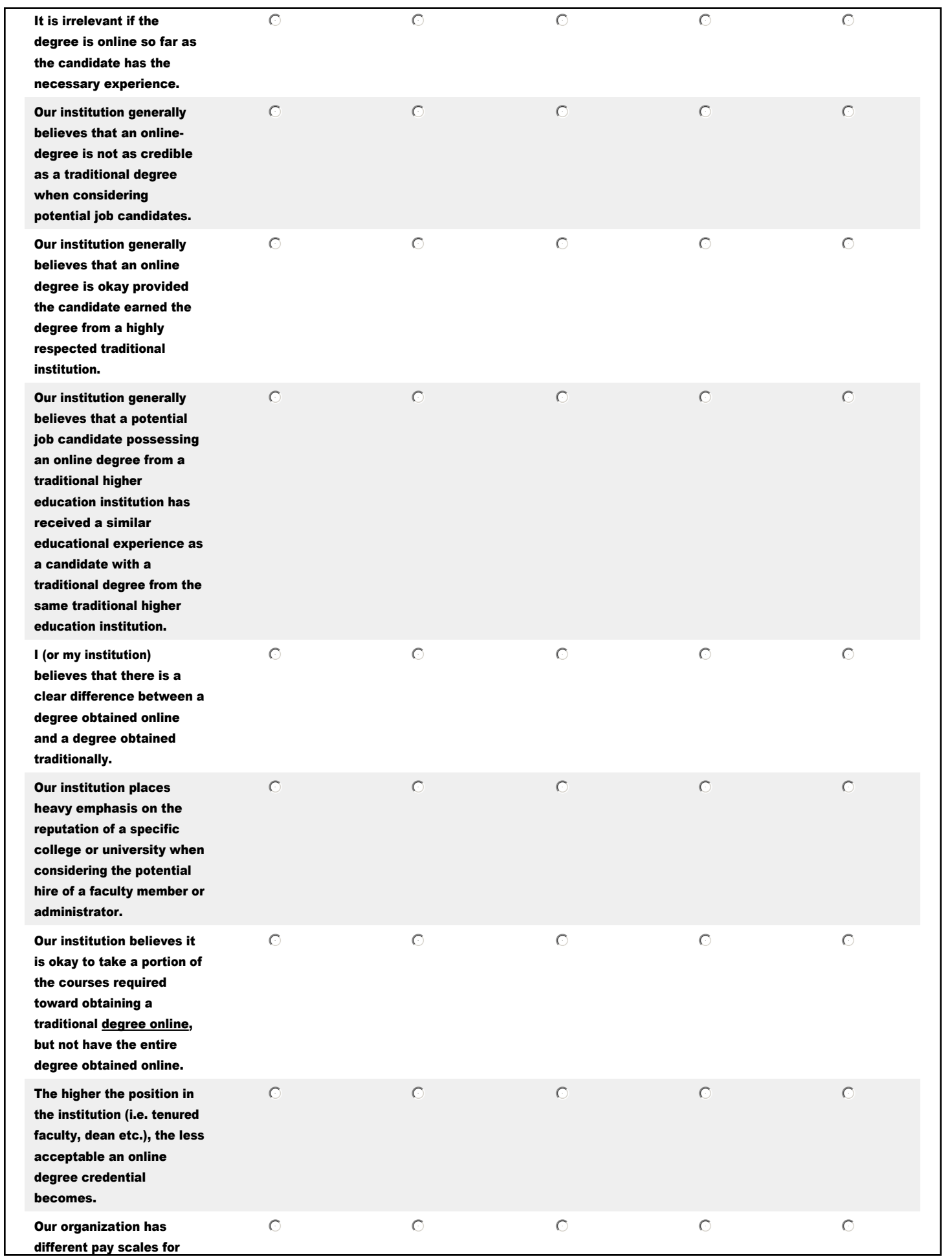




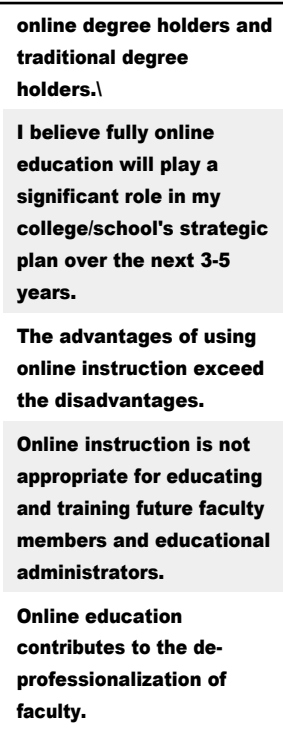

16. What is your organization's hiring policy regarding online degree holders?

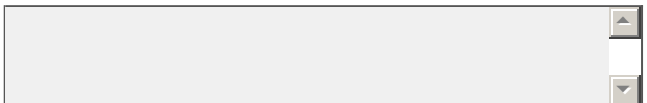

17. What are your personal perceptions regarding online education? 


\section{Hiring Practices}

Please rate your level of agreement with each of the following statements using a scale or $1=$ Strongly Disagree and $5=$ Strongly Agree

18. When hiring for a faculty/administrator position, I would choose a candidate with a degree completed in a traditional program from a traditional higher education institution over a candidate with an online doctoral degree from a traditional higher education institution.
Strongly Disagree
Disagree
Agree
Strongly Agree
Neutral
0

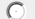
0
c

19. When hiring for a faculty/administrator position, I would choose a candidate with a degree completed in a traditional program from a traditional higher education institution over a candidate with an blended/asynchronous doctoral degree from a traditional higher education institution.

Strongly Disagree

Disagree

C
Agree

C
Strongly Agree

6
Neutral

20. When hiring for a faculty/administrator position, I would choose a candidate with a degree completed in a traditional program from a traditional higher education institution over a candidate with doctoral degree from a online only higher education institution.

Strongly Disagree

Disagree

Agree

Strongly Agree

Neutral

O

21. When hiring for a faculty/administrator position, I would choose a candidate with a degree completed in an online program from a traditional higher education institution over a candidate with a doctoral degree earned form an online only higher education institution.

Strongly Disagree Disagree Agree

Strongly Agree Neutral O

22. I would never considering hiring a faculty member or administrator who completed a degree online (regardless of the institution or program).

Strongly Disagree

O
Disagree

o
Agree

C
Strongly Agree

O
Neutral c

23. The type of degree (online or traditional) would not make any difference with regard to my hiring decision of a faculty member or administrator.

Strongly Disagree

C
Disagree

C
Agree
Strongly Agree

O
Neutral 
24. Do you have any additional thoughts, comments, insight, perceptions you may want to share regarding online education and/or hiring potential job candidates with online degrees?

\begin{tabular}{|r|r|}
\hline & $\Delta$ \\
\end{tabular}


APPENDIX B

INTERVIEW PROTOCOL 


\section{Interview Protocol}

1. Please describe your educational background. During your educational experience did you ever take an online course?

2. How long have you been an employee at your college or university?

3. What is your current position? What department/division do your work in?

4. Please provide a brief description of your institution (i.e. public, private, research, liberal arts, religious affiliated etc.)

5. What is your institution's position on online teaching and learning and online programs in general?

6. As an employee have you ever been involved in online teaching or online learning?

7. What immediately comes to mind when you hear the term "online degrees" or “online programs"?

8. In your opinion, how do online degrees or programs compare to traditional degrees or programs?

9. What are your current attitudes or beliefs regarding traditional institutions who offer online degrees or programs? How do you think the online degrees and programs offered by traditional institutions compare to those offered by virtual institutions such as Walden or Kaplan University?

10. What role do you play/have you played in making faculty or administrative hiring decisions? In other words, have you participated in or been a member of a faculty or staff hiring committee(s)? How often have you had to play such a role?

11. Can you please describe the criteria you use to make selection decisions regarding the pool of candidates for the faculty or administrative position? How do you determine which candidate gets to proceed to the next "hiring round"?

12. When you initially review a resume or curriculum vitae-what immediately strikes you as a "red flag"?

13. To what extent do you consider an institution's reputation when reviewing a candidate's credentials? 
14. What effect will the type of degree a candidate possesses have on your hiring decisions? For example, let's pretend that you were looking to hire an assistant professor. You have two candidates. Both are recent graduates and possess little "teaching" experience. One candidate has a degree from a traditional brick and mortar university such as Illinois State University, the other had an online degree from the same institution. How will you go about making a decision as to which of the two candidates you will prefer for the position? Will the type of degree they have matter? In what way will it matter? What about if the candidate posed a degree from a virtual university such as Walden or Kaplan University?

15. How would you consider/ weight these two types of degrees in your hiring decisions?

16. Have you received applications from online degree candidates? If yes, what was your initial reaction to such candidates?

17. Would you ever hire a candidate for a faculty or administrative position if he or she obtained a degree online? Why or why not?

18. What are the benefits to hiring a candidate who possesses an online degree?

19. What are the disadvantages to hiring a candidate who possesses an online degree?

20. Where do you think online education will be in five years? What about ten years? Do you think current perceptions will change in the Academy toward these degrees?

21. Do you think that higher education institutions offering online courses and advanced degree programs (i.e. doctoral programs) are just as willing to "hire back" these online degree candidates as faculty and administrators in their respective institutions?

22. Do you feel that online education contributes to the de-professionalization of individuals in academic positions? 
APPENDIX C

MEAN SCORES AND STANDARD DEVIATION BY POSITION

TYPE AND INSTITUTIONAL SIZE 
Table C-1

Mean Scores and Standard Deviation by Position Type

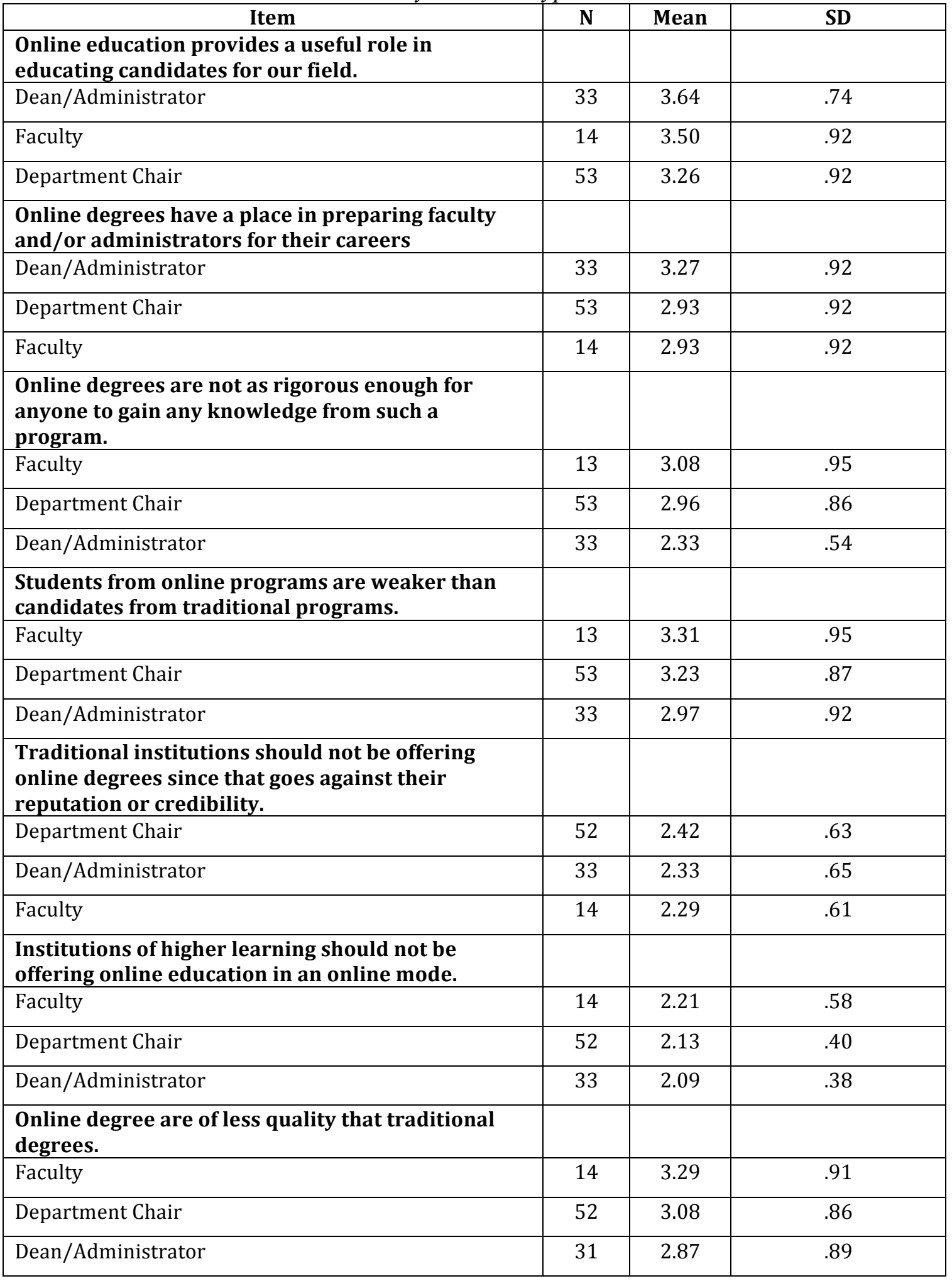




\begin{tabular}{|c|c|c|c|}
\hline Item & $\mathbf{N}$ & Mean & SD \\
\hline \multicolumn{4}{|c|}{$\begin{array}{l}\text { If one has the opportunity to take either an online } \\
\text { course or a traditional course, they should go for } \\
\text { the online course. }\end{array}$} \\
\hline Dean/Administrator & 33 & 2.55 & .56 \\
\hline Faculty & 14 & 2.36 & .75 \\
\hline Department Chair & 53 & 2.32 & .58 \\
\hline \multicolumn{4}{|c|}{$\begin{array}{l}\text { Students benefit from online course in a similar } \\
\text { way like they do from traditional courses. }\end{array}$} \\
\hline Dean/Administrator & 33 & 2.94 & .97 \\
\hline Department Chair & 53 & 2.79 & .86 \\
\hline Faculty & 14 & 2.29 & .73 \\
\hline \multicolumn{4}{|c|}{ Online degrees have no value at all. } \\
\hline Dean/Administrator & 33 & 2.21 & .55 \\
\hline Department Chair & 53 & 2.13 & .44 \\
\hline Faculty & 14 & 2.00 & .00 \\
\hline \multicolumn{4}{|c|}{$\begin{array}{l}\text { The institution from which a candidate earns their } \\
\text { degree is a very important consideration when } \\
\text { making hiring decisions in our institution. }\end{array}$} \\
\hline Department Chair & 53 & 3.87 & .44 \\
\hline Dean/Administrator & 33 & 3.70 & .68 \\
\hline Faculty & 14 & 3.57 & .85 \\
\hline \multicolumn{4}{|c|}{$\begin{array}{l}\text { It is irrelevant if the degree is online so far as the } \\
\text { candidate has the necessary experience. }\end{array}$} \\
\hline Dean/Administrator & 33 & 2.79 & .96 \\
\hline Department Chair & 53 & 2.64 & .88 \\
\hline Faculty & 13 & 2.31 & .75 \\
\hline \multicolumn{4}{|c|}{$\begin{array}{l}\text { Our institution generally believes than an online } \\
\text { degree is not a credible as a traditional degree } \\
\text { when considering potential job candidates. }\end{array}$} \\
\hline Department Chair & 53 & 3.43 & .80 \\
\hline Faculty & 14 & 3.29 & .83 \\
\hline Dean/Administrator & 33 & 3.27 & .91 \\
\hline \multicolumn{4}{|c|}{$\begin{array}{l}\text { Our institution generally believes that an online } \\
\text { degree is okay provided the candidate earned the } \\
\text { degree from a highly respected traditional } \\
\text { institution. }\end{array}$} \\
\hline Dean/Administrator & 32 & 3.41 & .87 \\
\hline Department Chair & 53 & 3.06 & .89 \\
\hline Faculty & 13 & 2.69 & .85 \\
\hline
\end{tabular}




\begin{tabular}{|c|c|c|c|}
\hline Item & $\mathbf{N}$ & Mean & SD \\
\hline \multicolumn{4}{|l|}{$\begin{array}{l}\text { Our institution generally believes that a potential job } \\
\text { candidate possessing an online degree from a } \\
\text { traditional higher educational institution has received } \\
\text { a similar educational experience as a candidate with a } \\
\text { traditional degree from the same traditional higher } \\
\text { education institution. }\end{array}$} \\
\hline Dean/Administrator & 32 & 3.06 & .95 \\
\hline Faculty & 13 & 2.62 & .87 \\
\hline Department Chair & 53 & 2.59 & .84 \\
\hline \multicolumn{4}{|l|}{$\begin{array}{l}\text { I (or my institution) believe that there is a clear } \\
\text { difference between a degree obtained online and a } \\
\text { degree obtained traditionally. }\end{array}$} \\
\hline Department Chair & 53 & 3.64 & .71 \\
\hline Faculty & 13 & 3.62 & .77 \\
\hline Dean/Administrator & 32 & 3.19 & .90 \\
\hline \multicolumn{4}{|l|}{$\begin{array}{l}\text { Our institution places heavy emphasis on the } \\
\text { reputation of a specific college or university when } \\
\text { considering the potential hire of a faculty member or } \\
\text { administrator. }\end{array}$} \\
\hline Dean/Administrator & 32 & 3.63 & .79 \\
\hline Department Chair & 53 & 3.60 & .77 \\
\hline Faculty & 14 & 3.29 & .91 \\
\hline \multicolumn{4}{|l|}{$\begin{array}{l}\text { Our institution believes it is ok to take a portion of the } \\
\text { course required toward obtaining a traditional degree } \\
\text { online, but not have the entire degree obtained online. }\end{array}$} \\
\hline Department Chair & 53 & 3.51 & .70 \\
\hline Faculty & 13 & 3.23 & .73 \\
\hline Dean/Administrator & 32 & 3.22 & .87 \\
\hline \multicolumn{4}{|l|}{$\begin{array}{l}\text { The higher the position in the institution (i.e. tenured } \\
\text { faculty, dean, etc.) the less acceptable an online degree } \\
\text { credential becomes. }\end{array}$} \\
\hline Faculty & 14 & 3.43 & .76 \\
\hline Department Chair & 53 & 3.28 & .86 \\
\hline Dean/Administrator & 33 & 3.16 & .95 \\
\hline \multicolumn{4}{|l|}{$\begin{array}{l}\text { Our organization has different pay scales for online } \\
\text { degree holders and traditional degree holders. }\end{array}$} \\
\hline Faculty & 13 & 2.38 & .51 \\
\hline Department Chair & 51 & 2.27 & .45 \\
\hline Dean/Administrator & 32 & 2.09 & .30 \\
\hline
\end{tabular}




\begin{tabular}{|l|c|c|c|}
\hline \multicolumn{1}{|c|}{ Item } & N & Mean & SD \\
\hline $\begin{array}{l}\text { I believe fully online education will play a significant } \\
\text { role in my college/school's strategic plan over the next } \\
\text { 3-5 years. }\end{array}$ & & & \\
\hline Dean/Administrator & 32 & 3.72 & .63 \\
\hline Faculty & 13 & 3.31 & .95 \\
\hline Department Chair & 53 & 3.21 & .91 \\
\hline $\begin{array}{l}\text { The advantages of using online instruction exceed the } \\
\text { disadvantages. }\end{array}$ & & & \\
\hline Dean/Administrator & 32 & 3.34 & .75 \\
\hline Department Chair & 53 & 3.04 & .76 \\
\hline Faculty & 13 & 2.85 & .90 \\
\hline $\begin{array}{l}\text { Online instruction is not appropriate for educating and } \\
\text { training future faculty members and educational } \\
\text { administrators. }\end{array}$ & & & .95 \\
\hline Faculty & 13 & 3.08 & .94 \\
\hline Department Chair & 53 & 2.96 & .72 \\
\hline Dean/Administrator & 32 & 2.47 & .86 \\
\hline $\begin{array}{l}\text { Online education contributes to the de- } \\
\text { professionalization of faculty. }\end{array}$ & & & \\
\hline Faculty & 53 & 3.08 & 2.50 \\
\hline Department Chair & & & \\
\hline Dean/Administrator & & \\
\hline
\end{tabular}


Table C-2

Mean Scores and Standard Deviation by Institutional Size

\begin{tabular}{|c|c|c|c|}
\hline Item & $\mathbf{N}$ & Mean & SD \\
\hline \multicolumn{4}{|c|}{$\begin{array}{l}\text { Online education provides a useful role in } \\
\text { educating candidates for our field. }\end{array}$} \\
\hline $20,001+$ & 20 & 3.65 & .75 \\
\hline $10,001-20,000$ & 23 & 3.61 & .72 \\
\hline $5,001-10,000$ & 25 & 3.48 & .82 \\
\hline $1,000-5,000$ & 32 & 3.09 & .96 \\
\hline \multicolumn{4}{|c|}{$\begin{array}{l}\text { Online degrees have a place in preparing faculty } \\
\text { and/or administrators for their careers }\end{array}$} \\
\hline $20,001+$ & 20 & 3.30 & .92 \\
\hline $1,000-5,000$ & 32 & 3.12 & .91 \\
\hline $5,001-10,000$ & 25 & 2.92 & .95 \\
\hline $10,001-20,000$ & 23 & 2.91 & .90 \\
\hline \multicolumn{4}{|c|}{$\begin{array}{l}\text { Online degrees are not as rigorous enough for } \\
\text { anyone to gain any knowledge from such a } \\
\text { program. }\end{array}$} \\
\hline $5,001-10,000$ & 24 & 2.75 & .90 \\
\hline $1,000-5,000$ & 32 & 2.72 & .88 \\
\hline $10,001-20,000$ & 23 & 2.70 & .76 \\
\hline $20,001+$ & 20 & 2.50 & .76 \\
\hline \multicolumn{4}{|c|}{$\begin{array}{l}\text { Students from online programs are weaker than } \\
\text { candidates from traditional programs. }\end{array}$} \\
\hline $5,001-10,000$ & 24 & 3.25 & .94 \\
\hline $1,000-5,000$ & 32 & 3.15 & .88 \\
\hline $20,001+$ & 20 & 3.10 & .97 \\
\hline $10,001-20,000$ & 23 & 3.09 & .85 \\
\hline \multicolumn{4}{|c|}{$\begin{array}{l}\text { Traditional institutions should not be offering } \\
\text { online degrees since that goes against their } \\
\text { reputation or credibility. }\end{array}$} \\
\hline $1,000-5,000$ & 32 & 2.44 & .67 \\
\hline $10,001-20,000$ & 23 & 2.43 & .73 \\
\hline $5,001-10,000$ & 25 & 2.36 & .57 \\
\hline $20,001+$ & 20 & 2.22 & .52 \\
\hline \multicolumn{4}{|c|}{$\begin{array}{l}\text { Institutions of higher learning should not be } \\
\text { offering online education in an online mode. }\end{array}$} \\
\hline $5,001-10,000$ & 24 & 2.25 & .61 \\
\hline $10,001-20,000$ & 23 & 2.17 & .49 \\
\hline
\end{tabular}




\begin{tabular}{|c|c|c|c|}
\hline Item & $\mathbf{N}$ & Mean & SD \\
\hline $1,000-5,000$ & 32 & 2.06 & .25 \\
\hline $20,001+$ & 20 & 2.05 & .22 \\
\hline \multicolumn{4}{|c|}{$\begin{array}{l}\text { Online degree are of less quality that traditional } \\
\text { degrees. }\end{array}$} \\
\hline $5,001-10,000$ & 25 & 3.12 & .88 \\
\hline $10,001-20,000$ & 22 & 3.09 & .81 \\
\hline $1,000-5,000$ & 31 & 3.00 & .97 \\
\hline $20,001+$ & 19 & 2.95 & .85 \\
\hline \multicolumn{4}{|c|}{$\begin{array}{l}\text { If one has the opportunity to take either an online } \\
\text { course or a traditional course, they should go for } \\
\text { the online course. }\end{array}$} \\
\hline $20,001+$ & 20 & 2.60 & .68 \\
\hline $10,001-20,000$ & 23 & 2.52 & .66 \\
\hline $1,000-5,000$ & 32 & 2.28 & .52 \\
\hline $5,001-10,000$ & 25 & 2.28 & .54 \\
\hline \multicolumn{4}{|c|}{$\begin{array}{l}\text { Students benefit from online course in a similar } \\
\text { way like they do from traditional courses. }\end{array}$} \\
\hline $5,001-10,000$ & 25 & 2.84 & .94 \\
\hline $10,001-20,000$ & 23 & 2.78 & .90 \\
\hline $1,000-5,000$ & 32 & 2.75 & .92 \\
\hline $20,001+$ & 20 & 2.70 & .86 \\
\hline \multicolumn{4}{|c|}{ Online degrees have no value at all. } \\
\hline $1,000-5,000$ & 32 & 2.22 & .55 \\
\hline $5,001-10,000$ & 25 & 2.16 & .47 \\
\hline $10,001-20,000$ & 23 & 2.09 & .42 \\
\hline $20,001+$ & 20 & 2.05 & .22 \\
\hline \multicolumn{4}{|c|}{$\begin{array}{l}\text { The institution from which a candidate earns their } \\
\text { degree is a very important consideration when } \\
\text { making hiring decisions in our institution. }\end{array}$} \\
\hline $5,001-10,000$ & 25 & 3.92 & .40 \\
\hline $20,001+$ & 20 & 3.85 & .49 \\
\hline $1,000-5,000$ & 32 & 3.69 & .69 \\
\hline $10,001-20,000$ & 23 & 3.65 & .71 \\
\hline \multicolumn{4}{|c|}{$\begin{array}{l}\text { It is irrelevant if the degree is online so far as the } \\
\text { candidate has the necessary experience. }\end{array}$} \\
\hline $1,000-5,000$ & 32 & 2.75 & .95 \\
\hline $20,001+$ & 20 & 2.70 & .86 \\
\hline $10,001-20,000$ & 23 & 2.56 & .90 \\
\hline
\end{tabular}




\begin{tabular}{|c|c|c|c|}
\hline Item & $\mathbf{N}$ & Mean & SD \\
\hline $5,001-10,000$ & 24 & 2.54 & .88 \\
\hline \multicolumn{4}{|c|}{$\begin{array}{l}\text { Our institution generally believes than an online } \\
\text { degree is not a credible as a traditional degree } \\
\text { when considering potential job candidates. }\end{array}$} \\
\hline $5,001-10,000$ & 25 & 3.48 & .77 \\
\hline $20,001+$ & 20 & 3.40 & .82 \\
\hline $10,001-20,000$ & 23 & 3.35 & .83 \\
\hline $1,000-5,000$ & 32 & 3.25 & .92 \\
\hline \multicolumn{4}{|c|}{$\begin{array}{l}\text { Our institution generally believes that an online } \\
\text { degree is okay provided the candidate earned the } \\
\text { degree from a highly respected traditional } \\
\text { institution. }\end{array}$} \\
\hline $20,001+$ & 20 & 3.45 & .83 \\
\hline $10,001-20,000$ & 22 & 3.23 & .87 \\
\hline $5,001-10,000$ & 24 & 3.00 & .93 \\
\hline $1,000-5,000$ & 32 & 2.94 & .91 \\
\hline \multicolumn{4}{|c|}{$\begin{array}{l}\text { Our institution generally believes that a potential job } \\
\text { candidate possessing an online degree from a } \\
\text { traditional higher educational institution has received } \\
\text { a similar educational experience as a candidate with a } \\
\text { traditional degree from the same traditional higher } \\
\text { education institution. }\end{array}$} \\
\hline $10,001-20,000$ & 22 & 3.05 & .95 \\
\hline $5,001-10,000$ & 24 & 2.71 & .86 \\
\hline $20,001+$ & 20 & 2.65 & .93 \\
\hline $1,000-5,000$ & 32 & 2.63 & .87 \\
\hline \multicolumn{4}{|c|}{$\begin{array}{l}\text { I (or my institution) believe that there is a clear } \\
\text { difference between a degree obtained online and a } \\
\text { degree obtained traditionally. }\end{array}$} \\
\hline $5,001-10,000$ & 24 & 3.63 & .65 \\
\hline $1,000-5,000$ & 32 & 3.53 & .84 \\
\hline $10,001-20,000$ & 22 & 3.45 & .86 \\
\hline $20,001+$ & 20 & 3.30 & .86 \\
\hline \multicolumn{4}{|c|}{$\begin{array}{l}\text { Our institution places heavy emphasis on the } \\
\text { reputation of a specific college or university when } \\
\text { considering the potential hire of a faculty member or } \\
\text { administrator. }\end{array}$} \\
\hline $20,001+$ & 20 & 3.80 & .62 \\
\hline $5,001-10,000$ & 25 & 3.68 & .69 \\
\hline $10,001-20,000$ & 22 & 3.50 & .86 \\
\hline $1,000-5,000$ & 32 & 3.38 & .91 \\
\hline
\end{tabular}




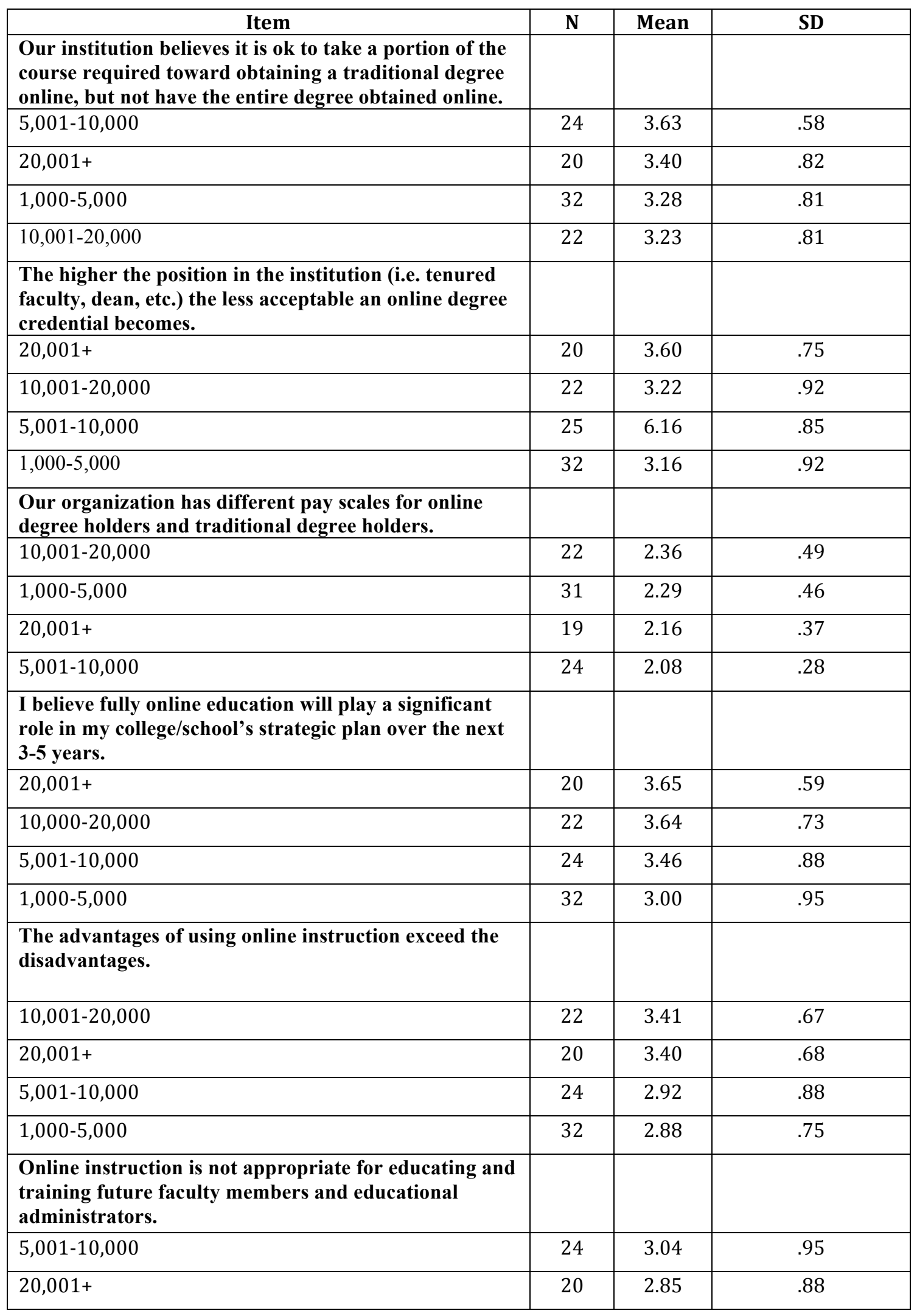




\begin{tabular}{|l|c|c|c|}
\hline \multicolumn{1}{|c|}{ Item } & $\mathbf{N}$ & Mean & SD \\
\hline $1,000-5,000$ & 32 & 2.75 & .92 \\
\hline $10,001-20,000$ & 22 & 2.63 & .85 \\
\hline $\begin{array}{l}\text { Online education contributes to the de- } \\
\text { professionalization of faculty. }\end{array}$ & & & \\
\hline $5,001-10,000$ & 24 & 3.04 & .95 \\
\hline $1,000-5,000$ & 32 & 2.88 & .87 \\
\hline $20,000+$ & 20 & 2.85 & .88 \\
\hline $10,001-20,000$ & 22 & 2.77 & .81 \\
\hline
\end{tabular}

